University of Louisville

ThinkIR: The University of Louisville's Institutional Repository

Electronic Theses and Dissertations

$5-2020$

\title{
Tobacco enhances bacterial-induced periodontal bone loss in mice.
}

Mina Iskander

University of Louisville

Follow this and additional works at: https://ir.library.louisville.edu/etd

Part of the Animal Sciences Commons, Biology Commons, Dentistry Commons, Immunology and Infectious Disease Commons, and the Microbiology Commons

\section{Recommended Citation}

Iskander, Mina, "Tobacco enhances bacterial-induced periodontal bone loss in mice." (2020). Electronic Theses and Dissertations. Paper 3573.

https://doi.org/10.18297/etd/3573

This Master's Thesis is brought to you for free and open access by ThinkIR: The University of Louisville's Institutional Repository. It has been accepted for inclusion in Electronic Theses and Dissertations by an authorized administrator of ThinkIR: The University of Louisville's Institutional Repository. This title appears here courtesy of the author, who has retained all other copyrights. For more information, please contact thinkir@louisville.edu. 
TOBACCO ENHANCES BACTERIAL-INDUCED PERIODONTAL BONE LOSS IN MICE

\author{
By \\ Mina Iskander \\ B.D.S., October 6 University, 2007 \\ Oral Surgery Diploma, Cairo University, 2010

\begin{abstract}
A Thesis
Submitted to the Faculty of the

School of Dentistry of the University of Louisville

in Partial Fulfillment of the Requirements
\end{abstract} \\ for the Degree of \\ Master of Science \\ in Oral Biology \\ Department of Oral Immunology and Infectious Disease \\ University of Louisville \\ Louisville, Kentucky
}

August 2020 
Copyright 2020 by Mina Iskander

All rights reserved 



\title{
TOBACCO ENHANCES BACTERIAL-INDUCED PERIODONTAL BONE LOSS IN MICE
}

\author{
By \\ Mina Iskander \\ B.D.S., October 6 University, 2007 \\ Oral Surgery Diploma, Cairo University 2010
}

Thesis Approved on

$7 / 30 / 2020$

by the following Thesis Committee:

Dr. David Albert Scott (Thesis Director)

Dr. Michele Pisano (Committee member)

Dr. Silvia Uriarte (Committee member) 


\section{DEDICATION}

I dedicate this thesis to my wife Mariam Habil, my parents, and my kids. I am eternally grateful for their love, and the sacrifices they made for me. 


\section{ACKNOWLEDGEMENTS}

I would first and foremost like to thank my mentor, Dr. David Scott, for his guidance and support in the entire periods of research. I am really grateful to him for offering me this valuable opportunity to work in his lab. Dr. Scott has spent countless hours guiding me and pushing me to pursue novel and challenging scientific questions. I am honored and feel very fortunate to work with such a dynamic, Extremely patience, optimistic and a great human being. He took care of me not only in science but also in a different sphere of life. I feel very blessed to have him as my mentor.

I would also thank my thesis committee member Dr. Pisano, for her encouragement and guidance. I am grateful for the independence you were willing to give me. Dr. Pisano provided invaluable timely help and continuous support on every step of my Master. She has pushed me to be my best and think critically.

I also would like to thank my thesis committee, Dr. Silvia Uriarte for agreeing to offer his expertise, valuable time, feedback, and assistance.

I would also like to show my gratefully thank to our lab manager, Gwyneth Lamont, for her guidance, help, kindness and friendship. 
Lastly, I would like to acknowledge my wife, Mariam Habil, who from the beginning supported me throughout this process and to press on when times were tough, she deserves more thanks then I could possibly express here. I am also extremely grateful of the love and encouragement I have received from my parents, brother, and sister throughout my time here at the University of Louisville. 


\begin{abstract}
TOBACCO ENHANCES BACTERIAL-INDUCED PERIODONTAL BONE

LOSS IN MICE

Mina Iskander

July 30,2020
\end{abstract}

Background: Tobacco smoking is the leading environmental risk factor for periodontal diseases. Delineation of the mechanisms underlying tobacco-induced or exacerbated periodontitis is hampered by the lack of an appropriate and reliable animal model.

Hypothesis: We hypothesized that Porphyromonas-gingivalis-infected, cigarette smokeexposed mice would represent reproducible models of acute (ligature model) and chronic (oral gavage model) tobacco-enhanced periodontitis that reflect multiple aspects of the disease noted in human smokers.

Methods: In a chronic oral gavage disease model, Balb/c mice (6-8 weeks, 4 groups of $n$ $=6$ per group) were exposed to smoke produced by a Teague- 10 smoking machine from 1R6F research cigarettes (20 cigarettes per day over 3 hours; mean carbon monoxide (CO), $150 \mathrm{ppm}$; mean particulate exposure, $4.9 \mathrm{mg} / \mathrm{m}^{3}$ ) or exposed to ambient air, over 68 days. The mice were repeatedly orally inoculated with Streptococcus gordonii and Porphyromonas gingivalis or sham inoculated. At euthanasia, the $\operatorname{lgM}$ and $\lg G$ response to infection; systemic inflammatory mediators; specific local gingival inflammatory indices (IL-1 $\beta$, MMP-8, MMP-9, CD14and CD45); as well as alveolar bone loss were assessed. 
In an acute ligature-induced disease model, Balb/c mice (6-8 weeks, 4 groups of $n=7$ per group) were exposed to smoke (20 cigarettes per day over 3 hours; mean CO, 200 ppm; mean particulate exposure, $9.8 \mathrm{mg} / \mathrm{m}^{3}$ ) or exposed to ambient air, over 14 days. The mice were repeatedly orally inoculated with $P$. gingivalis or sham inoculated. At euthanasia, IgM and IgG response to infection, alveolar bone loss was assessed. Plans to assess local and systemic inflammatory indices were curtailed by the Covid-19 outbreak.

Results: In a chronic model of periodontitis, tobacco smoke exposure enhanced bacteriainduced bone loss $(\boldsymbol{p}<0.01)$. Systemic innate immune suppression was also apparent, as indicated by reduced levels of systemic CCL2, CXCL1, MIP-1b,GM-CSF,IL-13, and IL-10 (all $\boldsymbol{p}<0.05)$, while local expression of MMP-8 was augmented in infected mice $(\boldsymbol{p}<0.05)$. However, tobacco smoke exposure did not influence murine mass, $\lg M$ or $\lg G$,or the mRNA signal of inflammatory mediator's in murine gingiva.

In the acute model of periodontitis, tobacco smoke exposure, again, enhanced bacteriainduced bone loss $(\boldsymbol{p}<0.01)$. Body mass differentials were also influenced by smoke exposure $(\boldsymbol{p}<0.001)$. However, no significant differences between groups were noted in the $\lg M$ and $\lg G$ responses.

Conclusions: Tobacco-enhanced periodontitis, as assessed by alveolar bone resorption, in both acute and chronic murine models. Such models will facilitate multiple studies that can provide mechanistic insights into increased susceptibility to periodontal diseases in smokers. 


\section{TABLE OF CONTENTS}

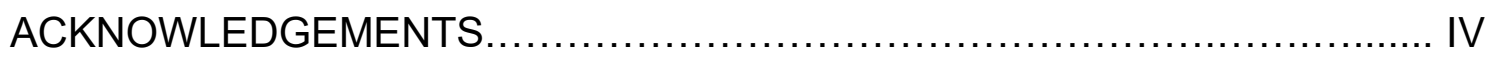

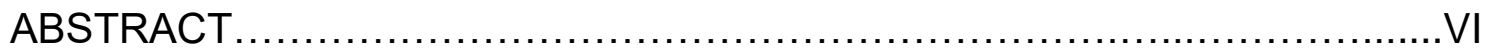

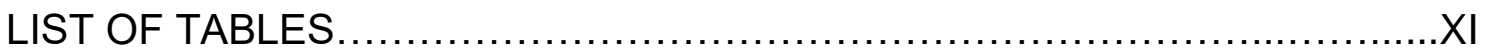

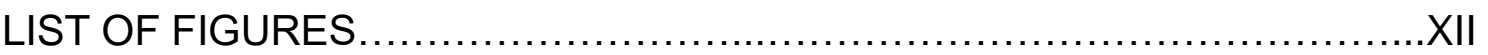

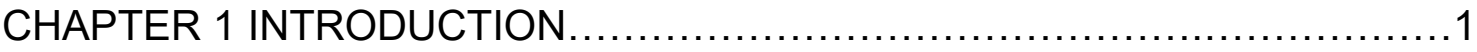

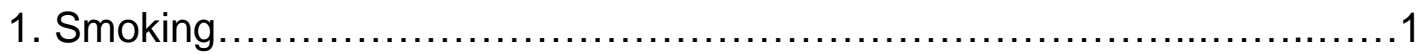

1.1 Smoking prevalence and III-health.......................................

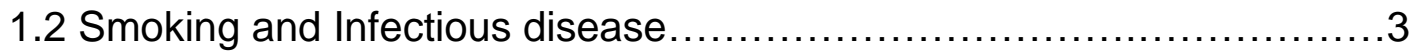

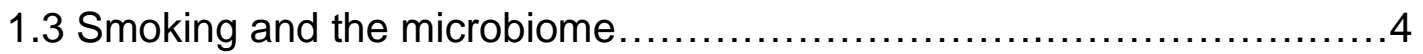

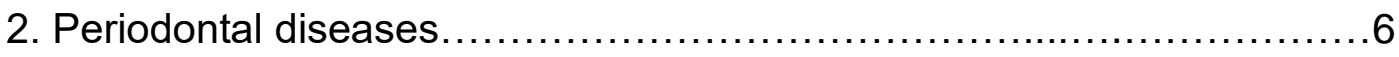

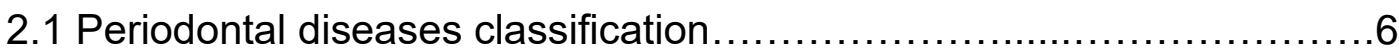

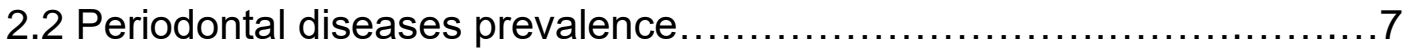

2.3 Systemic diseases and Periodontal disease association ...............

2.4 Periodontal diseases prevention and Treatment modalities.............8

2.5 The etiology of periodontal diseases................................... 10 
3. Smoking and Periodontal diseases.

3.1 Risk factors

3.2 Quantification of smoking related periodontal risk. ... 15

3.3 Potential mechanism of tobacco-enhanced periodontitis. 16

4. Porphyromonas gingivalis 20

4.1 Porphyromonas gingivalis characteristics. 20

4.2 Porphyromonas gingivalis and periodontal disease 21

4.3 Porphyromonas gingivalis virulence factors. 22

4.4 Smoking and Porphyromonas gingivalis prevalence 25

4.5 Smoking and Alteration of Porphyromonas gingivalis virulence .26

5. Animal models of periodontitis 27

5.1 Mouse models of periodontal diseases 28

5.2 Rat models of periodontal diseases .29

5.3 Canine models of periodontal diseases. .33

5.4 Nonhuman primates' model of periodontal diseases 33 HYPOTHESIS AND AIMS .36 CHAPTER 2 MATERIALS AND METHODS

Modified Baker model.

Ligature model .55 
CHAPTER 3 RESULTS.

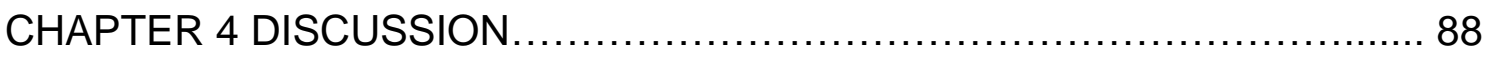

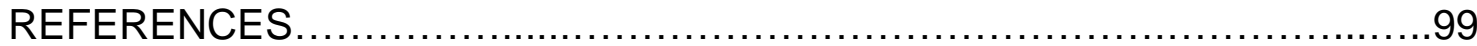

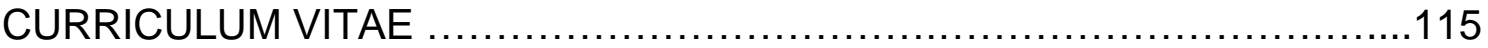




\section{LIST OF TABLES}

Table (1): Bacterial colonization of the oral cavity of mice in the absence of cigarette smoke.

Table (2): Bacterial colonization of the oral cavity of mice chronically 68 exposed to cigarette smoke

Table (3): Chronic smoke exposure alters aspects of the systemic 71 immune response to $P$. gingivalis. 


\section{LIST OF FIGURES}

Figure (1): Smoking Machine Teague Enterprises TE-10C. 40

Figure (2): Timeline strategy for Baker model bacterial inoculation. $\quad 44$

Figure (3): Mice group assignment for the Baker model. 46

Figure (4): Oral swab collection in the Baker model 49

Figure (5): Microscopic image of mice maxillary teeth. 54

Figure (6): Timeline strategy for ligature model bacterial inoculation. 56

Figure (7): Mice group assignment for Ligature model. 58

Figure (8): : Equal murine body mass at baseline in the chronic

smoke exposure model. $\quad 64$

Figure (9): Chronic smoke exposure does not influence murine body mass.

Figure (10): Chronic smoke exposure does not influence murine body mass differentials.

Figure (11): $P$. gingivalis-cognizant $\lg \mathrm{M}$ is elevated in chronically smoke exposed mice.

Figure (12): Infection induces a $P$. gingivalis-cognizant IgG response that is not influenced by chronic smoke exposure in mice.

Figure (13): Chronic cigarette smoke exposure does not influence IL$\beta$ message in murine gingiva.

Figure (14): Chronic cigarette smoke augments the MMP-8 signal in bacteria-infected murine gingiva.

Figure (15): Chronic cigarette smoke exposure does not influence the MMP-9 message in murine gingiva.

Figure (16): Chronic cigarette smoke exposure does not influence CD14 message in murine gingiva. 
Figure (17): Chronic cigarette smoke exposure does not influence the CD45 signal in murine gingiva.

Figure (18): Chronic tobacco smoke exposure enhances bacteriainduced alveolar bone loss in mice

Figure (19): Equal murine body mass at baseline in the acute periodontal disease model.

Figure (20): Bacterial infection increased murine body mass in smoke-exposed mice in an acute model of periodontitis.

Figure (21): Smoking suppressed body mass differentials in an acute periodontitis model in mice

Figure (22): Infection induces a $P$. gingivalis-cognizant IgM response that is not influenced by smoke exposure in an acute periodontitis model in mice.

Figure (23): $P$. gingivalis cognizant-lgG is not influenced by smoke exposure in an acute periodontitis model in mice.

Figure (24): Tobacco smokes enhances bacteria-induced alveolar bone loss in an acute model of periodontitis in mice. 


\section{CHAPTER 1: INTRODUCTION AND LITERATURE REVIEW}

\section{Smoking}

1.1 Smoking prevalence and ill-health:

Tobacco smoking is a primary preventable driver of morbidity and mortality globally accounting for 7 million deaths per annum, including the 480,000 fatalities associated with passive smoking [1]. In 2018, the prevalence of smoking in the U.S. population remains significant, with the number adult cigarette smokers estimated at $>34$ million adults [2] despite campaigns to minimize or eliminate consumption. According to the World Health Organization (W.H.O.), there were around 1.3 billion smokers worldwide in 2003 , primarily residing in middle-and lowincome countries, a number that is expected to rise to 1.7 billion by the end of 2020 [3]. U.S. smoking prevalence is highest among in middle-aged individuals (45-64 years) at $18.0 \%$, is $17.6 \%$ in adults of $25-44$ years, $13.1 \%$ in young adults (18-24 years), and $8.8 \%$ in the elderly (65 years or older) [4]. The W.H.O. suggests tobacco use is responsible for the annual deaths of 6 million people worldwide, a number projected to rise to 7 million in 2020 and to $>8$ million by 2030 , assuming unabated smoking rates [5].

Smoking imposes a heavy economic burden, particularly in North America and Europe, where the tobacco epidemic is most advanced [6] estimated to be 
approximately 0.5 trillion dollars annually all over the world[5]. In 2010, smoking was estimated to account for $8.7 \%$ of the aggregated annual healthcare spending in U.S. Approximately two-thirds of this cost was met through Medicaid, Medicare or other governmental programs [7]. In the United States the percent attributable fraction of deaths due to smoking in U.S. adults in 2014 was highest in Kentucky (22.1\%) followed by Arkansas (21.5\%), Nevada (21.3\%), Tennessee (21.1\%), West Virginia (20.6\%), Oklahoma (20.2\%) and Missouri (20.1\%) [8].

About half of all smokers suffer from serious smoking related diseases [9]. Smoking is the major driver of at least $30 \%$ of all cancer deaths and is associated with $80 \%$ of early deaths from cardiovascular disease and chronic obstructive pulmonary diseases [10]. Furthermore, smokers are more susceptible than nonsmokers to premalignant lesions, systemic lupus erythematosus, hypertension, osteoporosis, diabetes, Crohn's disease, impotence and destructive periodontal diseases [11-13].

The most common product smoked is cigarettes but also smoking can include electronic cigarettes, water pipes, pipes, cigar and cigarillos [14]. Indeed, more than 7000 constituents that are toxic to human health are contained in cigarettes and at least 69 are carcinogenic. Some of these constituents are naturally found in tobacco (e.g., nicotine), some are added during the manufacturing process (e.g., ammonia), but most are generated during the burning process (e.g., acrolein) [15, $16]$. 


\subsection{Smoking and infectious diseases:}

Smoking, either active or secondhand, increases susceptibility to a multitude of infectious, including tuberculosis [17], nasopharyngeal and respiratory tract infections [18], surgical infections [19], bacterial meningitis [20] and, of particular importance here, periodontal diseases [21, 22]. Whereas the evidence to correlate the harmful consequences of smoking to infectious diseases is clear, the underlying mechanisms of predisposition require elucidation [23]. To summarize, tobacco smoking could enhance the risk of bacterial infection through three general mechanisms: (a) tobacco-induced host structural and physiological changes, and / or (b) enhancement of bacterial virulence, and/ or (c) immune dysregulation [12].

The structural changes induced by tobacco smoke may be dependent on the specific tissue. For example, cerebral vessels dilate upon exposure to smoke [24], whereas, peripheral arterial vessels constrict [25]. In the gingival and periodontal tissues, smoking leads to suppression of the gingival inflammation characterized by a compromised bleeding response to plaque associated with angiogenesis impairment rather than any acute vasoactive activity [26].

With respect to bacterial virulence, it was recently reported that cigarette smoke promotes the pathogenicity of variant species, such as Staphylococcus aureus [27], Haemophilus influenzae, Streptococcus pneumoniae [28]and, the subject of this research project, Porphyromonas gingivalis [22, 29]. While there is still much 
research performed on this topic, smoking alters the phenotypic and genotypic virulence traits, to be addressed later.

Tobacco smoking affects both innate and adaptive immunity [30]. The innate immunity is significantly deregulated by smoke. For example, cigarette smoke negatively influences differentiation, viability and function, such as phagocytic capacity, of neutrophils and monocytes, aiding pathogenic colonization and infection [31, 32]. Tobacco smoke components also negatively regulates the maturation and function of dendritic cells, the primary antigen presenting cells required for adaptive immune function against pathogens [30, 33]. Indeed, T cell proliferation, antigen-mediated T-cell signaling and B cell responsiveness are all compromised by smoke exposure. function is compromised in smokers [34, 35]. There is a decrease in CD4 lymphocytes and increase in CD8 lymphocytes CD8 in heavy smokers [36]. Because CD4 lymphocytes stimulate B-cell proliferation and differentiation as well as synthesis of immunoglobulins, serum levels of Immunoglobulin G (IgG), an important anti-microbial antibody, in smokers are reduced when compared to non-smokers [35].

1.3Smoking and the microbiome:

In recent years, the effects of smoking on the oral microbiome were extensively studied and the oral microbiome shift occurs in response to this environmental stress [37-39]. However, after periodontal nonsurgical treatment and smoking cessation, a vast number of health associated species recolonize in the 
subgingival microbiome while a significantly lower abundance and prevalence of putative periodontal pathogens exists [40]. Smoking develops commensal-poor, pathogen-rich microbial ecosystem, allowing pathogen to proliferate even in clinically healthy individuals that closely resemble disease-associated communities [41, 42]. Smoking also may promote an anaerobic oral environment and a bacterial community with reduced capacity of xenobiotic degradation [37]. As mentioned early different infectious diseases are associated with smoking, we will focus on periodontal diseases. 


\section{Periodontal diseases}

2.1 Periodontal disease classification:

Periodontal diseases include a wide variety of chronic inflammatory conditions of the bone, ligament (the connective tissue collagen fibers that anchor a tooth to alveolar bone) and soft tissues supporting the teeth and/or the gingiva. Periodontal diseases begin with localized inflammation of the gingiva, or gingivitis, characterized by reversible redness, swelling, and bleeding [43]. This inflammatory response is induced by dental plaque, a complex bacterial biofilm attached to the teeth and gingival surface. Further, periodontal disease initiation and progression is thought to be associated with dysbiotic ecological changes in the oral microbiome composition that occurs due to fluctuations in available nutrients including tissue breakdown products, interspecies microbial interactions and immune system subversion [44]. Host-derived proteinases are a key factor among the multifaceted aspects of an overall inflammatory response, particularly matrix metalloproteinases and related destructive enzymes which are thought to be upregulated, activated, and involved in soft and hard tissue destruction. Among other consequences, such proteases lead to loss of periodontium fibers helping the bacterial biofilm to migrate along the root surface [45]. The classification periodontal disease subtypes depend on severity of the disease (e.g., periodontal pocket depth magnitude, clinical attachment loss and alveolar bone loss at the affected site) and the geographical context (the number of affected teeth) [46]. 


\subsection{Periodontal disease prevalence:}

The high prevalence of periodontitis reported in adolescents, adults and older people makes it a dominant public health concern [47]. It is considered the sixth most common human disease [48]. Globally $>500$ million people suffer from severe periodontal disease, while total tooth loss has been reported in $>270$ million people [49]. However, in USA, periodontitis has been reported to affect almost half of population aged over 30 years, representing over 60 million people [50]. Periodontitis-associated expenses comprise a significant part of the annual global economic burden over $\$ 400$ billion for oral diseases [51].

2.3 Systemic disease and periodontal disease association:

A consistent body of evidence supports a negative association between periodontal diseases and systemic diseases, such as pulmonary infections and chronic obstructive pulmonary disease (COPD) [52-54], poor glycemic control and diabetes $[55,56]$, cardiovascular diseases and stroke $[57,58]$, rheumatoid arthritis [59-62], poor pregnancy outcome [63] And specific cancers. As an example, negative associations between periodontal disease pancreatic, esophageal, gastric and head and neck cancer have been reported [64-68]. Interestingly, each millimeter of alveolar bone loss, a common measure of periodontal disease severity, has been estimated to increase the risk of tongue cancer $>5.23$ times [65]. 


\subsection{Periodontal disease prevention and treatment modalities:}

Good oral hygiene, which includes, regular tooth brushing and flossing, is crucial in preventing periodontal diseases [69]. Since smoking is a, or perhaps the, major risk factor for destructive forms of periodontal disease [26], smoking cessation can prevent a considerable proportion of periodontitis cases [70]. Indeed, the gingival bleeding response, suppressed in cigarette users [71], recovers rapidly following smoking cessation, indicating a recovery of the innate immune response to plaque bacteria [26]. Although the role of diet in dental caries is more significant compared to periodontal disease, poor diet can, nevertheless, negatively affect periodontal tissue homeostasis leading to disease progression [72]. For example, vitamin C scavenges excessive ROS, this nutrient is considered an important dietary oxidant in the periodontium [73]. Vitamin C also plays a key role in preventing and slows down the progression of periodontal disease by inducing the differentiation of periodontal ligament progenitor cells [74]. insufficient vitamin C intake increases periodontal disease risk in a dose-related manner [75].

The universal approach to treating periodontal disease is the instrumental debridement of dental plaque, sometimes accompanied by an antibiotic regimen. However, in case of severe subgingival pockets, surgical intervention can be necessary [76-78]. While mechanical debridement has been successfully implanted in the treatment of periodontal diseases, this technique has many drawbacks, for instance patient response is not ideally, universally and the outcome is multifactorial dependent [79]. Deep subgingival pockets may not be 
completely accessed by scaling devices, mechanical debriding might also be inefficient against all periodontal pathogens, as well as other negative impacts, particularly dentin hypersensitivity and teeth loss, reduce the efficiency of mechanical treatment approaches [80]. Consequently, in conjunction with mechanical debridement, antimicrobial therapy has been suggested to inhibit pathogenic bacterial colonization and enhance clinical results [81, 82]. Considering the benefits of conjunctional localized or systemic antibiotics to the mechanical approach, these strategies reveal non-specific activity and affect beneficial organisms living in the oral cavity. In addition, there are many other potential threats including the growth of resistant bacteria, possible allergic reactions and development of opportunistic fungal infections, suggesting careful consideration [83]. Indeed, various non-surgical and surgical options are available to treat periodontitis. However, no periodontal treatment option has shown superiority over another option [84].

2.5The etiology of periodontal diseases:

The onset and development of periodontal diseases are promoted by several factors, including the oral microbiome, the immune system, oral hygiene, systemic health, genetics and environmental risk factors, such diet, stress and - the focus of this work - tobacco use. Traditionally, two major hypotheses have been 
considered. The non-specific plaque theory posited that specific bacteria did not play a role in the development of periodontitis. Rather, the combined bacterial insult was considered the primary etiological factor [85]. The specific plaque theory, on the other hand, posited that there are specific microbial organisms correlated with the development of periodontitis [85]. In the latter years of the $20^{\text {th }}$ century, this developed into what is known as "red complex theory" which stated that a group of three bacterial species, Treponema denticola, Tannerella forsythia and Porphyromonas gingivalis, are most frequently associated with disease and so, treatment and prevention was aimed at their eradication [86]. However, this theory was based on assessments of bacterial species that were defined a priori. In other words, red complex theory is not a genuine reflection of the oral microbiome, which contains multiple uncultivable species and, more importantly, potential pathogens unrecognized at the time. In either case, the molecular probes that have been employed were highly selective.

The current paradigm, based on modern, total microbiome analyses in periodontal disease is based on the polymicrobial synergy and dysbiosis model, where periodontitis results from dysbiosis of the microbiome [87]. A diverse microbiota colonizes the gingival crevice where compatible organisms assemble into heterotypic communities. Normally, these communities are in balance with the host. The community's microbial components can vary over time, from site to site and from one individual to another. Theoretically, colonization even at low levels by a keystone pathogen, such as $P$. gingivalis, can negatively influence host defense mechanisms and enhance the virulence of the entire community [88]. 
Such microbial dysbiosis is associated with a disruption of tissue homeostasis and ultimately leads to periodontal tissue destruction.

III. 3. Smoking and periodontal disease

\subsection{Risk Factors:}

Non-modifiable risk factors

Genetics is key to the noted variations in predisposition to periodontal diseases [46] and may explain approximately half the population variance in periodontitis susceptibility [89]. Genetic variations contributing to functional defects in neutrophils and in genes involved in cytokine production are of particular importance [90-92]. For instance, the intrafamilial occurrence of Papillon-Lefèvre syndrome (PLS), which is a rare autosomal recessive disorder, is associated with onset of periodontitis at childhood and early loss of both deciduous and permanent teeth. This syndrome caused by mutation in the cathepsin $C$ gene [93, 94]. Prepubertal periodontitis in some families could represent partly penetrant PLS [95]. Another example, gene polymorphism of IL-1 $\alpha$ has been associated with about four-fold increase in IL-1 $\alpha$ protein levels in sever periodontitis patients [96]. IL-1 is a potent stimulators of bone resorption, and as hyperproduction of this cytokines following infection by periodontal pathogens is believed to be one of the mechanism of periodontal tissue destruction [97]. 
Different racial and ethnic groups frequently exhibit great variations in the outcome of periodontal diseases. Among the three largest race-ethnicity groups in the United States, adult blacks show the highest prevalence of periodontitis and the most periodontal tissue loss, followed by Mexican Americans, whereas whites show the lowest prevalence of disease and tissue loss [98].

Periodontal disease is regularly reported to be more prevalent or more severe in men than in women at compatible ages signifying a possible sex/gender entanglement in the disease pathogenesis [99-101]. Men exhibit poorer oral hygiene and report fewer visits to the dentist than do women. However, when correcting of oral hygiene, socioeconomic status, visits to the dentist and age, being male is still associated with more severe disease when either attachment loss or bone height is used as a measure of periodontal disease[102, 103].

Advancing age is another major non-modifiable risk factor [104], with clinical attachment loss significantly higher in patients aged 60-69 years compared to those in the 40-50 age bracket. [105].

Modifiable risk factors

Poor oral hygiene is associated with periodontal disease, and absence of sufficient tooth brushing and other oral hygiene measures may promote bacterial deposition and dental plaque buildup on teeth surface that can pave the way for inflammatory changes in periodontal tissue $[46,106]$.

Diabetes and periodontitis are complex chronic diseases, related by a close and bidirectional association. The risk of periodontitis in diabetic patients is 
increased up to three times relative to healthy individuals. Moreover, the degree of glycemic control is essential in evaluating the risk since the risk for periodontitis increased with poor glycemic control $[55,107]$. Periodontal disease is considered to be one of the six major complications of diabetes and the majority of evidence demonstrates a direct relationship between diabetes mellitus and periodontal disease [108]. Adult patients with type 2 diabetes or type 1 diabetic patients at all ages have more severe periodontal disease than age-matched healthy individuals [109-111].

It is also apparent that stress reduces salivary flow secretion which, in turn, can enhances plaque development [112]. A positive association was observed between stress scores, clinical attachment loss and tooth exfoliation [113]. Further, academic stress has been associated with poor oral hygiene and gingival inflammation, including elevated gingival crevicular levels of IL-1 [112].

Depression may be an additional risk factor for periodontal-disease. Various clinical studies imply a causal correlation between depression and periodontitis $[114,115]$. Moreover, periodontal disease may contribute to the onset of depression through psychosocial effects (e.g. shame, isolation, embarrassment, loneliness) of poor oral hygiene and halitosis, frequent characteristics of patients with periodontal disease [115].

Marijuana, which is used widely for medical and recreational purposes in the United States, is a major emerging risk factor for chronic periodontitis. Multiple human studies showed increased alveolar bone loss in people using cannabis. Data from the National Health and Nutrition Examination Survey (2011-2012) verify 
that frequent recreational cannabis use is associated with an increase in both pocket depth and clinical attachment loss, and higher chances of severe periodontitis [116]. Also, a recent meta-analysis demonstrated that cannabis use is associated with higher prevalence of periodontitis [117].

Cigarette smoking is perhaps the most significant environmental risk factors for periodontitis. Smoking alone may account for most cases of periodontitis in developed nations [26]. Smokers exhibits earlier disease onset [118], elevated rates of diseases progression [119], increased severity and prevalence of the disease $[118,120]$, and less favorable response to treatment [121], compared to non-smokers. Further, studies suggest that smoking has a strong dose-related influence on periodontal disease [122]. Clinical evidence shows increased gingival recession and greater periodontal ligament attachment loss and also deeper periodontal pocket depth formation and fewer teeth in smokers than non-smokers [21, 123, 124]. Compared to nonsmokers, young adult smokers aged 19 to 30 years have a higher prevalence and severity of periodontitis when controlled for plaque levels [125]. Nicotine, a major component of tobacco smoke, has been reported to contribute to degradation of periodontal collagen, and other key architectural proteins, by increasing expression and activity of matrix metalloproteinases (MMPs), and associated periodontal ligament detachment $[126,127]$. Multiple studies have also indicated that nicotine and one of its major metabolites, cotinine, adversely affect human periodontal fibroblasts proliferation, attachment and chemotactic responsive in a dose-related manner [128, 129]. Acrolein, another harmful component of smoke may be an impactful player in 
periodontal tissue destruction, producing a dose-related cytotoxic effect on human gingival fibroblasts, with complete inhibition of proliferation and attachment apparent at high concentrations [130]. In the inflamed area of periodontium in chronic periodontitis patients, a significant decrease in the number of vessels and a significant reduction in the intensity of the vascular reaction was observed in smokers versus nonsmokers [131]. These data suggest that smoking may induce angiogenesis suppression, providing a possible explanation of reduced gingival bleeding on probing (a common characteristics of periodontitis) in smokers compared to nonsmokers among periodontitis patients [26].

In sum, tobacco smokers are not only more susceptible to periodontal disease, but they are also more likely to develop a severe form of infection which is often times refractory to treatment $[12,21]$. Moreover, the clinical parameters of periodontitis (redness, edema and gingival bleeding) don't correlate to the disease level in tobacco smokers, who consistently manifest a reduced inflammatory response [21, 132].

\subsection{Quantification of smoking-related periodontitis risk:}

Worldwide, there are approximately 1.1 billion smokers, most of whom live in low- and middle-income countries, where the morbidity and mortality burden of smoking is higher [133]. In a study in New York State, involving 1361 people aged 25 to74 years, smokers where at greater risk of experiencing severe bone loss than nonsmokers, with odds ratios ranging from $3.25(95 \% \mathrm{Cl}: 2.33$ to 4.54$)$ to 7.28 
(95\% Cl: 5.09 to 10.31) for light and heavy smokers, respectively [103]. Data derived from the Third National Health and Nutrition Examination Survey, conducted in 1988 to 1994 on 12,329 adults conclude that smoking may be responsible for more than half of periodontitis cases among adults in the United States [70]. A recent meta-analysis, pooled adjusted risk ratio estimate that smoking increases the risk of periodontitis by $85 \%$ with risk ratio1.85 $(95 \% \mathrm{Cl}$ : 5 to 2.2) [134]. All of these findings and others $[135,136]$ provide extensive evidence that smoking may be the major preventable risk factor for periodontitis.

3.3 Potential mechanisms of tobacco-enhanced periodontal disease:

Smoking compromises multiple and varied aspects of the innate and adaptive immune responses $[13,137]$. Neutrophils are the primary leukocytes involved in host defense against bacterial invasion [91]. However, both in vivo and in vitro studies show that smoking impairs chemotaxis and phagocytosis in neutrophils in periodontal tissues $[138,139]$, leading to defective bacterial clearance and increased pathogen colonization.

Cigarette smoke exposure also causes T cell unresponsiveness. Nicotine impairs antigen mediated signal transduction in lymphocytes and induces a state of T cell anergy [140]. Nicotine inhibits the antibody forming cell responses through impairment of antigen mediated signaling in T cells by suppressing the intracellular calcium responses [36]. Besides affecting T cell responses, nicotine modulates the 
production of inflammatory cytokines by alveolar macrophages [141]. Higher levels of TNF- $\alpha$ have been reported in smoker's gingival cervical fluid (GCF) compared with non-smokers $[142,143]$. Also, elevation in interleukin (IL)-1 $\beta$, IL-6 and IL-8 levels in gingival cervical fluids was observed in periodontally diseased subjects as compared to healthy subjects [144]. In addition, higher concentration of matrix metalloproteinase (MMP)-8 [145] and MMP-9 in GCF, key host-derived destructive proteolytic enzymes, has been described $[145,146]$. Smokers have a vast increase in ratio between the receptor activator of nuclear factor- $\mathrm{k} \beta$ ligand (RANKL) and its inhibitor osteoprotegerin (OPG) [147]. Osteoclast which considered the key player in tissue degradation, differentiated from macrophage/monocyte precursor under the regulation of RANKL. Osteoclastic activity is promoted by TNF- $\alpha$ and IL-1 especially in inflammatory osteolysis states such as those seen in periodontitis [148]. Furthermore, smoking has been found to be inversely associated with levels of serum $\lg G$ antibodies specific to certain periodontal pathogens $[35,149]$, including $P$. gingivalis [150, 151]. Additionally, smoke can inhibit the reactive oxygen species in phagocytic innate cells, which are important in bacterial killing [152].

Taken all together, the neutrophils impairment, T-cell anergy, elevated TNF$\alpha$, higher destructive enzymes in GCF, inhibited immunoglobulins and ROS, and higher ratio of RANKL/OPG ultimately leads to upregulation of bone resorption and increase severity of periodontitis. 
Nicotine and periodontitis

Smokers oral tissues are exposed to high concentrations of nicotine which may have a negative impact on local cell population. The nicotine concentration in GCF has been reported to be almost 300 times that of plasma in smokers [153]. In smokers, nicotine binds to the root surface [154] and in vitro experiments indicate that it causes alteration of the fibroblast attachment [155] and integrin expression [156] as well as reduceing collagen production and enhancing collagenase synthesis [157]. Smokers root surfaces show reduced attachment of PDL fibroblasts compared to those of non-smokers [158]. Higher amounts of the proinflammatory cytokines IL-6 and IL-1 are produced from cultured fibroblasts [159] and keratinocytes [160], in contrast to the innate suppression widely reported in innate immune cells.

Moreover, there is strong evidence of a synergistic effect of nicotine and bacterial lipopolysaccharide $[159,161]$. Animal studies have clarified some of the negative impacts on bone healing following local nicotine exposure [162] being positively correlated to delayed revascularization [163] and inhibition of specific cytokines [164]. During hard and soft tissue wound recovery, smoking has been found to inhibit revascularization [163, 165], which is a crucial component of periodontal regeneration, dental implant success and plastic surgery procedures.

Tobacco smoke toxicity

The smoke generated from tobacco burning represents a dynamic, complex and reactive mixture of over 5000 chemicals $[63,166]$, including carbon monoxide, 
carbon dioxide, tar, ammonia, acrolein, formaldehyde, acetone, benzopyrenes, hydroxyquinone, cadmium, nitrogen oxides, and the primary neuroactive compound, nicotine [167]. Nicotine has been shown to be able to alter specific cellular functions. For example, nicotine exposure to human fibroblasts derived from periodontium affects cell growth, as well as attachment [168]. Both gingival fibroblasts (GFs) and periodontal ligament fibroblasts (PDLFs) exhibit lower cell viability with greater nicotine and cigarette smoke extract (CSE) concentrations [169], while. PDLFs are more sensitive to nicotine compared to GFs [170] and hence, nicotine induce cytotoxicity on PDLFs by inhibiting cell growth, proliferation and protein synthesis $[168,171]$.

\section{Dysbiosis}

There is a significant difference in the microbial profiles of smokers and nonsmokers. The microbial communities are more highly diverse and commensalpoor in smokers, versus non-smokers $[172,173]$. However, in another study, the overall oral microbiome composition of former smokers did not differ significantly from that of never smokers; indicating that smoking-related changes to the oral microbiome are not permanent [37]. Several important periodontal pathogens, including Treponema denticola, Fusobacterium nucleatum and $P$. gingivalis, are over-represented in cigarette users, relative to non-smokers [174], while commensal species, such as Streptococcus species, may be in higher abundance in non-smokers compared to smokers [38]. Several mechanisms were proposed to clarify how smoking may alter microbial ecology, including significantly low 
oxygen tension within the periodontal pockets in smokers, which might favor the growth of anaerobic periodontal pathogens even in shallow pockets [175]. This was supported by the clinical findings that smoking creates a favorable habitat for bacteria, such as $P$. gingivalis at shallow sites $(\leq 5 \mathrm{~mm})$ [138], increasing the acidity of saliva [176], influencing bacterial adherence to mucosal surfaces [177] and impairing host immunity [178].

\section{Porphyromonas gingivalis}

\subsection{Porphyromonas gingivalis characteristics:}

P. gingivalis is a Gram-negative, rod-shaped, asaccharolytic bacterium that is a secondary colonizer of subgingival plaque, forming black colonies on blood agar due to its potent hemin-acquisition capacity [179]. The primary site of $P$. gingivalis in the human oral cavity is the subgingival sulcus. $P$. gingivalis depends on the fermentation of amino acids for the production of energy and, thus, for its existence in deep periodontal pockets [180]. P. gingivalis possesses a variety of virulence factors that are important in colonization and persistence in the oral cavity [181]. The onset and progression of periodontal tissue damage is a complex process involving plaque deposition and dysbiosis, secretion of bacterial products and the inflammatory response of the host. 


\subsection{P. gingivalis and periodontal disease:}

The oral cavity houses the second most diverse microbial community in the body containing over 700 species of bacteria, only a small number of which have been associated with disease [181]. Of these, $P$. gingivalis is heavily implicated in periodontal disease development and progression. Undesirable shifts in periodontal biofilm communities, such as pathogenic $P$. gingivalis growth, drive the dysregulation of host homeostasis. P. gingivalis is the archetypal periodontal pathogen and, as such, will be used herein to induce periodontitis in mice. Indeed, P. gingivalis has been considered as a keystone pathogen of periodontitis, at least in mice [182]. P. gingivalis can be commonly isolated from plaque biofilms in periodontal disease patients but is rarely isolated from healthy individuals [183]. $P$. gingivalis has also been strongly associated with the extent of gingival pocket depth. There is an estimated 10 -fold rise in the number of $P$. gingivalis cells for every 1 - millimeter increase in pocket depth at human diseased sites [184].

An animal study [185] supports the evidence that $P$. gingivalis, even at low abundance, is capable of inducing significant alteration to host commensal microbiota in a way that supports its own viability while promoting pathogenesis of the disease. In this study, specific pathogen free mice infected with $P$. gingivalis exhibited significant bone loss, which is a major characteristic of periodontal disease. In contrast, germ free mice infected with $P$. gingivalis mono-infection showed no significant bone loss indicating that $P$. gingivalis cannot induce bone loss by itself. 


\subsection{P. gingivalis virulence factors:}

\section{Capsule}

The polysaccharide-rich external capsule of $P$. gingivalis serves a role in microbial adhesion to the teeth or mucosal surface. The capsule also provides protection from phagocytic clearance by neutrophils [186]. P. gingivalis shows at least six capsular antigen serotypes, K1-K6 [187]. Studies using mouse infection models showed that encapsulated $P$. gingivalis strains are much more virulent than non-capsulated. Non-encapsulated strains are mostly responsible for noninvasive, localized abscesses, whereas encapsulated strains are responsible for destructive lesions and systemic spreading. The non-encapsulated strains also suffer increased phagocytosis and are quickly removed by dendritic cells and macrophages [187]. Further, a decreased level of pro-inflammatory cytokines (IL$1 \beta, I L-6$, and IL-8) was detected when human gingival fibroblast was infected with a $P$. gingivalis mutant which lacks a capsule as opposed to a wild-type strain which produces a capsule [188]. Therefore, the capsule appears to be a key activator of the inflammatory response.

\section{Gingipains}

The RgpA, RgpB (arginine specific) and Kgp (Lysine specific) gingipains are a primary virulence factor of $P$. gingivalis [189] [190]. Gingipains are detected at high concentrations in GCF collected from deep pockets that are infected with $P$. gingivalis [191]. Their major roles in periodontitis pathogenicity are related to their 
ability to manipulate host immune defense and degrade host proteins. The broad specificity of gingipains means that they target multiple mammalian structural proteins (e.g., collagens and fibronectin, and laminin) and immune effector proteins (e.g., cytokines, antibodies, complement components, antimicrobial peptides and leukocytes surface receptors) $[192,193]$. In addition, RgpB activity is essential for assembly of fimbriae, another major virulence factor of $P$. gingivalis [194]. Treatment with a specific gingipain inhibitor strongly attenuates $P$. gingivalis virulence [195]. Importantly, gingipains are an attractive therapeutic target as immunization with purified gingipains or DNA vaccines protects against $P$. gingivalis infection in mice [196] .

Fimbriae:

Fimbriae are protein-like, filamentous appendages that protrude from the cell surface of bacteria. They play a vital role in virulence by promoting bacterial attachment to the host cell and other bacteria. $P$. gingivalis possesses both major fimbriae, largely comprised of the FimA protein [197], and minor fimbriae, largely comprised of Mfa1 protein [198].

P. gingivalis major fimbriae are crucial virulence to colonization, facilitating adhesion to several host proteins such as laminin, fibronectin, collagen and salivary proteins [199] and to other bacteria, such as oral streptococci species [197]. Fimbriae also help in the invasion of oral epithelial cells and gingival fibroblasts [200] and induce the expression several pro-inflammatory cytokines such as IL-1 $\beta, I L-6$ and TNF- $\alpha$, thus priming the immune system [201]. 
The minor fimbriae are key in adhesion to the primary periodontal colonizer, $S$. gordonii through specific interaction between Mfal and the SspB protein expressed on the surface of S. gordonii [202]. Unlike FimA [203], Mfa1 is highly inflammatory and induces IL-6,IL-1 $\beta$, TNF- $\alpha$ in mouse peritoneal macrophages and is associated with alveolar bone loss in various mouse models of periodontitis [204].

\section{Lipopolysaccharide}

Another virulence component of $P$. gingivalis is the lipopolysaccharide (LPS) that makes up outer leaflet of the bacterial outer membrane. LPS is a hybrid molecule of lipids and carbohydrates that is abundant in, and adds structure integrity to, the outer membrane $[205,206]$. LPS plays a crucial role in initiation of inflammation, triggering macrophage [207], neutrophils [208] and gingival fibroblasts [209] to secret inflammatory cytokine on interaction with cognizant innate receptor molecules. P. gingivalis LPS, as well as LPS from other Gramnegative species, induce the production of cytokines and other inflammatory mediators, through LPS-Toll-like receptor-4 (TLR-4)- nuclear factor-KB (NF-kB) axis [210]. P. gingivalis LPS has also been implicated in increasing the risk of important systemic conditions, such as atherosclerosis via the induction of foam cell formation in murine macrophages [211]. P. gingivalis LPS can directly activate osteoclasts and causes the release of the cytokines IL-1 $\beta$ and TNF- $\alpha$ from macrophages, monocytes, and fibroblasts [212]. These compounds are potent local mediators of bone resorption and, moreover, can inhibit collagen synthesis 
by osteoblasts and induce the production of host metalloproteases that destroy bone and connective tissue [148].

4.4 Smoking and P. gingivalis prevalence:

A correlation between cigarette smoking and subgingival infection with periodontal pathogens has been long established. $P$. gingivalis is found in significantly higher numbers in smokers compared to non-smokers and the infection is more persistent [213]. In a sample of 272 adults with periodontal disease, it was confirmed a significant difference in proportions of red-complex bacteria including $P$. gingivalis, in current smokers compared to those in former smokers and never smokers [214]. Another self-reported data on 1426 subjects aged 25 to 74, showed a significantly higher proportions of smokers harbored Aggregatibacter actinomycetemcomitans, Tanmirella forsythia and P. gingivalis than were non-smokers [215]. Eggert et al. showed that smoking extends a favorable habitat for bacteria such as $P$. gingivalis to shallow sites ( $\leq 5 \mathrm{~mm})$ [216]. Also, based on the results of GPCR, 40 smokers showed significantly higher amount of $P$. gingivalis than 40 nonsmokers in chronic periodontitis with equal probing depths [217]. From all these finding we conclude that the evidence for tobacco smoke increasing susceptibility to $P$. gingivalis infection and increasing the $P$. gingivalis infectious load is particularly strong. 


\subsection{Smoking and alterations to $P$. gingivalis virulence:}

Nicotine and its major metabolite, cotinine, do not influence the growth of $P$. gingivalis even at concentrations of $400 \mu \mathrm{g} / \mathrm{mL}$, which are higher than their physiological levels in saliva and GCF [218]; and indicative of profound resistance $\mathrm{t}$ these antimicrobial alkaloids [219]. Similarly, $P$. gingivalis growth showed to be unaffected by whole cigarette smoke extract (CSE) exposure at concentrations of $0.5,2$, and $4 \mu \mathrm{g} / \mathrm{mL}$ nicotine equivalents $[29,220]$. While $P$. gingivalis growth is not directly influenced by smoke, some changes in the virulence factors of bacteria are observed. For example; CSE influences the cell-bound Kgp and RgP gingipain production in a strain-specific manner (suppression in P. gingivalis ATCC 33277 but augmentation in $P$. gingivalis W83) [221]; CSE exposure decreased the proinflammatory capacity (TNF-a, IL-6) of $P$. gingivalis biofilms [22]; CSE exposure altered multiple gene expression profiles (such as DNA repair and oxidative stressrelated genes) [29]; CSE up-regulated the expression of FimA, suppressed the production of capsular polysaccharides, altered the proinflammatory response to CSE-exposed bacteria, and induced the expression of the outer membrane virulence factors, RagA and RagB [29, 201]. However, many of these effects were reversed when bacteria exposed to CSE were sub-cultured in fresh medium without CSE [29]. Therefore, smoking may profoundly influence the $P$. gingivalis phenotype and its subsequent interactions with the immune system. 
5. Animal models of periodontitis:

To gain better insight into the mechanisms underlying periodontal diseases, animal models that replicate key aspects of this human disease set will be useful. Despite the limitation of utilizing animal models, its often less severe than those encountering during in vitro experiments, in which cells are examined on plastic surface with limited number if cells types presented. Moreover, animal models often allow more definitive analysis of course and effect relationships than human clinical studies [222]. Animal periodontal disease models that have been employed include mice, rats, dogs and non-human primates [223]. Animal models generate substantial and relevant data on the interactions between soft and hard tissue, especially during inflammation, and hence periodontal inflammatory models, can be simulated and tested in animals. Another major advantage is that the potential mechanisms of systemic inflammation and its impact on periodontal healing processes can be studied in vivo using genetically produced transgenic and knockout animals [224]. A crucial aspect in animal models is the opportunity to explore complex interactions between bacteria and host which cannot be carried out under artificial laboratory conditions using single cell populations.

In contrast, animal models such as rodents differ substantially from humans in that their incisors lack a root structure and grow continuously throughout life, with only the front of the incisors having enamel and provide minute amount of gingival tissue. Therefore, relatively large numbers of animals per group are needed. Also, it is important to keep in mind these anatomical differences and similarities when 
considering which aspects of oral anatomy and health can be appropriately modeled in periodontitis [225].

However, tobacco-specific disease mechanisms have received relatively little attention in in vivo systems [26]. Characteristics of smoking-enhanced periodontitis in humans include a tobacco-specific microbial dysbiosis [226], dysregulated cytokine networks [30], amended neutrophil and other innate cell function [152], a protease-antiprotease imbalance [13], and an altered adaptive immune response [178], most notably reflected in a profound suppression of IgG production [227]. All of these phenomena culminate in increased soft and hard tissue destruction [228]. An ideal animal model, which does not exist, would encompass all of these disease-related traits.

\subsection{Mouse models of periodontitis:}

A model was developed in which mice were orally infected for studying the effect of host response on $P$. gingivalis-induced alveolar bone loss [229, 230]. It has been hypothesized that $P$. gingivalis initiates experimental periodontitis, at least in part, by alternating the endogenous subgingival biofilm to acquire increased virulence properties [231]. On one hand, this model may not reproduce all aspects of human periodontitis as the use of a single is not represenetive of the complex microflora that comprises the dental plaque biofilm [232]. On the other hand, the use of $P$. gingivalis in murine models provides many advantages such as allowing the study of natural history of periodontal tissue destruction, 
comparison of the level of virulence of $P$. gingivalis and other oral pathogens including ), a controlled environmental conditions, and estimations of efficacy of periodontal therapeutic strategies [234].

In an alternative periodontitis model, a silk ligature is be placed around the molar teeth in the gingival sulcus which enhances biofilm accumulation in addition to disturbing the gingival epithelium, which results in enahnced osteoclastogensis and bone loss [223]. A major benefit of the ligature-induced periodontitis model is that disease can be initiated in a matter of days with a predictable sequence of events culminating in alveolar bone loss [235]. However, in small animals such as mice, the possibility for mechanical trauma by the ligatures, might contribute to bone loss cannot be excluded [236].

\subsection{Rat models of periodontitis:}

Rats periodontal anatomy in the molar region shares some similarities with that of humans. So, they are often used in models of experimental periodontitis. Also, rats are easy to handle and can be obtained with different genomes and microbial status. Periodontitis can be induced by placing a bacterial plaque-retentive silk or cotton ligature in the gingival sulcus around the molar teeth [61]. In addition, injection of $P$. gingivalis can induce alveolar bone loss in rats [62]. Previous studies have shown the influence of smoking on the periodontal disease induced in rats. It has been found that cigarettes smoking potentiated bone loss in ligature-induced 
periodontitis in rats [237]. Also, smoke exposure cessation seems to reverse its impact on mandibular bone [238].

In sum, rodents include some unique features for evaluating microbial and host response to complement primate and human periodontal studies. Rodents have in each quadrant three molars and one incisor only [223].

One of periodontal disease aspects is bacterial colonization of the tooth surface and connective tissue invasion. A challenge with many rodent models of periodontal diseases is that the bacteria employed to induce the infection development only infect the oral cavity transiently, because rodents are not natural host for many human bacteria [230]. The presentation of human bacterial strains into the oral cavity and consequent effects on periodontal tissue has been studied in varies rodent models $[239,240]$. Different human bacterial strains were used in animal models such as Treponema denticola [241], A. actinomycetemcomitans [242], Tannerella forsythia [243] and $P$. gingivalis [229, 244]. In many cases, the oral infection by human bacteria is transient. Nevertheless, $T$. denticola has been detected 71 days after inoculation in mice [241]and $P$. gingivalis has been detected at up to 11 weeks [245]; $45 \%$ of rats exposed to $P$. gingivalis and $80 \%$ exposed to T. forsythia or $T$. denticola were found to harbor these bacteria after 4-6 weeks [246].

Another hallmark of periodontal diseases is the alveolar bone resorption [44]. Significant bone loss can be measured histologically, by macroscopic analysis or by micro-computed tomography. Alveolar bone resorption often assessed around the maxillary molars since bone resorption in lower molars is slower due to wider 
buccolingual dimensions and thicker cortical alveolar bone [230]. In many reports bone resorption was detectable 6 weeks after the final inoculation [229, 247], although other studies have shown a detectable alveolar bone loss as early as 3 weeks after first infection or 2 weeks after the final bacterial challenge [248]. Both mice and rats are susceptible to alveolar bone loss however there are differences in the susceptibility to experimental periodontal disease among various strains. BALB/c, DBA/2J and C3H/HEN are more susceptible than C57/B16, SJL/J and $\mathrm{C} 3 \mathrm{H} / \mathrm{HeJ}$ [249]. These differences are correlated to genetic variation in the strains affecting components of the immune response. For example, the point mutation on Toll-like receptor 4 (TLR4) in $\mathrm{C} 3 \mathrm{H} / \mathrm{HeJ}$ mice or differences in adaptive immunity [250]. Normal variation in the genetics, in addition to modification by genetic engineering, in mice creates a potentially valuable option for developing a causeand-effect association with both aspects of the host response and periodontal disease.

Bacterial inoculation-induced immune response in mice might be comparable to that associated with periodontitis in humans. Downregulation of the innate immune response promotes host-microbe homeostasis and highly orchestrated expression of certain host defense cytokines and mediators is associated with healthy periodontal tissues [251]. Virulence factors produced by some oral pathogens might inhibit neutrophils transmigration into the periodontium; cytotoxic to recruited neutrophils; or promote leukocytic longevity [91]. For example, $P$. gingivalis secrets a serine phosphatase enzyme (SerB), may play an important role in preventing granulocyte recruitment to the periodontal tissues as, in a rat 
model [245]. SerB also responsible for inhibition of interluiken-8 secretion from epithelial cells infected with $P$. gingivalis, so in the absence of SerB more neutrophils are recruited into the gingival tissue [245]. Also, in rats ligature induce periodontitis model, administration of nicotine enhanced alveolar bone loss concomitant with a reduced pro- and anti- acute inflammatory cytokine response to LPS (TNF, transforming growth factor- $\beta$, IL-10) [252]. Chronic exposure of rats to nicotine inhibits antibody-forming cell responses and this immunosuppression appears to be the result of impairment of antigen mediated T cell signaling [253, 254].

A variety of proteolytic enzymes are involved in the normal homeostatic remodeling of the periodontium including natural turnover and pathological degradation of the alveolar bone. In periodontal disease, degradation of ligament and alveolar bone can be excessive and lead to progressive break down of the periodontal supportive tissue [255]. Matrix metalloproteinase 8 (MMP-8), a collagenolytic enzyme responsible for pathological degradation of type I collagen, the predominant type of collagen in periodontium. The role of MMP-8 was investigated in mouse model study, where MMP-8 knockout mice and wild type mice were orally infected by $P$. gingivalis to induce periodontitis [256]. A histological analysis showed that bone loss was significantly higher in the $P$. gingivalis-infected $\mathrm{Mmp}^{-8^{-/}}$group compared to the $P$. gingivalis-infected WT group. The study concluded that MMP-8 plays a protective role in alveolar bone loss during periodontal infection, possibly by inactivating pro-inflammatory cytokines. 


\subsection{Canine models of periodontitis:}

Dogs provide a suitable model for testing naturally occurring gingivitis and periodontitis [257]. The genera isolated from the oral cavities of dogs were typical of those found in human dental plaque included Actinomyces, Porphyromonas, Fusobacterium, Neisseria, and Streptococcus [258]. Also, periodontal disease in dogs is highly correlated with aging and thus the etiopathology is closely related to humans [259]. A study to investigate deleterious effect of nicotine on the canine periodontium, oral or systemic nicotine administration to dogs has been associated with increased blood flow to the anterior gingiva, relative to untreated controls [260]. Another study noted that applying a solution of tobacco smoke to gingiva of dogs might suppress crevicular innate cell migration in neutrophils isolated from both inflamed and healthy sites [261].

As a limitation, some major difference exists between humans and dogs as the lack of lateral movements, presence of open contacts between teeth and no occlusal contacts for all premolars [262]. Other important differences between dogs and humans are lack off gingival sulcus and cervical fluids, and a different composition of periodontal plaque and calculus [263].

5.4 Non-human primate models of periodontitis

Monkeys have the advantage of probably being phylogenetically similar to humans. Most of species have same dental formula as human and have naturally 
occurring dental plaque, calculus, oral microbial pathogens (e.g., P. gingivalis), and periodontal disease [223, 262]. Microbiologically, in Macaca fascicularis (cynomolgus monkeys), the composition of the plaque is Gram positive rods and cocci for supragingival plaque and anaerobic Gram negative rods for subgingival plaque $[264,265]$. The inflammatory response to periodontal disease is quite similar to that found in humans wherein connective tissues are infiltrated by plasma cells, lymphocytes and neutrophils [262]. To study periodontitis and promote plaque formation, sutures or orthodontic elastics are commonly placed around selected molars until pocket formation is confirmed by probing [266]. Another alternative modification to use primates for periodontitis, Cynomolgus monkeys with no previously detectable $P$. gingivalis have been treated with the bacteria. About 5 months later, infection by $P$. gingivalis was confirmed and plaque formation leading to bone loss was observed [267].

The disadvantages of non-human primate models are difficulty in obtaining a large number of animals to perform adequate statistical analysis of the results, high cost to provide special husbandry requirements, animals are prone to systemic infections and diseases. Moreover, ethical considerations and regulations must be fulfilled in order to prevent any trafficking of protected species [268]. Collectively, these limitations make non-human primates a less practical model for periodontal disease.

In conclusion, relevant similarities in gingival and tooth anatomy between humans and mice, availability of mouse smoke-exposure chambers, existing literature on rodent models of periodontal disease and the need to prioritize the 
use of lower vertebrates, all collectively suggested mice as the most appropriate model to experimentally advance our knowledge of smoking-related periodontal disease mechanisms. 
Hypothesis and Aims

We hypothesized that Porphyromonas-gingivalis-infected, cigarette smokeexposed mice would represent reproducible models of acute (ligature model) and chronic (oral gavage model) tobacco-enhanced periodontitis that reflect multiple aspects of the disease noted in human smokers.

Aims

We set out to examine if tobacco-smoke exposure, in two murine bacterialinduced periodontitis models, was associated with:

- A suppressed local and / or systemic innate response,

- A suppressed anti-bacterial lgG response.

- Enhanced alveolar bone loss. 


\section{CHAPTER 2: MATERIALS AND METHODS}

Carboxymethyl cellulose (CMC) was purchased from Sigma Aldrich Corporation (St. Louis MO, USA). Phosphate Buffered Saline (PBS) was purchased from Life Technologies (Grand Island NY, USA). Streptococcus gordonii (S . gordonii) DL-1 and P. gingivalis 33277 were purchased from the American Type Culture Collection (Manassas, VA) and maintained as frozen stocks. BD BBL Brain-heart infusion broth, Mitis Salivarius agar and Difco bacteriological agar were purchased from Difco Laboratories Inc. Potassium tellurite was from SIGMA (St. Louis, MO). Gifu anaerobic medium was from (GAM; Nissui Pharmaceutical, Tokyo, Japan). Oral gavage needles were obtained from Cadence Science Inc. Cranston, RI). Puritan swabs were from (25-800 D 50) (Puritan Medical Products Co., Guilford, ME). Gentamicin solution was purchased from SIGMA (St. Louis, MO). Sheep blood was purchased from Lampire Biological Laboratories (Pipersville, PA). Midori Green was from Bulldog-Bio (Portsmouth, $\mathrm{NH}$ ). Methylene Blue and Eosin were obtained from Ricca Chemical Company (TX, USA). RNeasy mini kit and RLT buffer were from QIAGEN (Hilden, Germany). Taq 2X Master Mix (M0270) was from NEW ENGLAND BIOLABS (MA, USA). qScript XLT reverse transcriptase was from (Quantabio, USA). Real-Time PCR Master Mix and mouse primers were from TaqMan Thermo Fisher Scientific, USA. BD Microtainer blood collection tubes were from Becton Dickenson. Trizol ${ }^{\mathrm{TM}}$ Reagent 
was from Thermo Fisher Scientific, USA). Mouse/Rat Cotinine ELISA was from CALBIOTECH (CA, USA). Genomic DNA Purification kits were from Promega (Madison, WI). 16s PCR primers were purchased from Bio-Synthesis Inc. (Lewisville, TX, USA). Anti- mouse IgM-HRP antibody was purchased from BETHYL Laboratories (Montgomery, TX) and horse anti-mouse lgG-HRP antibody from Cell Signaling Technology (Danvers, MA). Mouse Cytokine / Chemokine Magnetic Bead Panel was purchased from (MiliporeSigma, USA). Immunocal was purchased from StatLab Medical Products (McKinney TX, USA). Research cigarettes (1R6F) were purchased from University of Kentucky. Membrane filters were from Pall life sciences (Port Washington, NY). 6-0 black non absorbable surgical silk (SURGICAL SPECIALTIES LOOK Co, USA). DEXDOMITOR was from Zoetis, USA. Ketamine was from Henry Schein, Inc Co. Puralube Vet Ointment was from (1-800-PetMeds, Delray Beach, FL). Heat Pad from K \& H Pet Products. Ligature holders were from University of North Carolina [269] and the modified design was from University of Louisville Oral Health and Rehabilitation Department. CO2 was provided by Welders Supply Co. (Louisville, KY). Nikon SMZ 800 dissecting microscope (40X, Nikon Instruments Inc., Melville,35 NY, USA) fitted with a Boeckeler VIA-170K video image marker measurement system was from Boeckeler Instruments Inc, Tucson, AZ, USA. 
Mice

White BALB/c mice, 6-8 weeks old, females, were purchased from Jackson laboratory. All the experimental procedures were performed in accordance with the Guidelines of the Institutional Animal Care and Use Committee of University of Louisville, as described in the Federal Guidelines for the Care and Use of Laboratory Animals. Animals were housed and maintained at the University of Louisville, School of Dentistry in a room maintained by the Research Resources Facility. Cages for animal housing were changed weekly, unlimited food and water provided throughout the duration of the experiment with a 12-hour light/dark cycle and controlled temperature and humidity.

\section{Smoking machine and cigarettes :}

Teague TE-10 whole body smoke inhalation exposure system was utilized to conduct the mouse exposures (Teague Enterprises; Davis, CA) [270]. 1R6F research cigarettes were from University of Kentucky $(8.58 \mathrm{mg}$ of tar/cigarette; $0.721 \mathrm{mg}$ nicotine/cigarette; additives). 


\section{Smoking Machine Teague Enterprises TE-10C :}
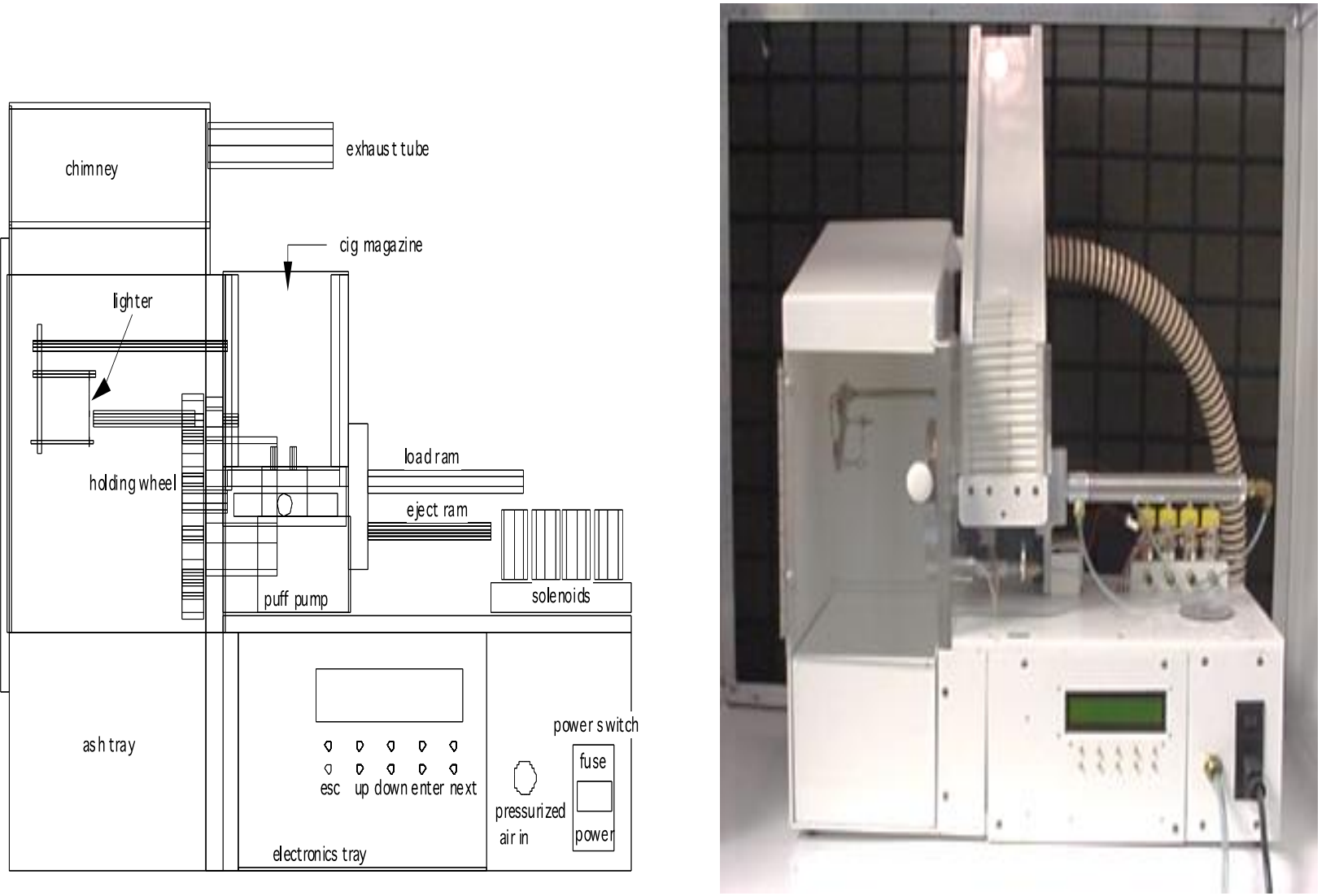

Figure 1: The smoking machine Teague Enterprises TE-10C

The TE-10c is a microprocessor-controlled cigarette smoking machine that produces smoke from research cigarettes. From one to ten cigarettes can be smoked at a time. The machine's applications include use with animal and cell culture exposure systems and serial animal exposure chambers. The machine is composed of four sections: cabinet, cigarette handling, chimney, and ash collection tray. 
We performed two different in vivo experiments. Firstly, a modified Baker Model was utilized where an S. gordonii infection was added along with an increase in the number of $P$. gingivalis infections with smoke/no smoke exposure for 68 days. Secondly, we utilized a ligature model with $P$. gingivalis infection with smoke/no smoke exposure for 14 days.

\section{Growth of Bacterial Strains}

S. gordonii was cultured anaerobically for $16 \mathrm{hr}$. at $37^{\circ} \mathrm{C}$ without shaking in brain-heart infusion supplemented with $1 \%$ yeast extract. $P$. gingivalis was cultured in Gifu medium under anaerobic conditions ( $80 \% \mathrm{~N} 2,10 \% \mathrm{H} 2$, and $10 \% \mathrm{CO} 2)$ at $37^{\circ} \mathrm{C}$. Growth was monitored by tracking optical density at a wavelength of 600 $\mathrm{nm}$. The oral infection of mice by S. gordonii and/or P. gingivalis was performed as showed in Figure 2 timeline strategy.

\section{Animal Exposure to Smoke}

Female white BALB/C mice were placed into either a cigarette smoke exposure (CSE) chamber or a sham exposure chamber (ambient filtered room air) of the Teague TE-10C exposure apparatus chamber for a period of 3 hours daily. Cigarettes were smoked using the standard Federal Trade Commission method: a two second, $35 \mathrm{~cm}^{3}$ puff, once a minute for a total of 9 minutes. One pack of 20 research cigarettes was used per day. In order to monitor the daily cigarette smoke levels, carbon monoxide (CO) concentration and total suspended particulates 
(TSPs) were measured twice daily. The level of $\mathrm{CO}$ within each exposure chamber was determined using a carbon monoxide detector with a digital readout in parts per million. TSPs were recorded twice daily by drawing a known volume of air during a 5-minute period from the exposure chamber via a sampling port and collecting TSPs on a piece of filter paper. The difference in weight pre- and postsampling was divided by the volume of air that was drawn from the chamber during an interval of five minutes while sampling the exposure chamber. After the smoke exposure, animals were returned to their home cages. Food and water were changed daily in smoke cages.

For the Baker model, mice were exposed to ambient air or cigarette smoke, 20 cigarettes per day over 3 hours, 7 days per week for 68 days. CO levels during the exposure were kept at an average of $150 \mathrm{ppm}$. Mean TSP throughout the experiment was $4.9 \mathrm{mg} / \mathrm{m}^{3}$. For the ligature model, mice were exposed to ambient air or cigarette smoke 20 cigarettes per day over 3 hours, 7 days per week for 14 days. CO levels during the exposure were kept at an average of 200 ppm. TSP mean was $9.8 \mathrm{mg} / \mathrm{m}^{3}$. 


\section{Modified Baker Model:}

The Baker Model of bacterially initiated periodontal disease [229] describes a method of orally infecting mice with $P$. gingivalis leading to alveolar bone loss. It is aimed at allowing mice to naturally develop periodontitis over a period of time similar to development of periodontitis in humans. It closely mimics the chronic nature of periodontitis. Alveolar bone loss is detected after 10 weeks.

In our modified Baker Model, mice were repeatedly orally inoculated with $S$. gordonii and $P$. gingivalis $\left(10^{9}\right.$ colony-forming units (CFU) in $100 \mathrm{ml} 2 \%$ carboxymethylcellulose) or sham inoculated (vehicle alone) as shown in Figure 2. 
Timeline strategy for Baker model bacterial inoculation

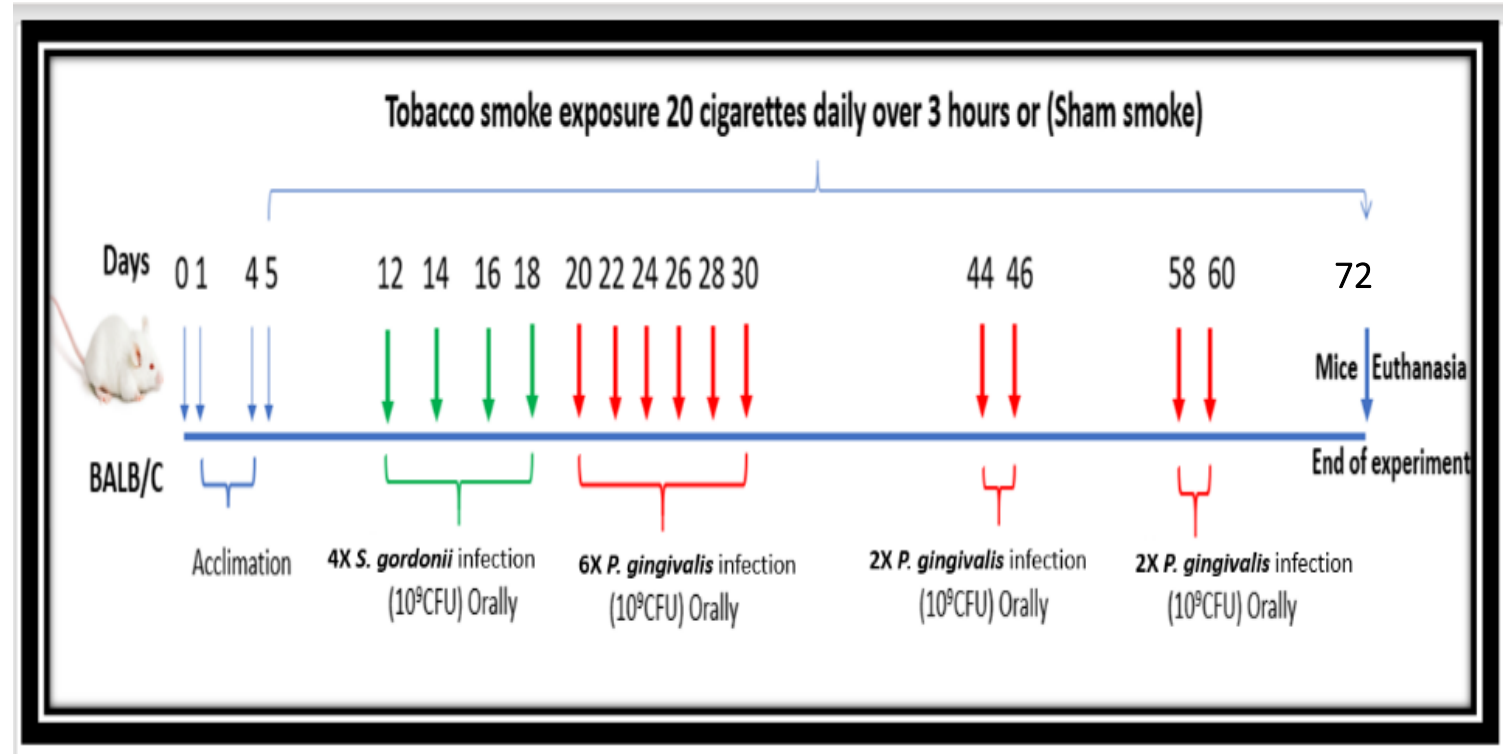

Figure 2: Bacterial inoculation timeline for smoke- or ambient air-exposed mice. Days of inoculation are represented by green arrows for S. gordonii $\left(10^{9} \mathrm{CFU}\right)$ and red arrows for $P$. gingivalis $\left(10^{9} \mathrm{CFU}\right)$. 
Day 0

There were 4 groups:

1. Group 1 (Sham infection / no smoking exposure),

2. Group 2 (Bacteria infection / no smoking exposure),

3. Group 3 (Sham infection / smoking exposure),

4. Group 4 (Bacteria infection / smoking exposure). 
Mice group assignment for Baker model

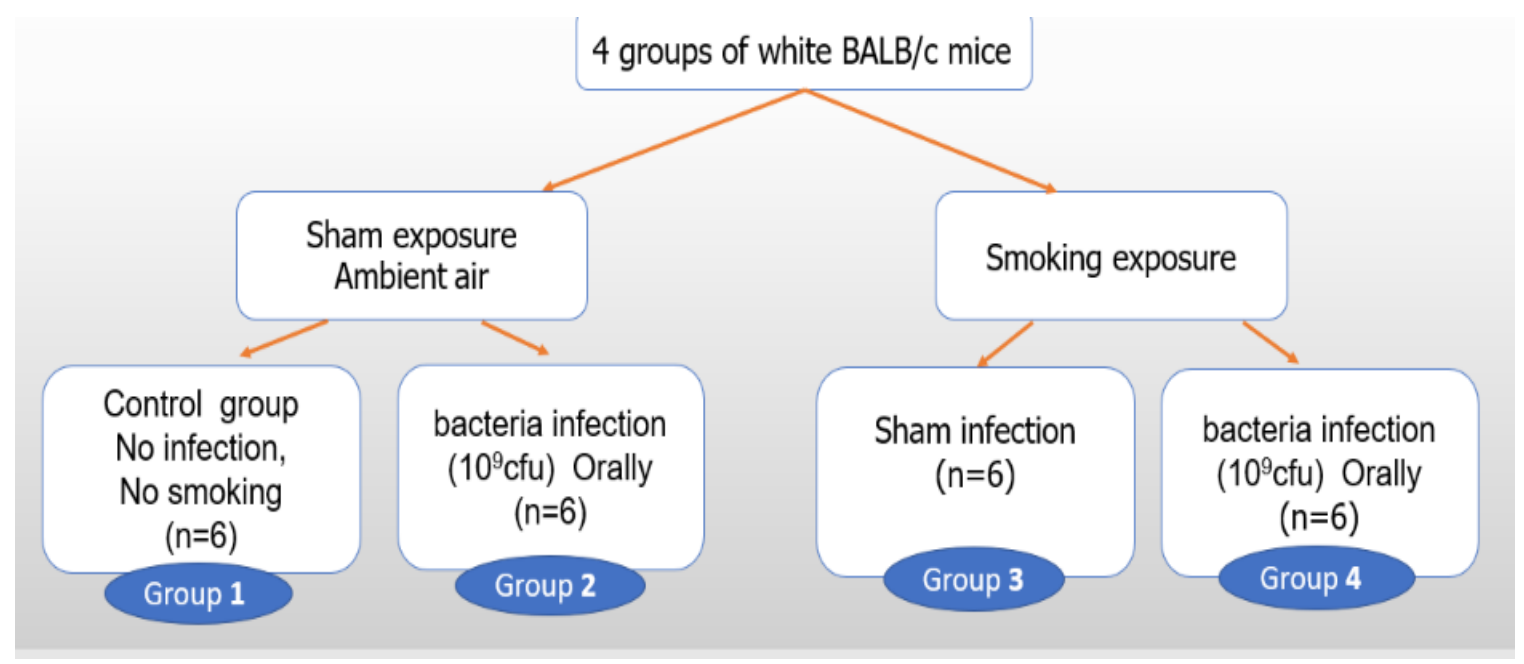

Figure 3: Baker model group assignment: Female Balb/c mice (6-8 weeks) distributed in four groups ( $n=6)$. Group 1, sham infection and no smoking exposure; Group 2, bacterial infection and no smoking exposure; Group 3, sham infection and smoking exposure and Group 4, bacterial infection and smoking exposure. 
Day 0 through Day 4

Mice acclimated to the surrounding environment; no smoking exposure or infection was done at this time.

\section{Day 5}

Mice were exposed to ambient air or cigarette smoke (20 cigarettes per day over 3 hours), continued daily until euthanasia.

Day 12 though Day 18

Mice were infected orally with S. gordonii in PBS and carrier CMC at a concentration of $10^{9} \mathrm{CFU} /$ mouse in $100 \mu \mathrm{l}$ PBS and 2\% CMC. A gavage needle was used to infect mice locally in the buccal vestibule around the molar area. Sham infected mice received $2 \% \mathrm{CMC}$ in $100 \mu \mathrm{PBS}$ with $2 \% \mathrm{CMC}$. The mice were infected with S. gordonii for a total of four times. The infection was done every other day.

Day 20 through Day 55

Mice were infected orally with $P$. gingivalis in PBS and carrier CMC at a concentration of $10^{9} \mathrm{CFU} /$ mouse in $100 \mu \mathrm{l}$ PBS and 2\% CMC. A gavage needle was used to infect mice locally in the buccal vestibule around the molar area. Sham infected mice received $2 \% \mathrm{CMC}$ in $100 \mu \mathrm{I}$ PBS. The infection was done every other day for six times followed by two subsequent infections every two weeks for a total of ten times infection. The sham-infected mice were treated in the same manner as the bacterial infected mice except that they received just PBS and CMC. 


\section{Day 72}

Mice were euthanized 42 days after the last $P$. gingivalis infection. Inhalation of carbon dioxide was used as the standard method to euthanize the mice. The flow of carbon dioxide was maintained at (1.5 liters) until at least 1 minute after respiratory arrest. The secondary method was decapitation/exsanguination.

Oral swabs for S. gordonii and P. gingivalis:

Oral swabs were obtained from all mice by swabbing the buccal vestibule molar area of the gingiva using Puritan polyester tipped swabs. This was done to detect the presence of $S$. gordonii in the oral cavity, to assess the effectiveness of $S$. gordonii infection, to monitor the prevalence of $S$. gordonii in the different treatment groups, to detect the presence of $P$. gingivalis in the oral cavity, to assess the effectiveness of $P$. gingivalis infection and to monitor the prevalence of $P$. gingivalis in the different treatment groups. Oral swabs were collected for S. gordonii detection one day after the second infection, one day after the third infection, one day after the six rounds of $P$. gingivalis infection, then every two weeks until the final swab at the time of euthanasia. 
Oral swabs time frame for Baker model.

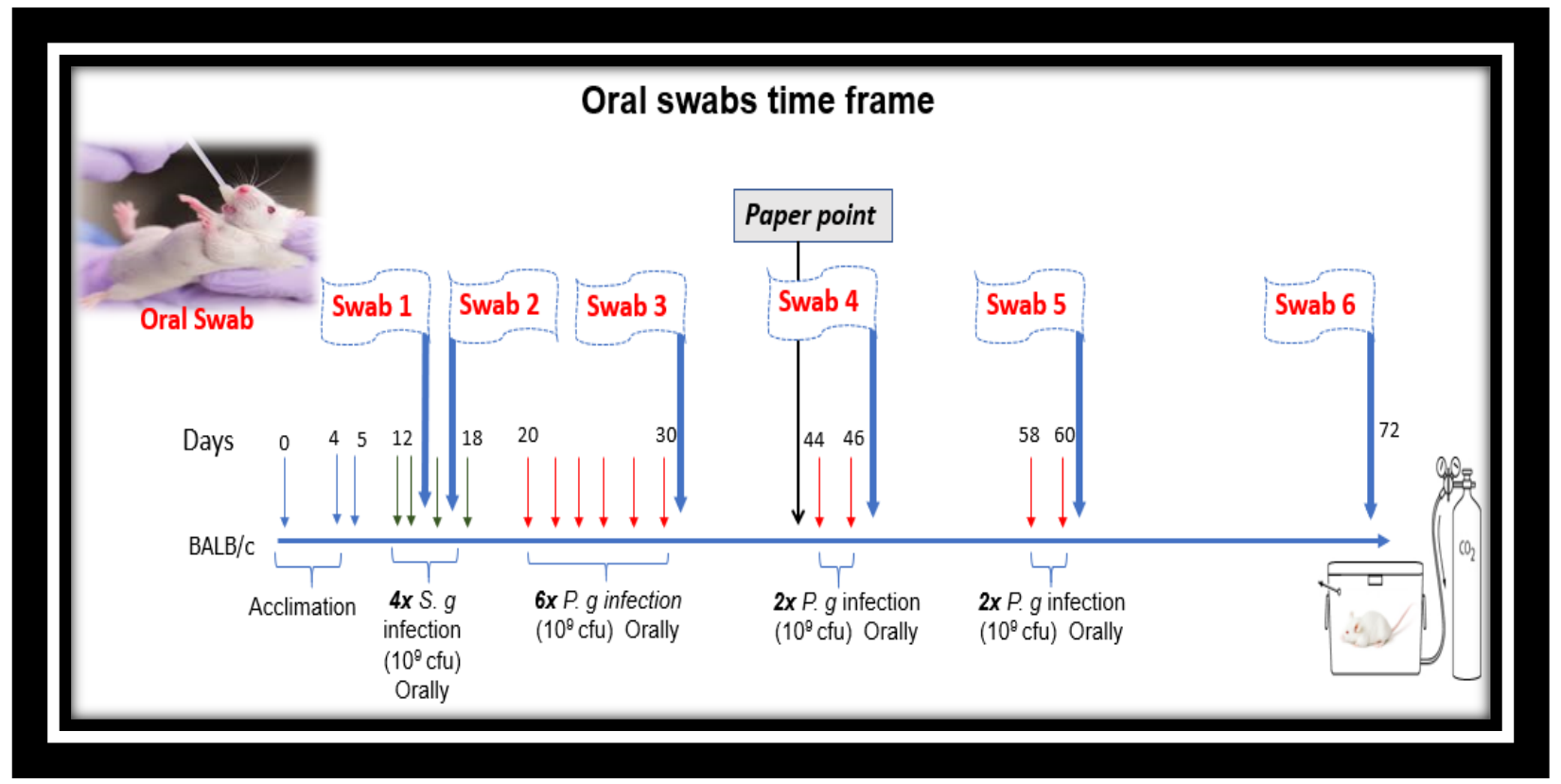

Figure 4: Oral swabs time frame for Baker model represented by blue arrows. 


\section{S. gordonii detection was performed by two methods:}

1. Plate culture:

The periodontal microbiota was sampled by swabbing the buccal vestibule around the molars, then streaked directly onto Mitis Salivarius agar plates supplemented with $0.1 \%$ potassium tellurite solution (1\%) for aerobic culture at $37^{\circ} \mathrm{C}$ for $1-2$ days.

Plates were examined for appearance of colonies and those with small deep dense colonies believed to be more representative of $S$. gordonii colonies. Entire plates scraped into $200 \mu \mathrm{l}$ nuclease free water. $5 \mu \mathrm{l}$ suspension used in the $\mathrm{gftG}$ PCR.

2. . Standard Polymerase Chain Reaction for S. gordonii:

Entire plates scraped into $200 \mu$ l nuclease free water. $5 \mu$ l suspension used for Standard PCR procedure and run on $2 \%$ agarose gel electrophoresis at $120 \mathrm{~V}$ to detect the presence of the amplified glucosyltransferase Gene ( $g f t G)$ [271].

- gftG primers, Fragment size is 440 (bp);

gftG upstream 5'-CTATGCGGATGATGCTAATCAAG-3'

gftG downstream 5'-GGAGTCGCTATAATCTTGTCAGA-3'

and the cycling conditions: $10 \mathrm{~min}$ at $95^{\circ} \mathrm{C}, 35$ cycles of $15 \mathrm{sec}$ at $950 \mathrm{C}, 35$ cycles of $15 \mathrm{sec}$ at $50^{\circ} \mathrm{C}, 35$ cycles of $30 \mathrm{sec}$ at $68^{\circ} \mathrm{C}, 5 \mathrm{~min}$ at $68^{\circ} \mathrm{C}$ and holding at $4^{\circ} \mathrm{C}$. This assay was done to detect presence of $S$. gordonii only using a crude preparation. No attempt was made for quantification. 


\section{P. gingivalis detection:}

Mice were sampled by swabbing the maxillary gingiva using Puritan swabs. This was done to detect the presence of $P$. gingivalis in the oral cavity, to assess the effectiveness of infection and to monitor the prevalence and persistence of $P$. gingivalis in the different treatment groups. Oral swabs were collected for $P$. gingivalis detection one day after each infection and then every two weeks after last infection.

\section{P. gingivalis detection was performed by two methods:}

1. Plate culture.

The periodontal microbiota was sampled by swabbing the buccal vestibule around molars, then the swab tips were submerged into $300 \mu$ anaerobic balanced GAM broth followed by plating onto blood agar plates (100 $\mu$ l/plate) and CFU were enumerated following anaerobic growth for 1 month and examined at 1, 2 and 4 weeks. $P$. gingivalis was identified by black pigmented colonies and Gram staining.

2. Standard PCR procedure and $2 \%$ agarose gel electrophoresis at $120 \mathrm{~V}$ to detect the presence of the amplified $P$. gingivalis 165 Gene [272].

- P. gingivalis $16 \mathrm{~S}$ primers, Fragment size is 404 (bp);

$$
\text { P. gingivalis 16S upstream 5'AGGCAGCTTGCCAT ACTGCG-3' }
$$

P. gingivalis 16S downstream 5'ACTGTTAGCAACTA CCGATGT-3'

and the cycling conditions: $30 \mathrm{sec}$ at $95^{\circ} \mathrm{C}, 30$ cycles of $15 \mathrm{sec}$ at $950 \mathrm{C}, 30$ cycles of $15 \mathrm{sec}$ at $48^{\circ} \mathrm{C}, 30$ cycles of $1 \mathrm{~min}$ at $68^{\circ} \mathrm{C}, 5 \mathrm{~min}$ at $68^{\circ} \mathrm{C}$ and holding at $4-10^{\circ} \mathrm{C}$. 
Specimen collection and analysis:

1. Tissue harvest

Gingival tissue of the entire maxilla was excised around the molar area and was immersed in RLT buffer (Qiagen). Samples were flash frozen on dry ice then, stored at $-80^{\circ} \mathrm{C}$. The tissue was disrupted by sonication and RNA prepared using RNeasy kit following the manufacturer's protocol. RNA concentration was determined using a NanoDrop nucleic acid quantification instrument (Thermo Fisher) and equalized before cDNA preparation using qScript XLT (Quanta bio). Real-time quantitative PCR (qPCR) analysis of gingival tissue was performed using the TaqMan system to determine cytokine mRNA expression of inflammatory markers (IL-1 $\beta$, MMP-8, MMP-9, CD14, CD45) with GAPDH housekeeping gene.

\section{Serum:}

Cardiac puncture was used to collect blood from each mouse, which was added to gel tubes (BD Microtainer) and allowed to clot at room temperature for 30 minutes followed by centrifuging according to the protocol. Sera were aliquoted and stored at $-80^{\circ} \mathrm{C}$ for later assessment of systemic inflammatory mediators by multiplex ELISA and $\lg$ and $\lg$. $\quad P$. gingivalis reactive antibodies were quantified by ELISA. 
Serum $P$. gingivalis immunoglobulin detection protocol

Serum was tested for $P$. gingivalis cognizant $\lg G$ and $\lg M$ antibodies, as determined by ELISA. Briefly, P. gingivalis was fixed in formalin and washed three times in PBS and diluted to an $\mathrm{OD}_{600 \mathrm{~nm}}$ of 0.3 and plated in 96 well microtiter plate after blocking for 12 hours at $4^{\circ} \mathrm{C}$ as described [245]. Diluted mouse sera (1:200) were reacted with bacteria for $2 \mathrm{~h}$ at room temperature. After washing, goat antimouse IgM or horse anti-mouse IgG (both conjugated to HRP) (1:1000) were added to the plate. After washing 7 times, TMB was applied and incubated for 5 min. The assay reactions were terminated by the addition of $1 \mathrm{~N} \mathrm{H}_{2} \mathrm{SO}_{4}$ and analyzed at an $\mathrm{OD}_{450 \mathrm{~nm}}$ using a Bio-Rad microplate reader.

3. Alveolar bone loss evaluation:

Freshly harvested skulls were submerged in tap water and boiled for 8 minutes. After de-fleshing gently with micro brushes and running water, the skulls were immersed overnight in 3\% hydrogen peroxide. The following day, the skulls were immersed for $1 \mathrm{~min}$ in $1 \%$ bleach, washed and air dried. The maxillae were stained with $0.5 \%$ eosin for 5 min followed by $1 \%$ methylene blue for 1 minute. Alveolar bone loss was measured using a SMZ 800 dissecting microscope fitted with a VIA$170 \mathrm{~K}$ video image marker measurement system. Bone loss was measured at 14 predetermined points on the maxillary molars of de-fleshed maxillae, determined as the distance from the cementoenamel junction (CEJ) to the alveolar bone crest $(A B C)$. Bone loss was calculated by subtracting the mean CEJ-ABC distance of the control group from the CEJ-ABC distance of each experimental group. 
Microscopic image of mice maxillary teeth

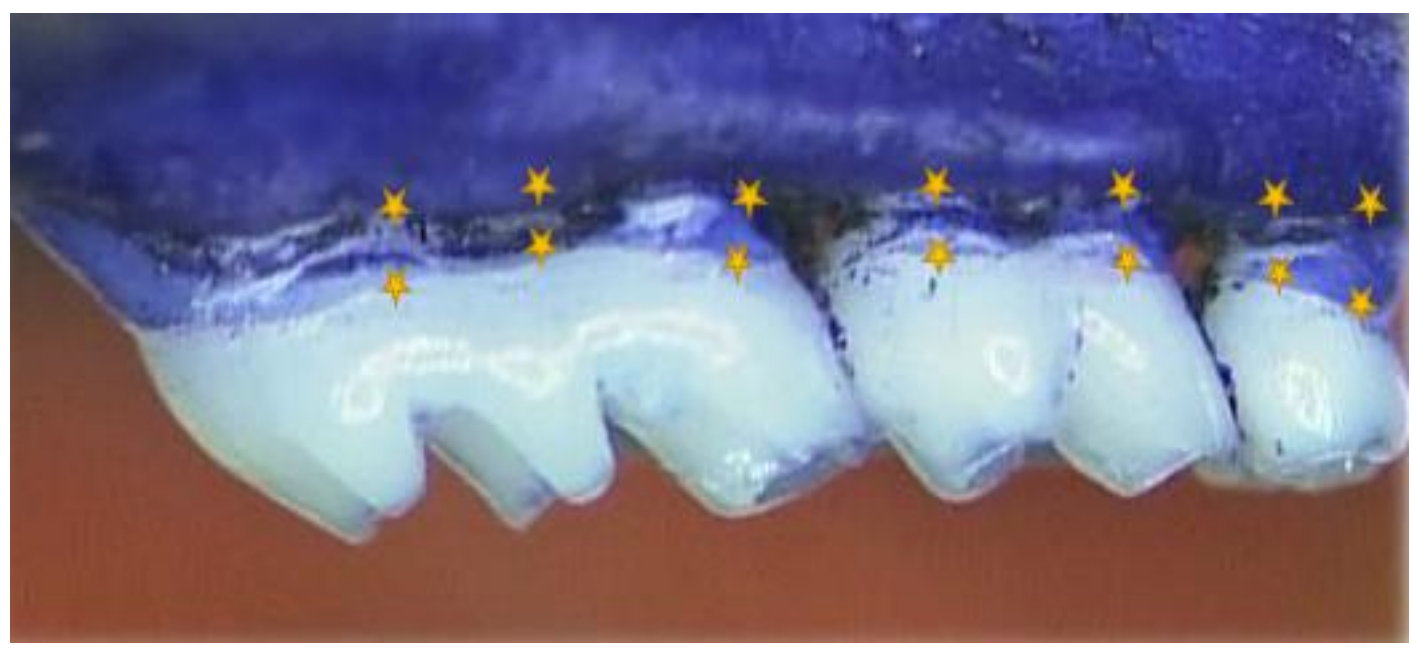

Figure 5: Microscopic image of mice maxillary teeth showing the seven sites of measurement from the CEJ to $A B C$ (depicted by yellow stars) on the left buccal side after staining with methylene blue for visualization of the CEJ. 
Ligature model:

The ligature-induced periodontitis model is another method of modeling periodontal disease. This model has the advantage of being initiated at a known time with a predictable sequence of events culminating in alveolar bone loss within a few days [235]. In the present study, mice were repeatedly orally inoculated with P. gingivalis ( $10^{9}$ colony-forming units (CFU) in $100 \mathrm{ml} \%$ carboxymethylcellulose) or sham inoculated (vehicle alone) as in Figure 6. 
Timeline strategy for ligature model bacterial inoculation

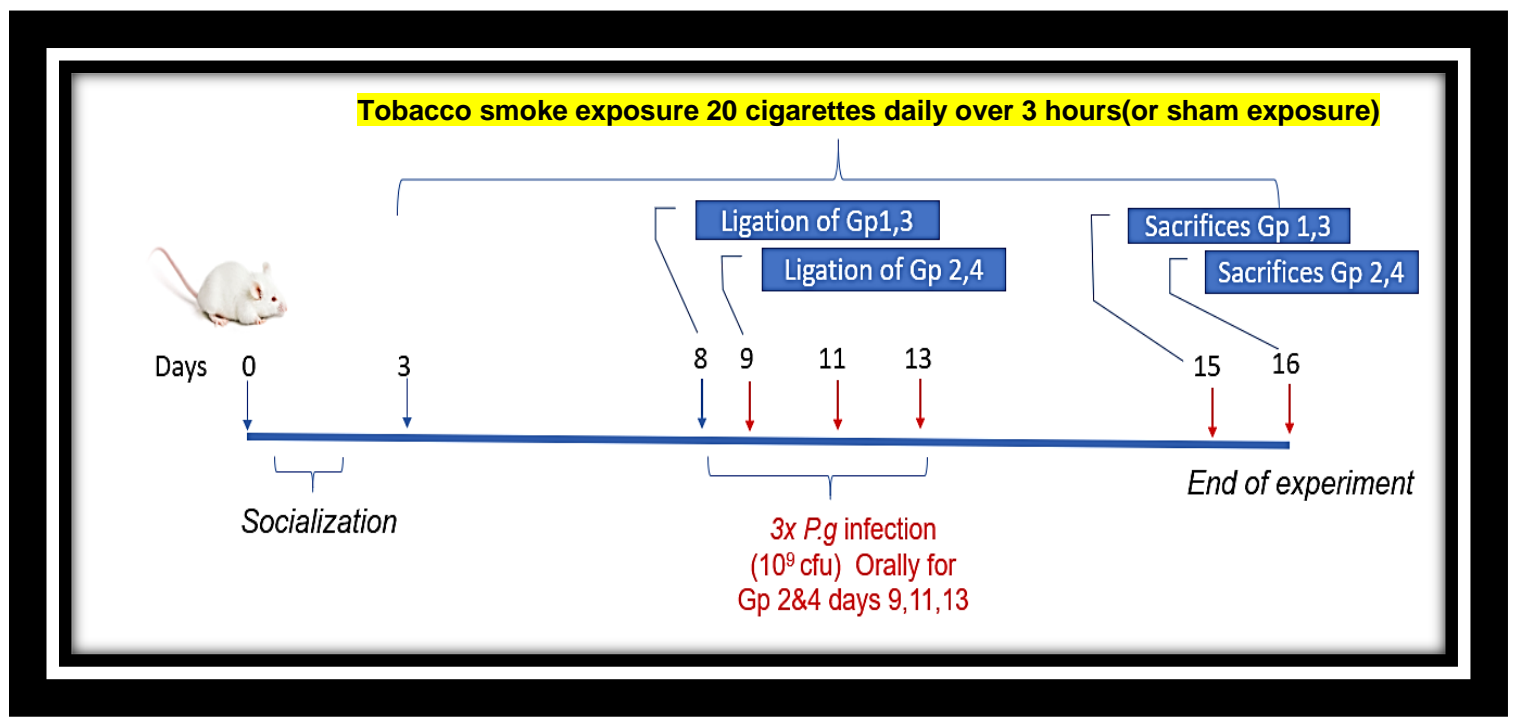

Figure 6: Ligature placement and bacterial inoculation strategy for smoke- or ambient air-exposed mice. Days of inoculation are represented by red arrows where $P$. gingivalis $\left(10^{9} \mathrm{CFU}\right)$ or sham infections $(\mathrm{CMC})$ were administered orally 3 times/as shown in the timeline. 
Day 0

Upon arrival of mice, mice were randomized and distributed in groups $(n=7$ per group). Mice tails were marked for identification of groups and individual animals. Mice weights were recorded every other day till the end of experiment.

There were 4 groups of mice:

1. Group 1 (Sham infection / no smoking exposure / Ligature),

2. Group 2 (Bacteria infection / no smoking exposure/ Ligature),

3. Group 3 (Sham infection / smoking exposure/ Ligature),

4. Group 4 (Bacteria infection / smoking exposure / Ligature). 


\section{Mice group assignment for Ligature model}

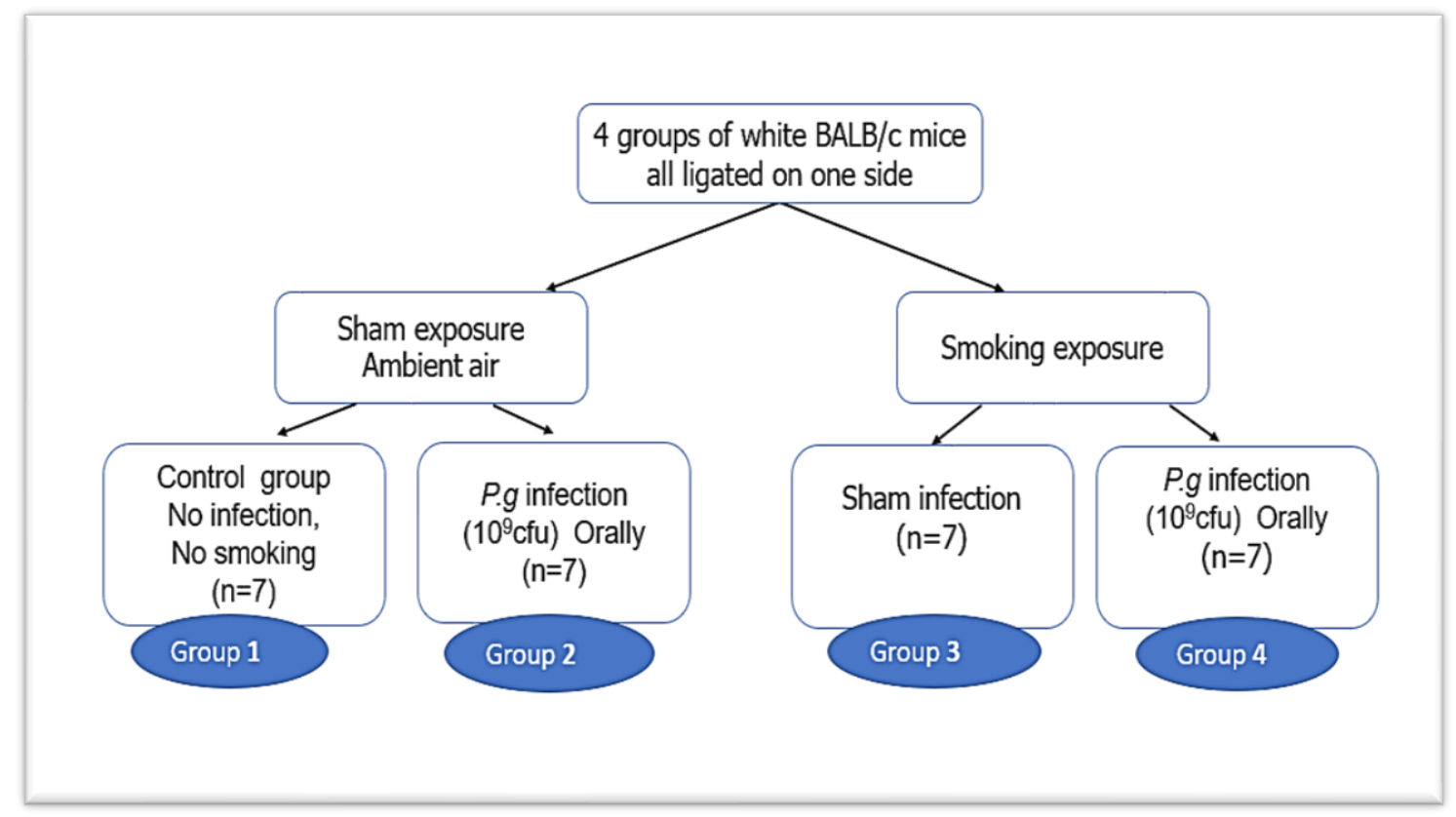

Figure 7: Ligature model mouse group assignment: female Balb/c mice (8 weeks) distributed in four groups ( $n=7)$. Group 1 ligature, sham infection and no smoking exposure, Group 2 ligature, Bacteria infection and no smoking exposure, Group 3 ligature, sham infection and smoking exposure and Group 4 ligature, Bacteria infection and smoking exposure. 
All four experimental groups had their right maxillary second molar ligated by 6-0 black non absorbable surgical silk positioned around the tooth with the ligature holder [269] and then tied gently with a lingual side knot to prevent damage to the periodontal tissue. The contralateral molar tooth in each mouse was left unligated to serve as baseline control for bone height measurements.

Day 0 through Day 3

Mice acclimated to the surrounding environment. No smoking exposure or infection was done at this time.

Day 3 through Day 7

Mice were exposed to ambient air or cigarette smoke 20 cigarettes per day over 3 hours till the day of euthanasia.

Day 8

Mouse groups number 1 and 3 were anesthetized for the placement of the ligature around the right maxillary second molar with Ketamine/ Dexmedetomidine. Dosing was as follows:

Ketamine dose is $65 \mathrm{mg} / \mathrm{kg}$.

Dexmedetomidine dose is $0.65 \mathrm{mg} / \mathrm{kg}$.

Mice were placed on a heating bed until recovered from anesthesia, and eye ointment was applied to protect against eye dryness. Mice were sham infected locally around maxillary molars with $100 \mu \mathrm{l}$ PBS (2\% CMC) as described previously. Sham infection was repeated on alternate days for three times (Days 8,10 and 12). 
Day 9

Mouse groups 2 and 4 were anesthetized for the placement of the ligature around the right maxillary second molar with the same previously mentioned dose followed by oral infection with $P$. gingivalis ( $10^{9} \mathrm{CFU} /$ mouse) in $100 \mu \mathrm{l} \mathrm{PBS} / 2 \%$ CMC. The infection was repeated every other day for three days (Days 9, 11 and 13).

Day 15

Mouse groups number 1 and 3 were euthanized 7 days after the ligature placement. Inhalation of carbon dioxide was used as the standard method to euthanize the mice. The flow of carbon dioxide was to 1.5 liters per minute. Carbon dioxide flow was maintained for at least 1 minute after respiratory arrest. The secondary method was decapitation/exsanguination.

Day 16

Mouse groups number 2 and 4 were euthanized 7 days after the ligature placement. Inhalation of carbon dioxide was used as the standard method to euthanize the mice. The flow of carbon dioxide at 1.5 liters per minute was maintained for at least 1 minute after respiratory arrest. The secondary method was decapitation/exsanguination. 
Specimen collection:

1. Tissue harvest

Gingival tissue of the entire maxilla was excised around the molar area and immersed in buffer (Trizol $500 \mu \mathrm{l})$. Samples were stored at $-80^{\circ} \mathrm{C}$ until used for RNA isolation following the manufacturers protocol. Real-time quantitative PCR (qPCR) analysis of gingiva is planned to determine cytokine mRNA expression of inflammatory markers using TaqMan system. However, this was not possible due to lab and core facilities closure associated with the COVID-19 outbreak.

\section{Serum:}

Cardiac puncture was used to collect blood from each mouse. Serum was stored at $80^{\circ} \mathrm{C}$ for later assessment. Serum was tested for $P$. gingivalis exposure by analyzing total $P$. gingivalis cognizant $\lg G$ and $\lg M$ antibodies, as determined by ELISA. Analysis of systemic inflammatory mediators by multiplex ELISA is planned. However, this was not possible due to lab and core facilities closure associated with the COVID-19 outbreak

3. Alveolar bone loss evaluation:

Freshly harvested skulls were submerged in deionized water and boiled for 8 minutes, followed by de-fleshing, and gentle cleaning with micro brushes and running water. Skulls were then soaked overnight in 3\% hydrogen peroxide before being immersed for $1 \mathrm{~min}$ in $1 \%$ bleach, washed and air dried. The maxillae were stained with $0.5 \%$ eosin for 5 min followed by $1 \%$ methylene blue for 1 minute. Alveolar bone loss was measured in millimeters at 14 predetermined points on the 
maxillary molars of de-fleshed maxillae as the distance from the cementoenamel junction (CEJ) to the alveolar bone crest (ABC).

Statistical analysis:

Data were evaluated by ANOVA or t-test, as appropriate, using InStat v3.06 program (GraphPad, San Diego, CA), unless otherwise described. Significance was set at the $p<0.05$. 


\section{CHAPTER 3 RESULTS}

We examined the influence of cigarette smoke exposure on oral health in two different murine models of periodontitis. First, 68 days, bacterial-induced, chronic disease model was exploited. Second; a 14 day, acute disease model in which bacterial-induced bone loss was accelerated by the placement of molar ligatures was utilized.

\subsection{Chronic Disease (Baker) Modeling}

As detailed in the Materials and Methods section, mice were randomly assigned into 4 groups (6 mice per group): uninfected and sham smoked controls; uninfected, smoke-exposed (68 days, 20 cigarettes/day, 3 hrs. per day); mice orally inoculated multiple times with $S$. gordonii then $P$. gingivalis and sham smoked; and mice both infected and smoke-exposed. Mass was assessed at baseline (Figure 7) and prior to euthanasia (Figure 8). Weight gain was also monitored (Figure 9). The IgM and IgG response to infection (Figures 10 and 11); systemic inflammatory mediators (Table 1); specific local gingival inflammatory indices, IL-1 $\beta$ (Figure 12), MMP-8 (Figure 13), MMP-9 (Figure 14), CD14 (Figure 15) and CD45 (Figure 16); as well as alveolar bone loss (Figure 17) were assessed. 
Figure 8: Equal murine body mass at baseline in the chronic smoke exposure model.

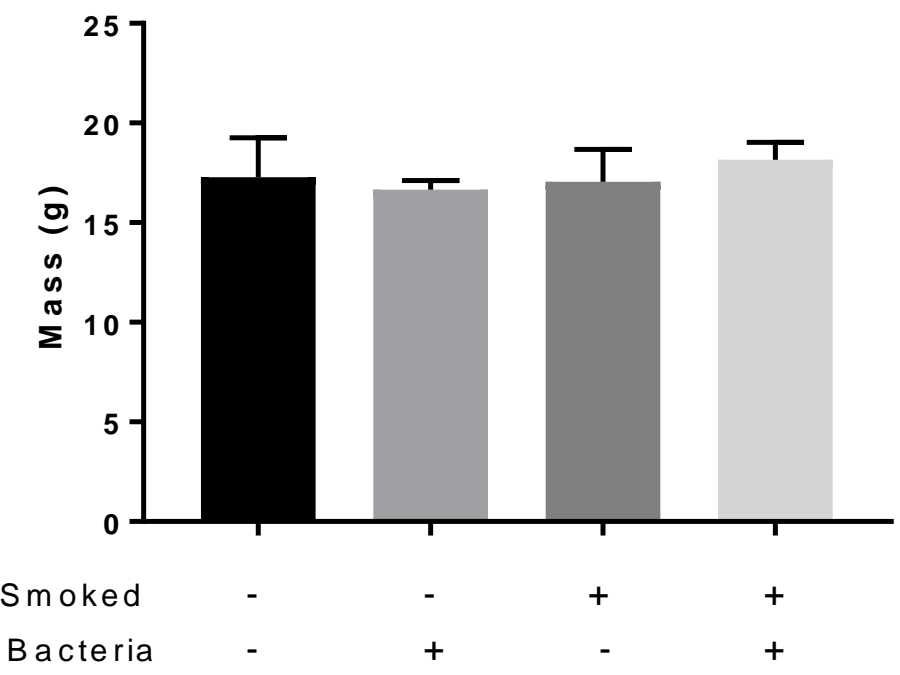

6-8-week-old, female Balb/c mice were randomly divided into 4 groups $(\boldsymbol{n}=6$ / group) and weighed prior to induction, or not, of bacterial-induced chronic periodontal disease in the presence or absence of mainstream stream smoke.

Data is presented as mean \pm s.d.

There were no significant differences in baseline mass between groups, as determined by ANOVA $(\boldsymbol{p}>0.05)$. 
Figure 9: Chronic smoke exposure does not influence murine body mass.

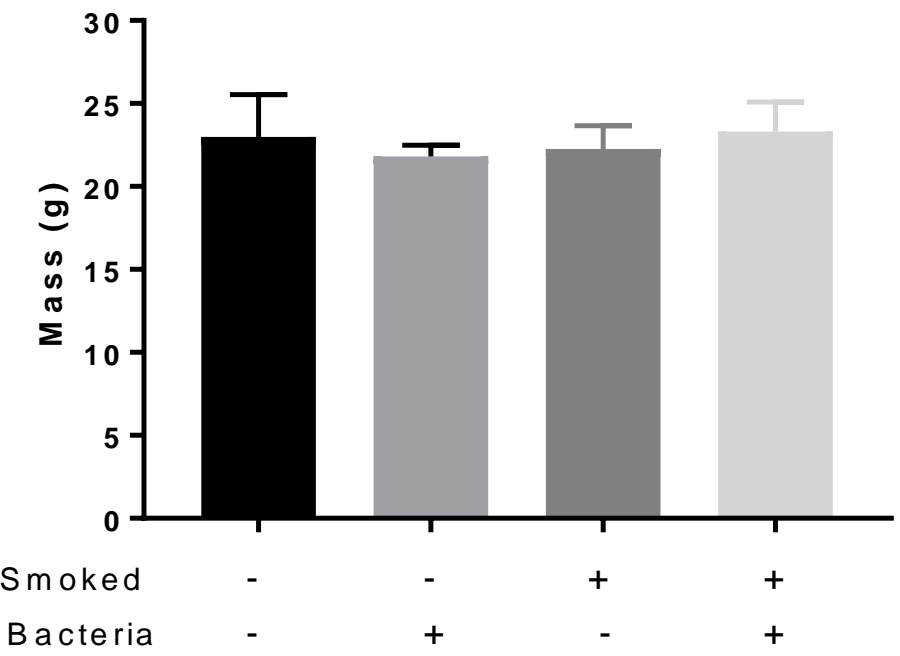

Balb/c mice were weighed at 68 days following the induction, or not, of bacterial-induced chronic periodontal disease in the presence or absence of mainstream stream smoke ( $\boldsymbol{n}=6$ / group).

Data are presented as mean \pm s.d.

There were no significant differences in murine mass between groups at euthanasia, as determined by ANOVA $(\boldsymbol{p}>0.05)$. 
Figure 10: Chronic smoke exposure does not influence murine body mass differentials.

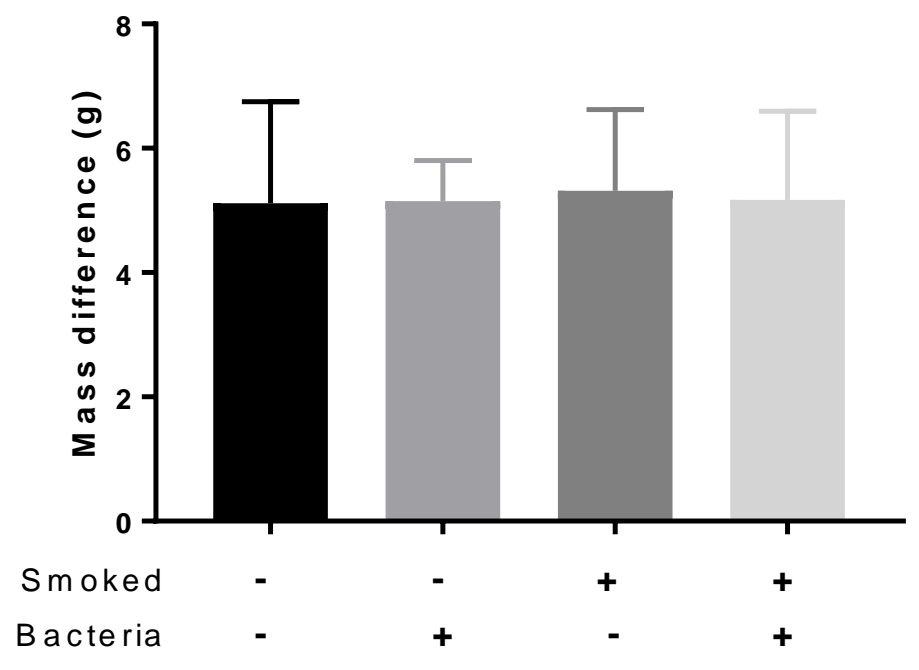

Difference of Balb/c mice body mass between base line weight and the weight at 68 days following the induction, or not, of bacterial-induced chronic periodontal disease in the presence or absence of mainstream stream smoke ( $\boldsymbol{n}=6$ / group). Data are presented as mean \pm s.d.

There were no significant differences in murine mass differentials between groups, as determined by ANOVA $(\boldsymbol{p}>0.05)$. 
Table 1: Bacterial colonization of the oral cavity of mice in the absence of cigarette smoke.

\begin{tabular}{|c|c|c|c|c|c|c|c|c|}
\hline Bacterium & $\begin{array}{c}\text { Detection } \\
\text { method }\end{array}$ & $\begin{array}{c}\text { SWAB } \\
1\end{array}$ & $\begin{array}{c}\text { SWAB } \\
2\end{array}$ & $\begin{array}{c}\text { SWAB } \\
3\end{array}$ & $\begin{array}{l}\text { Paper } \\
\text { Point }\end{array}$ & $\begin{array}{c}\text { SWAB } \\
4\end{array}$ & $\begin{array}{c}\text { SWAB } \\
5\end{array}$ & $\begin{array}{c}\text { SWAB } \\
6\end{array}$ \\
\hline \multirow{2}{*}{ S. gordonii } & PCR & + & + & & - & + & & + \\
\hline & Culture & + & + & & + & + & & + \\
\hline \multirow{2}{*}{ P. gingivalis } & PCR & & & & - & - & $\begin{array}{llll}+ & & & \end{array}$ & - \\
\hline & Culture & & & & & + & - & - \\
\hline
\end{tabular}

A positive colonization score for S. gordonii, by PCR, was defined as the visualization of $440 \mathrm{bp}$ amplicons in samples isolated from $>3$ / 6 mice.

A positive colonization score for $P$. gingivalis, by PCR, was defined as the visualization of 405 bp amplicons in samples isolated from $>3$ / 6 mice.

A positive colonization score for S. gordonii, by culture, was determined by the visualization of streptococcal-like colonies on Mitis Salivarius agar plates.

A positive colonization score for $P$. gingivalis, by culture, was determined by the visualization of black pigmented colonies on blood agar plates. 
Table 2: Bacterial colonization of the oral cavity of mice chronically exposed to cigarette smoke.

\begin{tabular}{|c|c|c|c|c|c|c|c|c|}
\hline Bacterium & $\begin{array}{l}\text { Detection } \\
\text { method }\end{array}$ & $\begin{array}{c}\text { SWAB } \\
1\end{array}$ & $\begin{array}{c}\text { SWAB } \\
2\end{array}$ & $\begin{array}{c}\text { SWAB } \\
3\end{array}$ & $\begin{array}{l}\text { Paper } \\
\text { Point }\end{array}$ & $\begin{array}{c}\text { SWAB } \\
4\end{array}$ & $\begin{array}{c}\text { SWAB } \\
5\end{array}$ & $\begin{array}{c}\text { SWAB } \\
6\end{array}$ \\
\hline \multirow[t]{2}{*}{ S. gordonii } & PCR & + & + & & - & + & & + \\
\hline & Culture & + & + & & + & + & & + \\
\hline \multirow[t]{2}{*}{ P. gingivalis } & PCR & & & & $\begin{array}{ll}- \\
-\end{array}$ & $\begin{array}{ll}- \\
-\end{array}$ & & . \\
\hline & Culture & & & . & & & & - \\
\hline
\end{tabular}

A positive colonization score for S. gordonii, by PCR, was determined by the visualization of $440 \mathrm{bp}$ amplicons in samples isolated from $>3$ / 6 mice.

A positive colonization score for $P$. gingivalis, by PCR, was determined by the visualization of $405 \mathrm{bp}$ amplicons in samples isolated from $>3$ / 6 mice.

A positive colonization score for S. gordonii, by culture, was determined by the visualization of streptococcal-like colonies on Mitis Salivarius agar plates.

A positive colonization score for $P$. gingivalis, by culture, was determined by the visualization of black pigmented colonies on blood agar plates. 
Figure 11: $P$. gingivalis-cognizant $\lg M$ is elevated in infected, chronically smokeexposed mice.

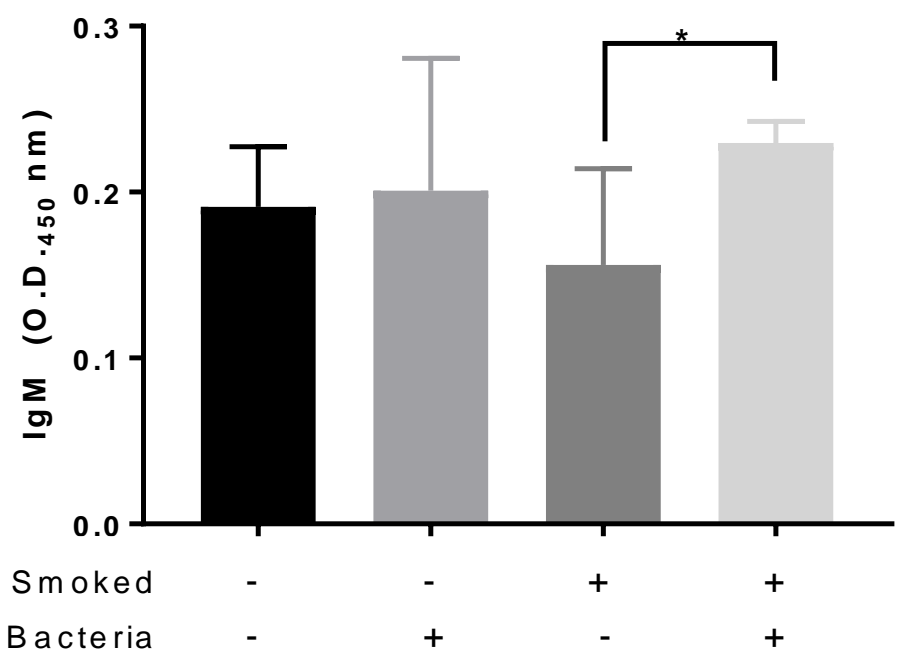

IgM titers were measured by ELISA post-euthanasia.

Differences between groups were determined by ANOVA.

Data are presented as mean \pm s.d. values ( $\boldsymbol{n}=6$ per group). ${ }^{*} p<0.05$ 
Figure 12: Infection induces a $P$. gingivalis-cognizant $\lg G$ response that is not influenced by chronic smoke exposure in mice.

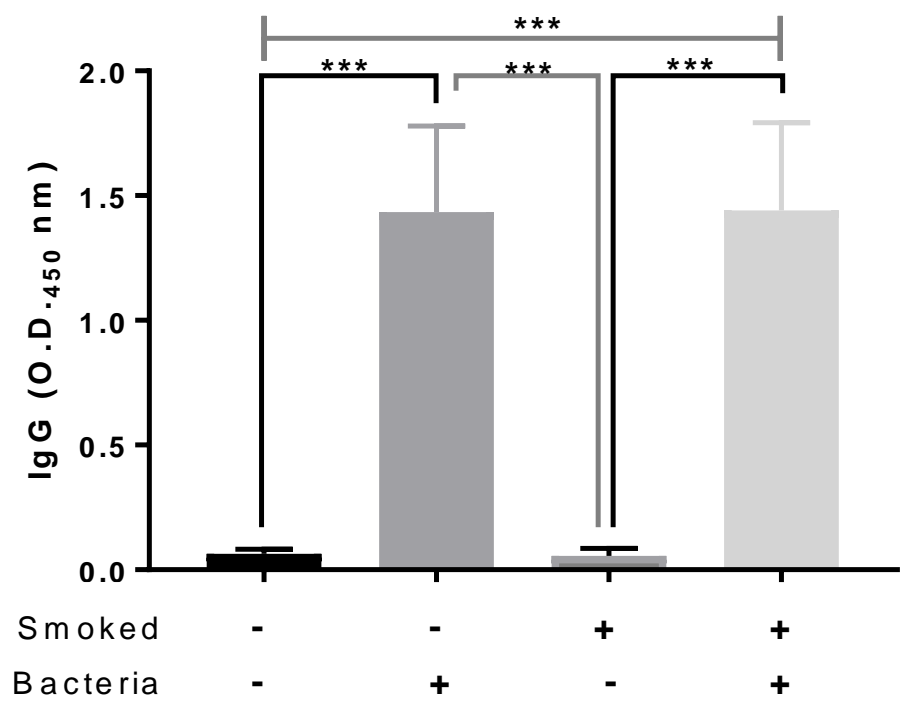

IgG titers were measured by ELISA post-euthanasia.

Differences between groups were determined by ANOVA.

Data are presented as mean \pm s.d. values ( $\boldsymbol{n}=6$ per group).

${ }^{* * *} \boldsymbol{p}<0.001$. 
Table 3: Chronic smoke exposure alters aspects of the systemic immune response to $P$. gingivalis.

\begin{tabular}{|c|c|c|}
\hline \multirow[t]{2}{*}{ Inflammatory Mediator } & Bacteria/Sham Smoked & Bacteria/Smoke \\
\hline & \multicolumn{2}{|c|}{ Mean (s.d.) [pg/ml] } \\
\hline CCL2 & $52(14)$ & $20(22)^{\star \star}$ \\
\hline CCL5 & $17(7)$ & $17(6)$ \\
\hline CXCL1 & $133(23)$ & $85(30)^{\star *}$ \\
\hline CXCL10 & 499(74) & $509(113)$ \\
\hline MIP-1a & $73(21)$ & $47(38)$ \\
\hline MIP-1b & 104(16) & $84(14)^{*}$ \\
\hline G-CSF & $375(168)$ & $435(177)$ \\
\hline GM-CSF & $35(14)$ & $11(15)^{\star \star}$ \\
\hline IFN-g & $6(2)$ & $4(3)$ \\
\hline TNF-a & $11(2)$ & $9(1)$ \\
\hline IL-1a & $755(163)$ & $689(186)$ \\
\hline IL-5 & $21(8)$ & $18(10)$ \\
\hline $\mathrm{IL}-10$ & $21(3)$ & $17(2)^{*}$ \\
\hline IL-13 & $67(10)$ & $57(5)^{*}$ \\
\hline IL-15 & 18(29) & $17(20)$ \\
\hline IL-17 & $3(3)$ & $5(4)$ \\
\hline IL-9 & $198(45)$ & $283(89)^{*}$ \\
\hline
\end{tabular}

Concentrations of inflammatory mediators in mouse serum were measured by multiplex ELISA following euthanasia.

Differences between groups were determined by t-test.

Data are presented as mean \pm s.d. values ( $\boldsymbol{n}=6$ per group). 
(IL-12p40, IL-12p70, IL-7, IL-6, IL-4, IL-2, and IL-1b) fell outside the range of the standard curve.

${ }^{*} \boldsymbol{p}<0.001,{ }^{* *} \boldsymbol{p}<0.01$, respectively. 
Figure 13: Chronic cigarette smoke exposure does not influence IL- $\beta$ message in murine gingiva.

A

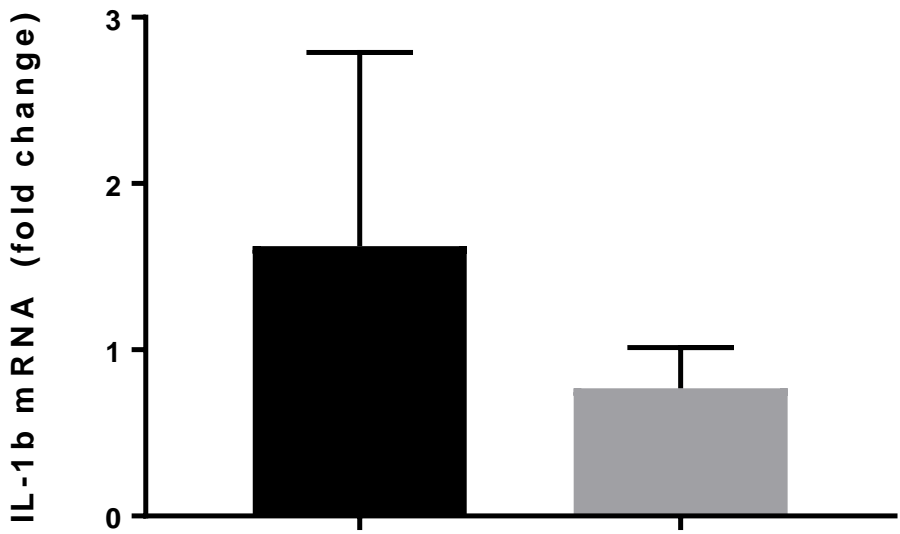

Smoked

B a cteria

B

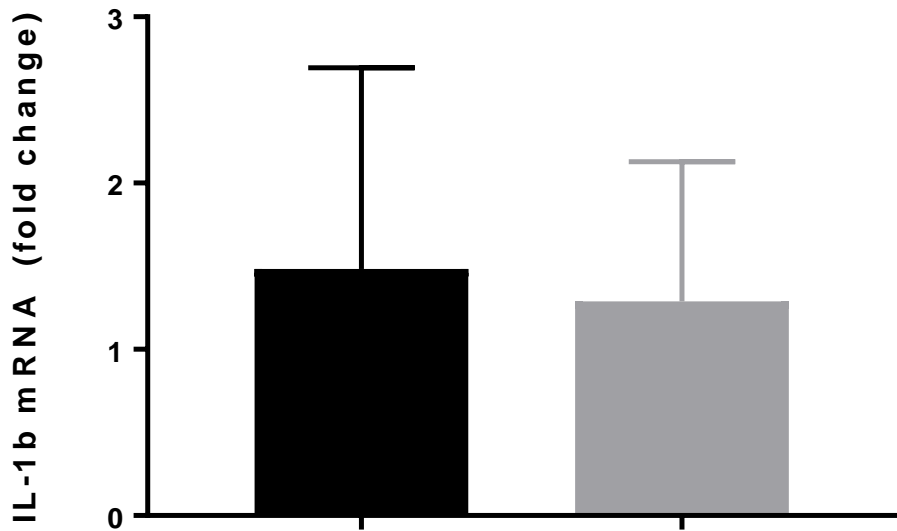

Smoked

B acteria

The IL-1 $\beta$ mRNA relative to that of glyceraldehyde 3-phosphate dehydrogenase (GAPDH) was measured post-euthanasia by qPCR in gingival tissues in (A) noninfected exposed and $(B)$ infected mice.

Differences between groups were determined by t-test.

Data are presented as mean \pm s.d. values ( $\boldsymbol{n}=6$ per group). $p>0.05$. 
Figure 14: Chronic cigarette smoke augments the MMP-8 signal in bacteriainfected murine gingiva.

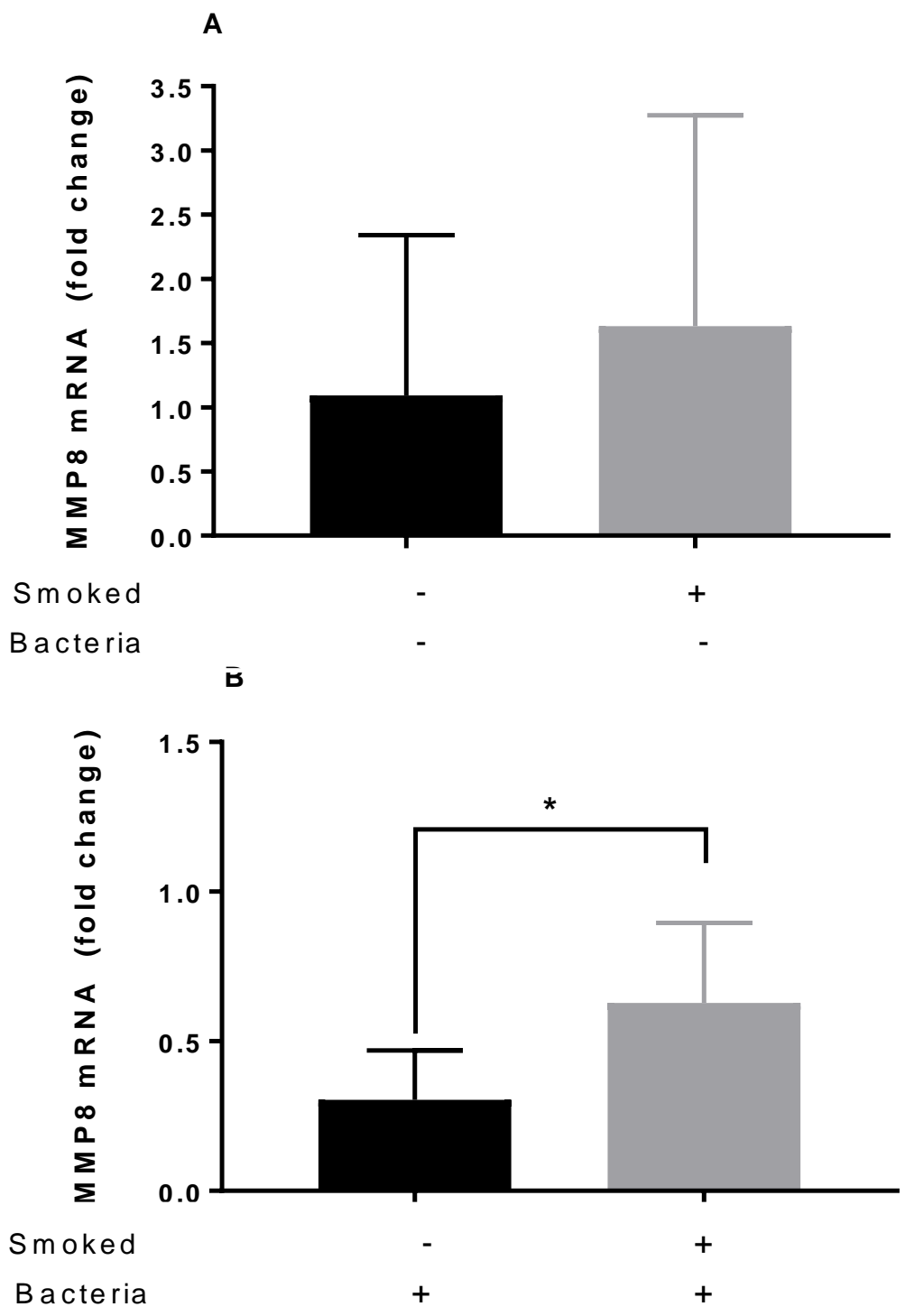

The MMP-8 mRNA signal, relative to that of glyceraldehyde 3-phosphate dehydrogenase (GAPDH) was measured post-euthanasia by qPCR in gingival tissues in (A) non-infected exposed and (B) infected mice.

Differences between groups were determined by t-test.

Data are presented as mean \pm s.d. values ( $\boldsymbol{n}=6$ per group). ${ }^{*} \boldsymbol{p}<0.05$. 
Figure 15: Chronic cigarette smoke exposure does not influence the MMP-9 message in murine gingiva.

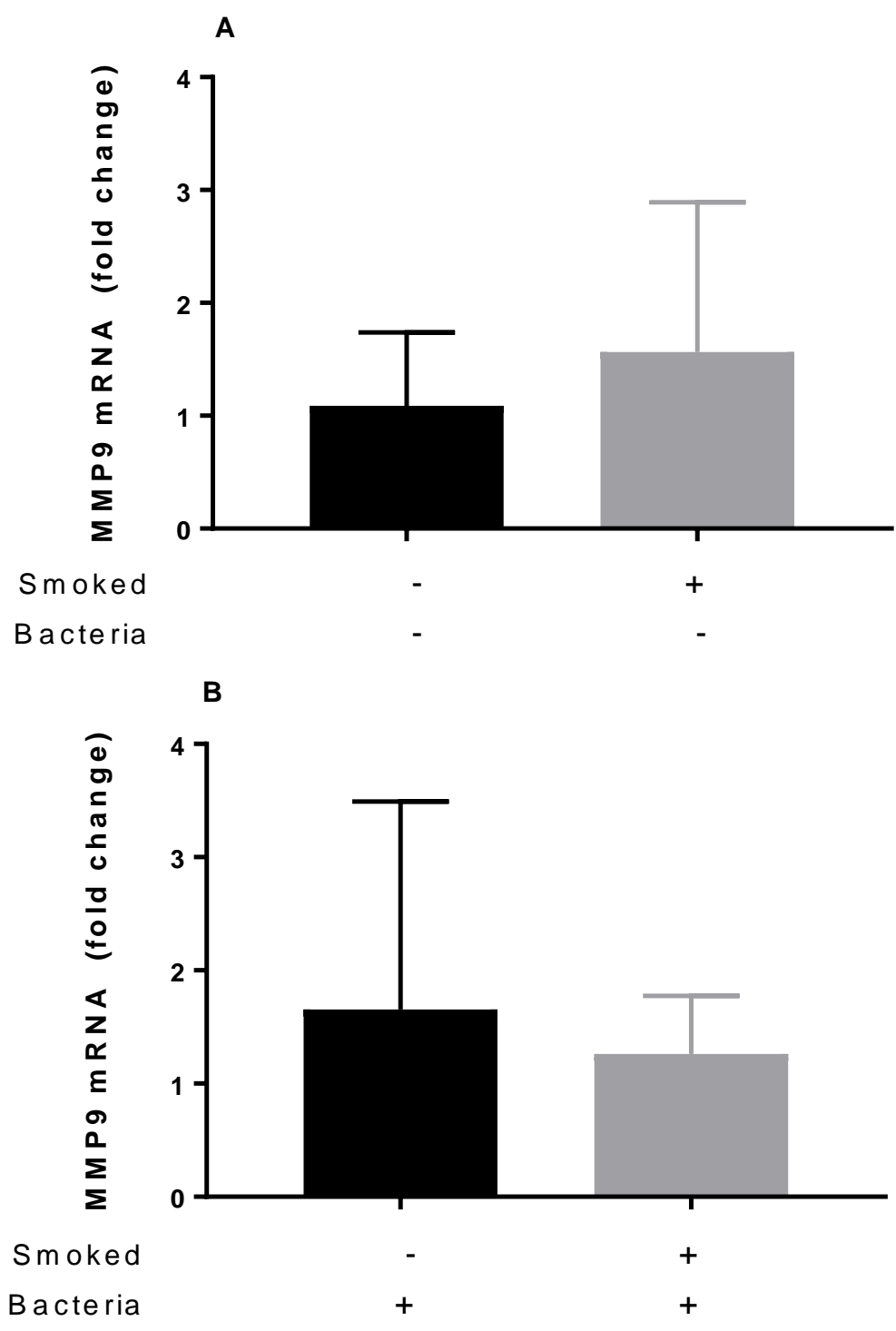

The MMP-9 mRNA signal, relative to that of glyceraldehyde 3-phosphate dehydrogenase (GAPDH) was measured post-euthanasia by qPCR in gingival tissues in (A) non-infected and (B) infected mice.

Differences between groups were determined by t-test.

Data are presented as mean \pm s.d. values ( $\boldsymbol{n}=6$ per group).

${ }^{*} \boldsymbol{p}>0.05$. 
Figure 16: Chronic cigarette smoke exposure does not influence CD14 message in murine gingiva.
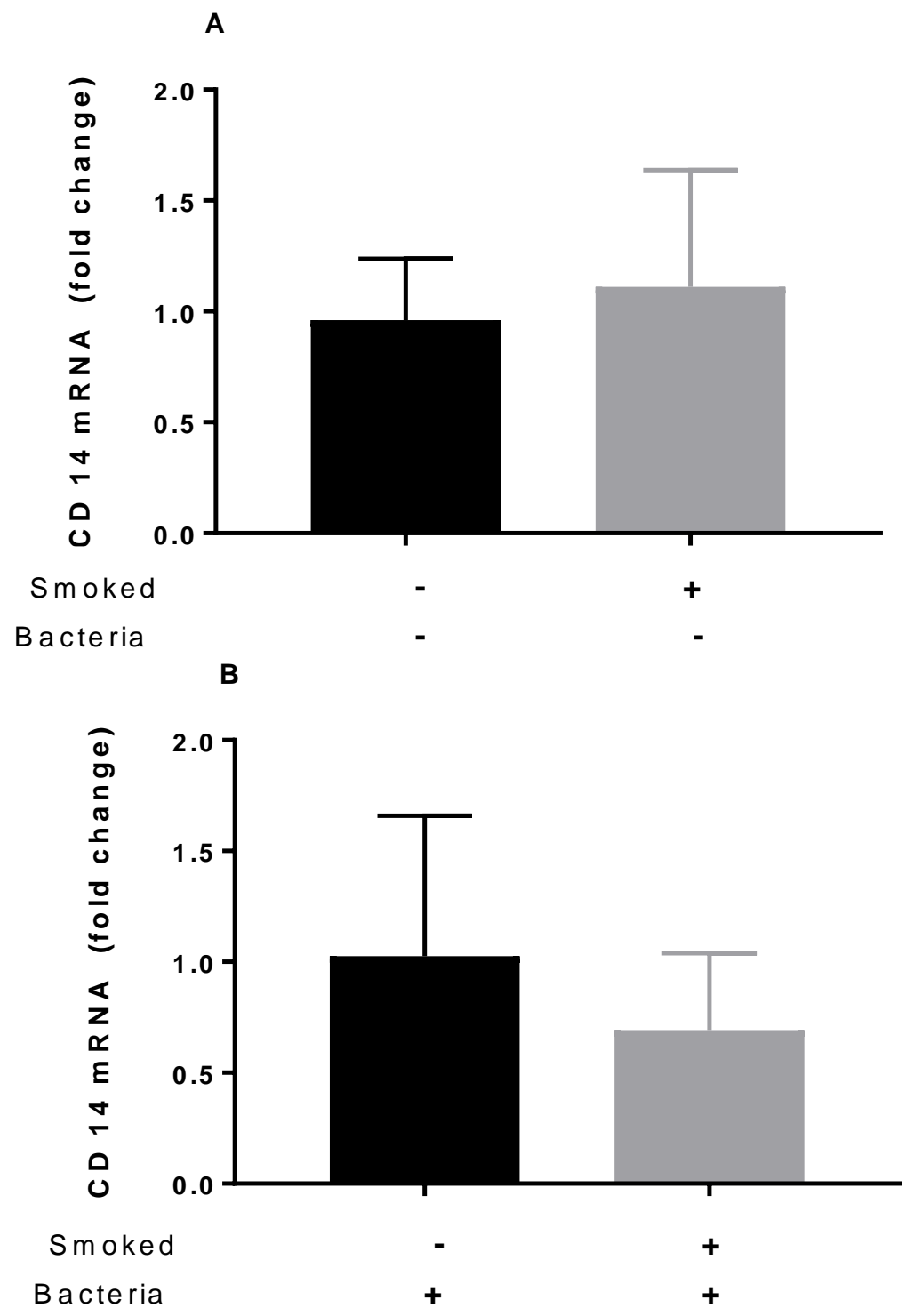

The CD14 mRNA signal, relative to that of glyceraldehyde 3-phosphate dehydrogenase (GAPDH) was measured post-euthanasia by qPCR in gingival tissues in (A) non-infected and $(B)$ infected mice.

Differences between groups were determined by t-test.

Data are presented as mean \pm s.d. values ( $\boldsymbol{n}=6$ per group). ${ }^{*} \boldsymbol{p}>0.05$. 
Figure 17: Chronic cigarette smoke exposure does not influence the CD45 signal in murine gingiva.

A
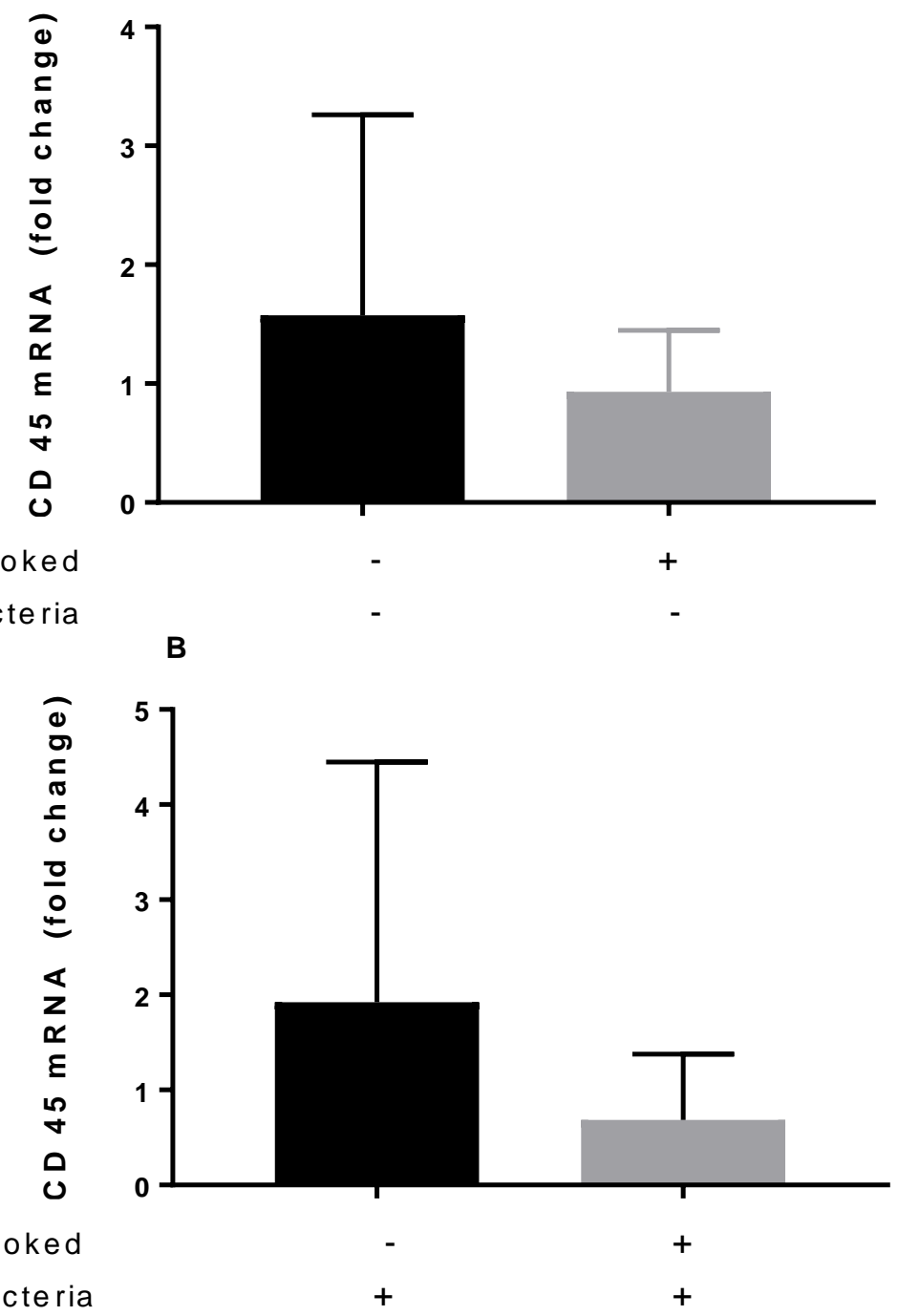

The CD14 mRNA signal, relative to that of glyceraldehyde 3-phosphate dehydrogenase (GAPDH) was measured post-euthanasia by qPCR in gingival tissues in (A) non-infected and (B) infected mice.

Differences between groups were determined by t-test.

Data are presented as mean \pm s.d. values ( $\boldsymbol{n}=6$ per group). ${ }^{*} \boldsymbol{p}>0.05$. 
Figure 18: Chronic tobacco smoke exposure enhances bacteria-induced alveolar bone loss in mice.

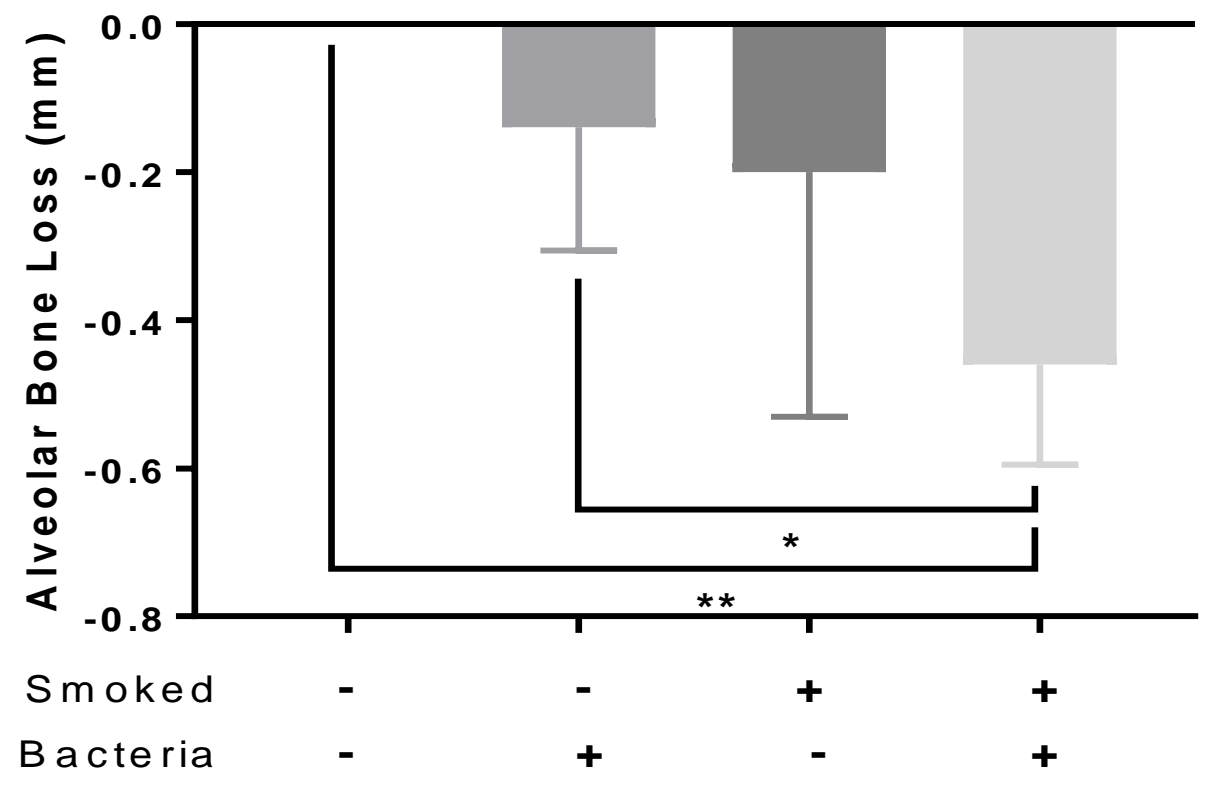

Alveolar bone loss was determined as the distance from the CEJ to $A B C$ at 14 predetermined maxillary buccal sites.

Differences between groups were determined by ANOVA.

Data are presented as mean \pm s.d. values ( $\boldsymbol{n}=6$ per group).

${ }^{*} /{ }^{* *} \boldsymbol{p}<0.05,0.01$, respectively. 
3.2 Acute Disease (Ligature) Modelling

As detailed in the Materials and Methods section, mice were randomly assigned into 4 groups (7 mice per group): Uninfected and sham smoked controls; uninfected, smoke-exposed (14days, 20 cigarettes/day, 3 hrs per day); mice orally inoculated multiple times with $P$. gingivalis and sham smoked; and mice both infected and smoke-exposed. Mass was assessed at baseline (Figure 18) and prior to euthanasia (Figure 19). Weight gain was also monitored (Figure 20) as were the $\lg M$ and $\lg G$ response to infection (Figures 21 and 22). As in the chronic disease model, it was planned to monitor systemic inflammatory mediators, and specific local gingival inflammatory indices. However, these experiments were curtailed by the COVID-19 outbreak. However, alveolar bone loss (Figure 23) was assessed. 
Figure 19: Equal murine body mass at baseline in the acute periodontal disease model.

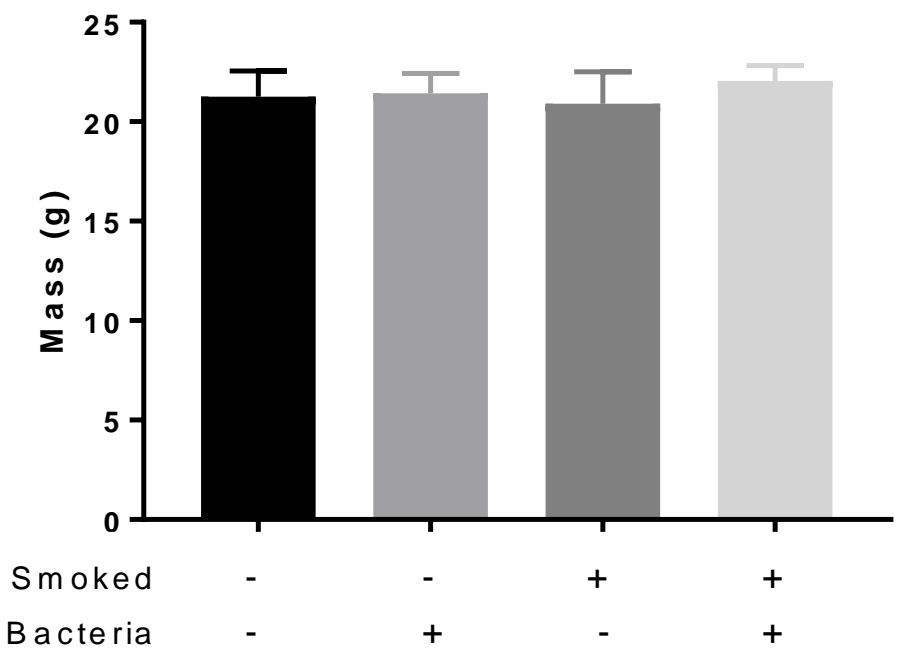

6-8-week-old, female Balb/c mice were randomly divided into 4 groups $(\boldsymbol{n}=7$ / group) and weighed prior to induction, or not, of bacterial-induced acute periodontal disease in the presence or absence of mainstream stream smoke.

Data is presented as mean \pm s.d.

There were no significant differences in baseline mass between groups, as determined by ANOVA $(\boldsymbol{p}>0.05)$. 
Figure 20: Bacterial infection increased murine body mass in smoke-exposed mice in an acute model of periodontitis.

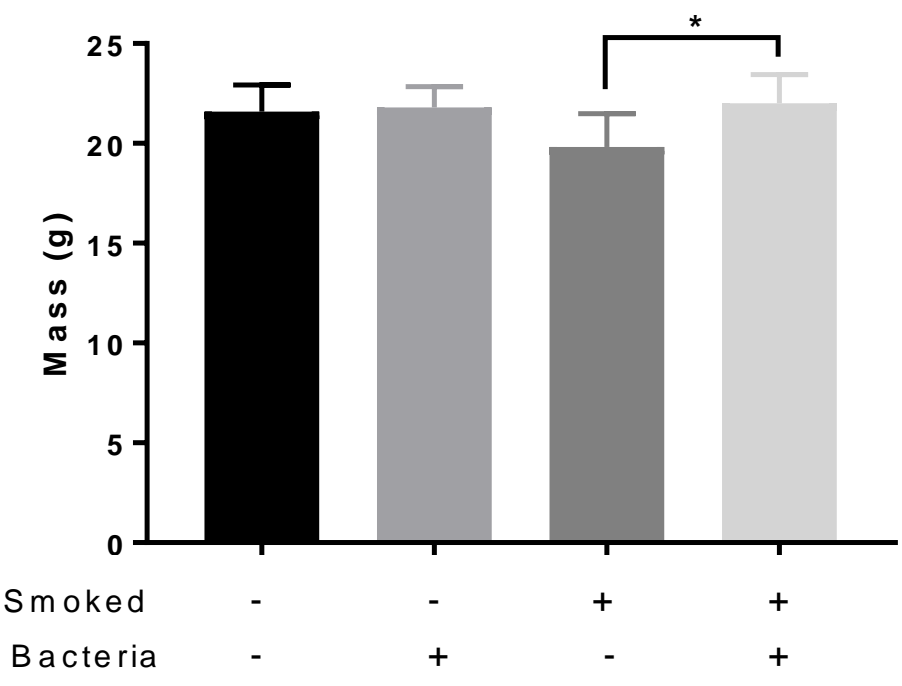

Balb/c mice were weighed at following the induction, or not, of bacterial-induced acute periodontal disease in the presence or absence of mainstream stream smoke ( $\boldsymbol{n}=7$ / group).

Differences between groups were determined by ANOVA.

Data are presented as mean \pm s.d.

${ }^{*} \boldsymbol{p}<0.05$ 
Figure 21: Smoking suppressed body mass differentials in an acute periodontitis model in mice.

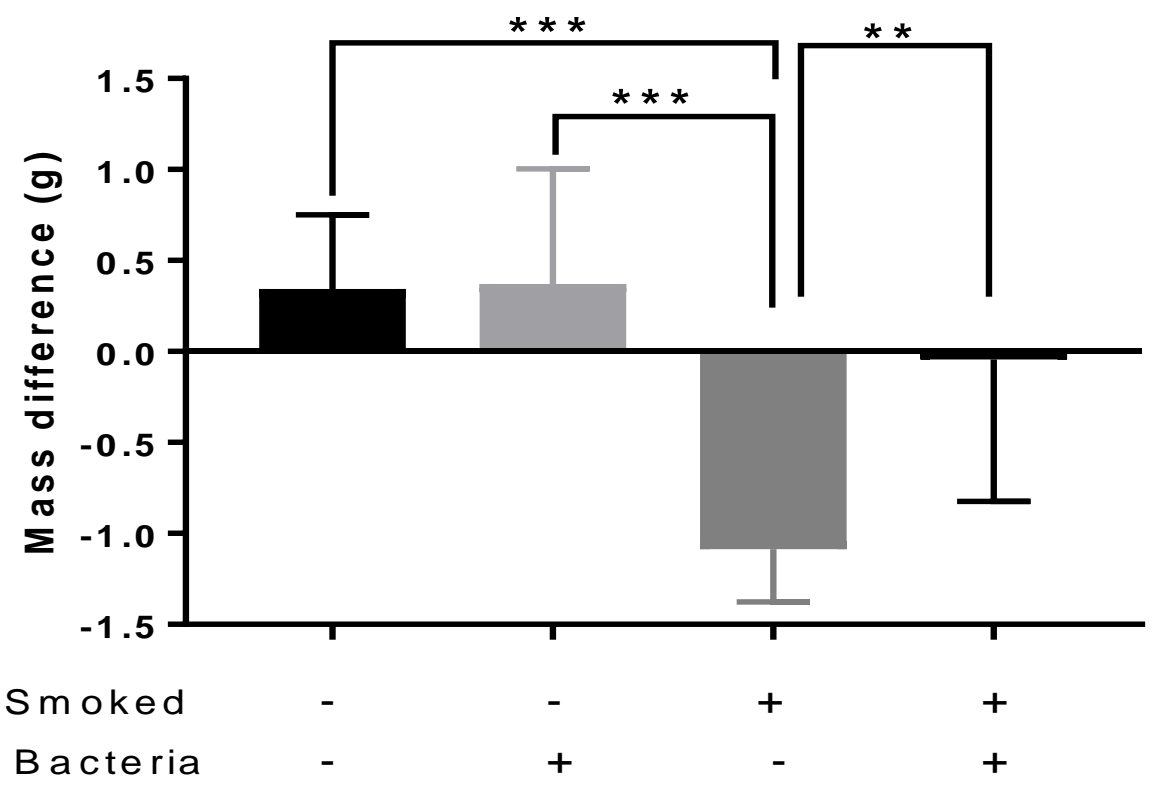

Difference of Balb/c mouse body mass between the base line weight and the weight at time of euthanasia following the induction, or not, of bacterial-induced acute periodontal disease in the presence or absence of mainstream stream smoke ( $\boldsymbol{n}=7$ / group).

Differences between groups were determined by ANOVA.

Data are presented as mean \pm s.d.

${ }^{* *} /{ }^{* * *} \boldsymbol{p}<0.01,0.001$, respectively. 
Bacterial colonization of the oral cavity in acute periodontitis model in mice:

Detection of bacterial colonization-by culture and PCR in the acute periodontitis model was planned. However, this was not possible due to lab and core facilities closure associated with the COVID-19 outbreak. 
Figure 22: Infection induces a $P$. gingivalis-cognizant IgM response that is not influenced by smoke exposure in an acute periodontitis model in mice.

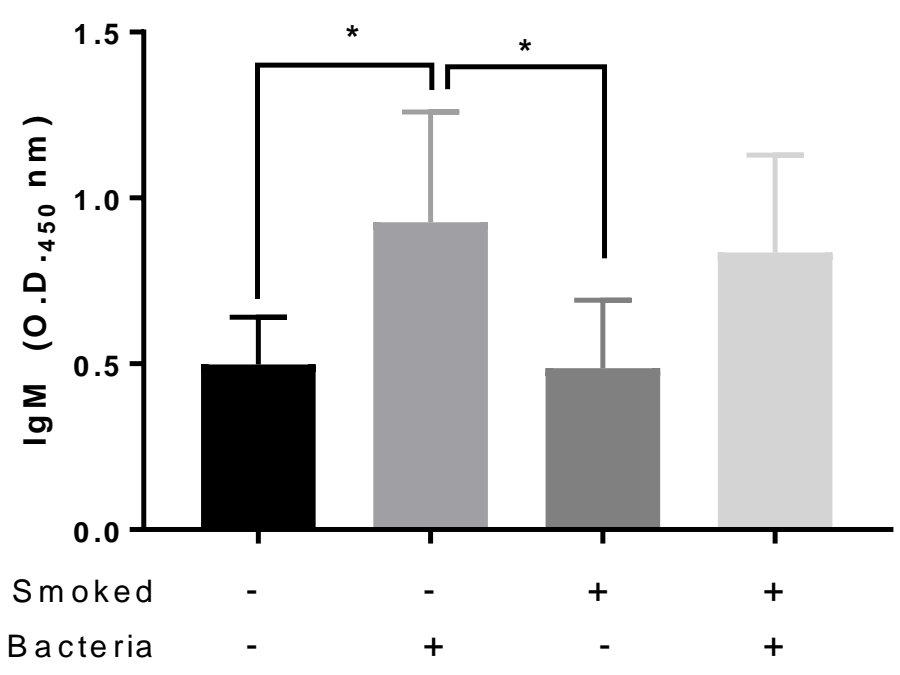

IgM titers were measured by ELISA post-euthanasia.

Differences between groups were determined by ANOVA.

Data are presented as mean \pm s.d. values ( $n=7$ per group).

${ }^{*} \boldsymbol{p}<0.05$ 
Figure 23: $P$. gingivalis cognizant-lgG is not influenced by smoke exposure in an acute periodontitis model in mice.

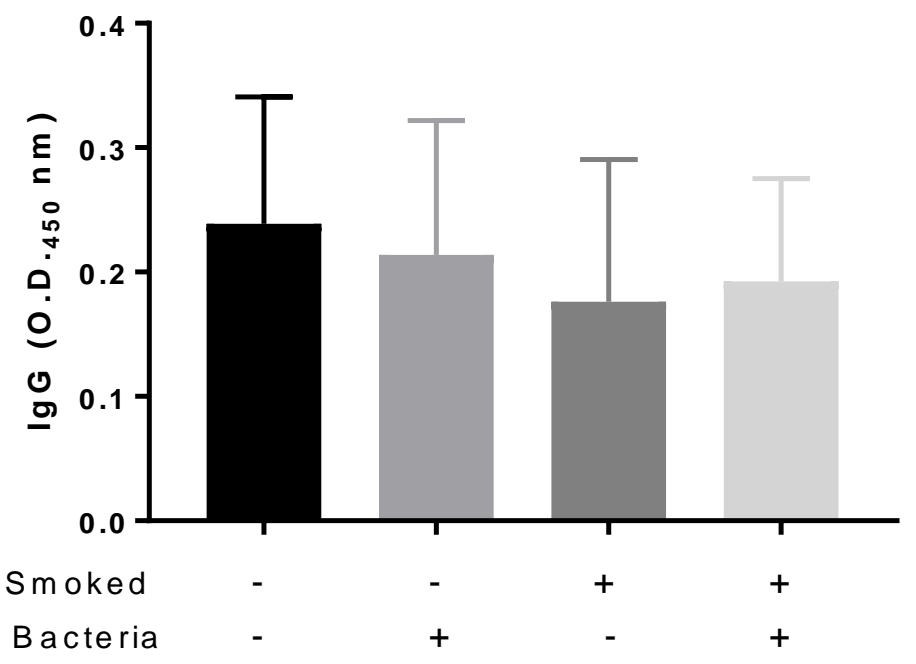

IgG titers were measured by ELISA post-euthanasia.

Differences between groups were determined by ANOVA.

Data are presented as mean \pm s.d. values ( $n=7$ per group).

All, $\boldsymbol{p}>0.05$. 
The influence of smoke exposure on the systemic immune response to $P$. gingivalis in an acute model of periodontitis.

Concentrations of inflammatory mediators in mouse serum were to be measured by multiplex ELISA following euthanasia. However, this was not possible due to lab and core facilities closures associated with the COVID-19 outbreak.

The influence of smoke exposure on the gingival immune response to $P$. gingivalis in an acute model of periodontitis.

Specific local gingival inflammatory mediators were planned to be measured post-euthanasia by qPCR in gingival tissue. However, this was not possible due to lab and core facilities closure associated with the COVID-19 outbreak. 
Figure 24: Tobacco smokes enhances bacteria-induced alveolar bone loss in an acute model of periodontitis in mice.

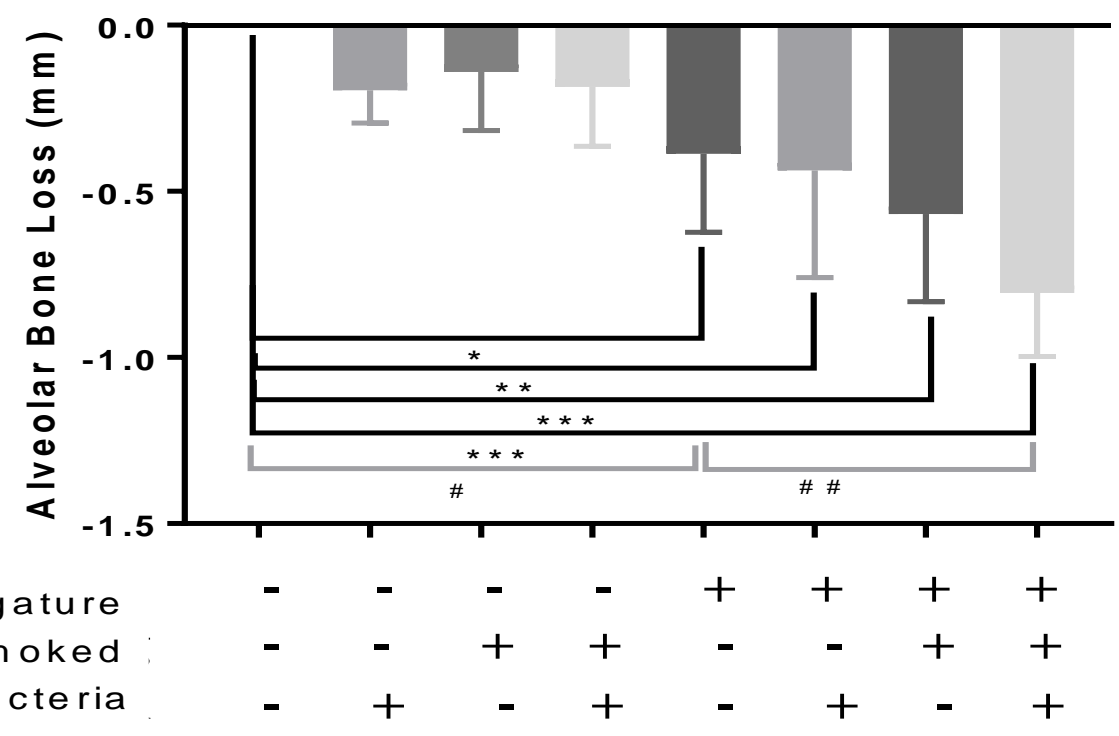

Alveolar bone loss was determined as the distance from the CEJ to $A B C$ at 7 predetermined buccal sites on contralateral sides of maxilla (ligated and non-ligated control sides).

Differences from the non-ligated and ligation-only control groups were determined by ANOVA.

Data are presented as mean \pm s.d. values ( $\boldsymbol{n}=7$ per group).

${ }^{*} /{ }^{* *} /{ }^{* * *} \boldsymbol{p}<0.05,0.01,0.001$ respectively, compared to untreated group.

$\# / \#$ / $\boldsymbol{p}<0.05,0.01$, respectively, compared to compared to ligature only group. 


\section{CHAPTER 4 DISCUSSION}

Periodontal diseases are highly prevalent, chronic inflammatory diseases of the tissue surrounding the teeth that lead to significant oral depilation [273]. Disease initiates and progresses when the balance of a complex interplay between the host immune response and microorganisms of the dental biofilm - or homeostasis - is disrupted. P. gingivalis, a causative agent of periodontal disease, is a Gramnegative, black pigmented, assacharolytic anaerobic bacteria that facilitates the subversion of the host immune response and, as a consequence, is thought to promote dysbiotic polymicrobial synergy $[187,273,274]$. Tobacco smoking is considered the strongest modifiable environmental risk factor for periodontitis [138].

Finding a reliable and reproducible animal model of periodontal disease that reproduces all aspects of human disease is unlikely. However, we hypothesized that two murine models would reflect at least some of the tobacco-specific facets of periodontal disease in humans. Most importantly, enhanced alveolar bone loss. Mice are an attractive model due to relevant gingival and tooth anatomy relatively low cost, availability of extensive genetic tools, a large existing literature 
and availability of rodent smoke-exposure chambers. When aligned with the prioritization of the use of lower vertebrates, mice appear to be the appropriate animal, to explore in the context of smoking-related periodontal disease mechanisms.

There are key aspects of tobacco-enhanced human periodontal disease that differ from the disease in non-smokers i) enhanced and persistent infection with $P$. gingivalis and other periodontal pathogens [12, 138]; ii) a suppressed IgG response to pathogens $[35,149]$; iii) a suppressed local and systemic proinflammatory response [26]; iv) an elevated endogenous protease burden [146]; and, most critically, (v) exacerbated oral bone loss [123, 124]. In addition, we were cognizant of the reduced body mass apparent in human smokers. Thus, we evaluated these human disease traits in acute and, where possible, chronic, smoke-exposed disease models.

Murine mass was equal in all groups at the start of the experimental period in both models. In the acute, but not chronic model, bacterial infection was associated with increased body mass in smoke-exposed mice.

A positive correlation between weight gain and periodontitis risk has been established in humans [275]. It is suggested that lipopolysaccharide (LPS) of Gram-negative periodontal bacteria could lead to hepatic dyslipidemia and insulin resistance [276]. On the other side, smoking is suggested to reduce weight by suppressing the appetite and/or increasing energy expenditure in humans [277, 
278]. Also, cross-sectional studies clarify that body weight is lower in smokers than nonsmokers [279]. However, in our study, smoking by itself did not affect body mass.

In the chronic model, persistent colonization with the commensal bacterium, $S$. gordonii, was readily established in both the sham-smoked and smoked groups, as determined by both PCR and culture. This is consistent with the literature, where multiple reports confirm colonization of Streptococcus species in the oral cavity of mice [280-282].

Unlike S. gordonii, we could not detect persistent $P$. gingivalis colonization, other than a single positive culture of black-pigmented rods early in the inoculation protocol. Therefore, we must think of our model as a series of transient infections rather than the established and persistent colonization by $P$. gingivalis seen in humans [230]. This is most likely explained by the fact that mice are not a natural host for $P$. gingivalis [230]. The interaction between $S$. gordonii and $P$. gingivalis is well established [202, 283]. Therefore, we had hypothesized that an initial infection with S. gordonii would enhance colonization of $P$. gingivalis in our chronic model of periodontitis. However, while the $P$. gingivalis infections may have been transient, a robust adaptive immune response was nevertheless induced, as determined by the IgG response, while, critically, infection-associated differentials in alveolar bone loss were apparent, both phenomena to be discussed later. 
A robust antibody response to $P$. gingivalis, reflective of colonization, is noted in patients with periodontitis [150,151]. In our study we examined the association between smoking and levels of serum $\operatorname{lgM}$ and $\lg G$. In the chronic and acute disease models, smoking did not influence the $P$. gingivalis-cognizant $\lg M$ or $\lg G$ titers. The IgM signal in the presence or absence of $P$. gingivalis infection likely reflects the presence of related Bacteroidetes or other bacteria that may share a sub-set of antigens with $P$. gingivalis.

Such findings are in contrast to the situation in humans, where the overall and pathogen-specific lgG response is significantly suppressed in smokers compared to nonsmokers, both in general and specifically in patients with periodontal disease $[35,227,284]$.

Cigarette smoking alters the development and effector function of innate immune cells [30]. However, due to prioritization of experimental outcome measures, only systemic and local inflammatory profiling was addressed herein.

In the chronic model of periodontitis, we observed that smoke exposure altered specific aspects of the systemic immune response to bacterial infection, with significantly reduced levels of CCL2, CXCL1, MIP-1b, GM-CSF, IL-13, and IL-10 noted in serum from smoked-exposed mice relative to non-smoked control animals. Interleukin-10 (IL-10) is a potent anti-inflammatory cytokine that can contribute to the maintenance of bone mass through inhibition of osteoclastic bone 
resorption and regulation of osteoblastic bone formation [285]. Also, IL-10-deficient mice possess hyperinflammation and are highly susceptible to $P$. gingivalisinduced periodontitis [286]. In addition, IL-13 prevents osteoclast precursors from differentiating into osteoclasts [287]. Moreover, Granulocyte-macrophage colonystimulating factor (GM-CSF) inhibits osteoclastogenesis by diverting osteoclast precursors to a macrophage lineage [288]. Among the infected groups, our results showed significant lower serum levels of GM-CSF, IL-10, and IL-13 in smoked mice relative to non-smoked mice in the chronic model of periodontitis. This can explain the associated bone loss in smoked mice discussed later in the current study. Our findings are consistent with clinical studies. For instance, it has been found that decreased salivary IL-10 level was significantly lower in patients with chronic periodontitis as compared with healthy controls [289] Also, Zein et al. reported that levels of IL-10, IL-13 were significantly lower in plasma of aggressive periodontitis patients compared with healthy [290].In addition, serum GM-CSF level was reduced insignificantly in chronic periodontitis patients compared to healthy control group [291].

We also analyzed the effect of smoking on the mRNA signal of the inflammatory markers, IL1 $\beta$, MMP-8, MMP-9, CD14 and CD45, in the maxillary gingiva of mice. IL-1 $\beta$ is an archetypal proinflammatory mediator, whose upregulation contributes to inflammation and the destructive sequelae that are characteristic features of periodontal diseases [292]. IL-1 is detected early in any immune response to pathogens [293]. Therefore, elevated IL-1 $\beta$ levels have been suggested as a potentially sensitive aid in monitoring clinical disease activity [294]. In the chronic 
model of periodontitis, tobacco smoke exposure was associated with reduced expression of IL-1 $1 \beta$ in the maxillary gingiva, regardless of infection, although the effect showed high variability and did not reach statistical significance. Rawlinson et al. (2003) have previously reported that the IL-1 $1 \beta$ signal is lower in gingival crevicular fluid of adult periodontitis smokers vs. nonsmokers [295]. Indeed, a recent review by Buduneli and Scott reported that a general suppression of the gingival innate immune response is a consistent conclusion of multiple clinical studies [26].

Matrix metalloproteinases (MMPs) are a group of enzymes that, in concert, are able to degrade most, if not all, extracellular matrix proteins and are considered key mediators of periodontal disease progression [296]. Indeed, MMP inhibitors, in the form of sub-antimicrobial tetracycline antibiotics, represent an important therapeutic tool for use in recalcitrant disease cases [297]. During periodontal disease, MMPs are secreted by multiple types of inflammatory cells, including macrophages and neutrophils [298, 299]. In smokers, higher concentrations of MMPs, in particular MMP-8 and MMP-9, have been reported in gingival crevicular fluid and periodontium connective tissue $[145,146]$.

In our chronic periodontitis experiments, smoking exposure significantly augments MMP-8 message in the infected group. This increase in the MMP-8 signal is reflective of another key aspect of periodontitis that is seen in human smokers. 
CD14 is glycosylphosphatidylinositol-anchored receptor [300] expressed predominantly on monocytes and macrophages and, at 10-times lower levels, on neutrophils [301]. It is known to serve as a co-receptor for several Toll-like Receptors (TLRs) both at the cell surface and in the endosomal compartment. CD14, as a co-receptor with TLR4, facilitates cellular responses to low doses of bacterial lipopolysaccharide and activation of innate immunity [209, 302, 303]. CD45 is, a leukocyte-specific protein tyrosine phosphatase, an abundant cell surface protein on lymphocytes [304]. CD45 isoforms are present on all nucleated hematopoietic cells and appear to play an important role in the immune cell response to stimuli [305]. CD45 causes increase in cytokine production and T-cell proliferation [306]. As CD14 and CD45 are, present on the surface of particular leukocytes and their expression levels are considered, on this occasion, to act as surrogate markers for monocyte and pan-leukocytes infiltration, respectively, into the periodontal tissues In the chronic periodontitis model, smoking does not affect the expression of CD14 mRNA or CD45 expression in murine gingiva. This is consistent with previous studies. For instance, Chen et al. has reported that CD 14 expression in alveolar macrophages did not differ in smokers versus nonsmokers [307]. In addition, smoking did not increase the level of CD 45 in healthy or periodontitis gingiva [308]. This can be explained by the masking effect of smoking on inflammatory cells infiltration in gingiva. Also, as recently reviewed by Buduneli and Scott, it has been found that smoking suppresses angiogenesis and this in turn leads to reduced inflammatory response [26, 309]. Further, a previous clinical study showed that smokers had a decreased blood vessel density and 
inflammatory cells compared to nonsmokers although they have had an increased probing depth and overall increased clinical attachment loss [123]. This confirms the paradoxical action of smoking that it leads to reduced inflammation, however, apparent deleterious bone loss.

The equivalent experiments in the acute model have not been completed due to the Covid-19 outbreak.

A critical hall mark of periodontitis is alveolar bone resorption [44]. In both the chronic and acute models of periodontitis, smoke exposure significantly enhanced bacterial and/or ligature--induced alveolar bone loss. In the acute model, not only ligation enhances alveolar bone loss, but also infection and smoke exposure together had a synergistic effect on the alveolar bone. Successive representation of this aspect in-vivo is a reflective of a diagnostic key feature in periodontitis human smokers as confirmed by multiple studies [102, 310-312] and thus, in turn, validate these models as tools for study the association between $P$. gingivalis, smoking and periodontitis.

In summary, reference cigarette smoke-exposure in a chronic model of periodontitis, altered aspects of systemic immune response to infection, augmented MMP-8 local expression and significantly enhanced bacterial-induced alveolar bone loss. While full analysis of the acute disease model was curtailed by the Covid-19 outbreak, smoke exposure clearly augmented alveolar bone loss. 
Thus, both models reflect some, but not all, aspects of tobacco-enhanced periodontitis in humans.

In the current study we presented two models of periodontitis. The acute model is less intensive and could be used to more rapidly screening for tobaccoenhanced disease factors: e.g. P. gingivalis strains with mutants in tobaccoessential genes; mice genetically manipulated in genes considered key to tobaccoenhanced periodontitis. However, the chronic model, which better reflects the disease in humans, but is long-term and labor intensive, could subsequently be employed to examine relevant phenomena identified in the acute screening.

These models could be improved by the following approaches:

i) Polymicrobial infections: Periodontal diseases are multibacterial. This model is amenable to both the minimalist approach presented herein as well as more complex infection protocols. IFurther, it has been previously shown that polymicrobial infection enhances colonization by P. gingivalis, T. denticola, and T. forsythia compared to their levels in monomicrobial infections [246].

ii) Wound healing: Incorporation of phase of ligature removal into the time scheme of the acute model can be useful to assess the healing phase or to study the effect of anti-periodontitis medications [235].

iii) Optimize tobacco dosing: While our initial protocol was successful in demonstrating tobacco-enhanced periodontal bone loss, it may be 
possible to further exaggerate this phenomenon through optimizing exposure regimens.

In conclusion, these models could be employed for:

i) Study the association between gene mutations either in the pathogen or the host and their relevance to periodontitis. For example, IL-10 knockout mice e hyperinflammation and are highly susceptible to $P$. gingivalis-induced periodontitis [286]. Also, clinical studies revealed that IL-10 gene polymorphism seems to be associated with severe chronic periodontitis [314].

ii) Alternate treatment regimens for smokers based on mechanistic insights into smoke-enhanced bacterial induced periodontal diseases. For example, the Green tea catechin showed a bactericidal effect against Gram-negative rods and improved the periodontal status [315].

iii) Study tobacco-periodontitis-systemic disease exploitation. For instance, utilizing these models to study periodontitis association with increased risk of cardiovascular diseases [316]. Also, the direct correlation between diabetes mellitus and periodontitis [317].

iv) Study tobacco-related microbial dysbiosis in a reproducible system. Smoking showed a potential contribution in the alteration of microbial 
equilibrium in subgingival tissues, thus worsening the severity of periodontal disease [226].

v) Adapt model to environmental tobacco smoke or passive smoking related periodontal disease through use of side stream smoking machine [318].

vi) Adapt model to study marijuana-exacerbated disease: increasing evidence suggests that inhalation of cannabis smoke is also negatively associated with periodontal health as recently reported [51].

vii) Evaluate the impact of smoking cessation to clinical and microbial variables such as the bone loss and the bacterial colonization: studies show an early benefit of smoking cessation in terms of less reduction in pocket depth and gain in the level of clinical attachment in former smokers compared to smokers [319].

viii) Delivery of electronic cigarettes aerosol through modified nebulizer to the oral tissues to evaluate the effect of e-cigarettes in the current models [320]. Previous studies have shown the deleterious effects of e-cigarettes. For instance, E-cig containing nicotine affects oral myofibroblast differentiation in e-cig users; and hence may affect their ability to heal wounds by decreasing wound contraction by myofibroblasts[321]. Reactive aldehydes/carbonyls derived from e-cig aerosol can cause protein carbonylation and DNA adducts/damage, and carbonyls are cleaved by aldehyde dehydrogenase (ALDH). Protein carbonylation leads to autoantibody production, which may lead to destruction of matrix and bone loss during periodontitis [321]. 


\section{REFERENCES}

1. National Center for Chronic Disease, P., S. Health Promotion Office on, and Health, Reports of the Surgeon General, in The Health Consequences of Smoking-50 Years of Progress: A Report of the Surgeon General. 2014, Centers for Disease Control and Prevention (US): Atlanta (GA).

2. Creamer, M.R., et al., Tobacco Product Use and Cessation Indicators Among Adults United States, 2018. MMWR. Morbidity and Mortality Weekly Report, 2019. 68(45): p. 1013-1019.

3. Rabinoff, M., et al., Pharmacological and Chemical Effects of Cigarette Additives. American Journal of Public Health, 2007. 97(11): p. 1981-1991.

4. Jamal, A., et al., Current Cigarette Smoking Among Adults - United States, 2016. MMWR. Morbidity and Mortality Weekly Report, 2018. 67(2): p. 53-59.

5. Ekpu, V.U. and A.K. Brown, The Economic Impact of Smoking and of Reducing Smoking Prevalence: Review of Evidence. Tobacco Use Insights, 2015. 8: p. TUI.S15628.

6. Goodchild, M., N. Nargis, and E. Tursan D'Espaignet, Global economic cost of smokingattributable diseases. Tobacco Control, 2018. 27(1): p. 58-64.

7. $\mathrm{Xu}, \mathrm{X}$. , et al., Annual Healthcare Spending Attributable to Cigarette Smoking. American Journal of Preventive Medicine, 2015. 48(3): p. 326-333.

8. Ma, J., et al., Smoking-attributable Mortality by State in 2014, U.S. American Journal of Preventive Medicine, 2018. 54(5): p. 661-670.

9. Stämpfli, M.R. and G.P. Anderson, How cigarette smoke skews immune responses to promote infection, lung disease and cancer. Nature Reviews Immunology, 2009. 9: p. 377.

10. Smoking-attributable mortality, years of potential life lost, and productivity losses--United States, 2000-2004. MMWR Morb Mortal Wkly Rep, 2008. 57(45): p. 1226-8.

11. Huang, C. and G. Shi, Smoking and microbiome in oral, airway, gut and some systemic diseases. Journal of Translational Medicine, 2019. 17(1).

12. Bagaitkar, J., D.R. Demuth, and D.A. Scott, Tobacco use increases susceptibility to bacterial infection. Tobacco induced diseases, 2008. 4(1): p. 12-12.

13. Johannsen, A., C. Susin, and A. Gustafsson, Smoking and inflammation: evidence for a synergistic role in chronic disease. Periodontology 2000, 2014. 64(1): p. 111-126.

14. Peacock, A., et al., Global statistics on alcohol, tobacco and illicit drug use: 2017 status report. Addiction, 2018. 113(10): p. 1905-1926.

15. Identifying principles for effective messages about chemicals in cigarette smoke.

16. Noar, S.M., et al., Identifying principles for effective messages about chemicals in cigarette smoke. Preventive Medicine, 2018. 106: p. 31-37.

17. Kolappan, C., Tobacco smoking and pulmonary tuberculosis. 2002. 57(11): p. 964-966.

18. Brook, I. and A.E. Gober, Effect of Smoking Cessation on the Microbial Flora. Archives of Otolaryngology-Head \& Neck Surgery, 2007. 133(2): p. 135. 
19. Huttunen, R., T. Heikkinen, and J. Syrjänen, Smoking and the outcome of infection. Journal of Internal Medicine, 2011. 269(3): p. 258-269.

20. Stanwell, R.E., et al., Smoking, the environment and meningococcal disease: a case control study. 1994. 112(02): p. 315.

21. Palmer, R.M., et al., Mechanisms of action of environmental factors - tobacco smoking. Journal of Clinical Periodontology, 2005. 32(s6): p. 180-195.

22. Bagaitkar, J., et al., Tobacco Smoke Augments Porphyromonas gingivalis - Streptococcus gordonii Biofilm Formation. PLoS ONE, 2011. 6(11): p. e27386.

23. Costenbader, K.H. and E.W. Karlson, Cigarette smoking and autoimmune disease: what can we learn from epidemiology? Lupus, 2006. 15(11): p. 737-45.

24. Bernardi, L., et al., Autonomic and cerebrovascular abnormalities in mild COPD are worsened by chronic smoking. European Respiratory Journal, 2008. 32(6): p. 1458-1465.

25. Akishima, S., et al., Cigarette-Smoke-Induced Vasoconstriction of Peripheral Arteries. 2007. 71(3): p. 418-422.

26. Buduneli, N. and D.A. Scott, Tobacco-induced suppression of the vascular response to dental plaque. Molecular Oral Microbiology, 2018. 33(4): p. 271-282.

27. Hwang, J.H., et al., Electronic cigarette inhalation alters innate immunity and airway cytokines while increasing the virulence of colonizing bacteria. Journal of Molecular Medicine, 2016. 94(6): p. 667-679.

28. Gilpin, D.F., et al., Electronic cigarette vapour increases virulence and inflammatory potential of respiratory pathogens. Respiratory Research, 2019. 20(1).

29. Bagaitkar, J., et al., Tobacco-induced alterations toPorphyromonas gingivalis-host interactions. Environmental Microbiology, 2009. 11(5): p. 1242-1253.

30. Qiu, F., et al., Impacts of cigarette smoking on immune responsiveness: Up and down or upside down? Oncotarget, 2017. 8(1): p. 268-284.

31. Guntsch, A., et al., Effect of smoking on crevicular polymorphonuclear neutrophil function in periodontally healthy subjects. Journal of Periodontal Research, 2006. 41(3): p. 184188.

32. Sørensen, L.T., et al., Effect of smoking and abstention on oxidative burst and reactivity of neutrophils and monocytes. Surgery, 2004. 136(5): p. 1047-53.

33. Chen, I.L., et al., Electronic cigarette vapour moderately stimulates pro-inflammatory signalling pathways and interleukin-6 production by human monocyte-derived dendritic cells. Archives of Toxicology, 2020.

34. Johnson, J.D., et al., Effects of Mainstream and Environmental Tobacco Smoke on the Immune System in Animals and Humans: A Review. Critical Reviews in Toxicology, 1990. 20(5): p. 369-395.

35. Knight, E.T., et al., Risk factors that may modify the innate and adaptive immune responses in periodontal diseases. Periodontology 2000, 2016. 71(1): p. 22-51.

36. Sopori, M.L., et al., Nicotine-induced modulation of $T$ Cell function. Implications for inflammation and infection. Adv Exp Med Biol, 1998. 437: p. 279-89. 
37. Wu, J., et al., Cigarette smoking and the oral microbiome in a large study of American adults. ISME J, 2016. 10(10): p. 2435-46.

38. Shchipkova, A.Y., H.N. Nagaraja, and P.S. Kumar, Subgingival Microbial Profiles of Smokers with Periodontitis. Journal of Dental Research, 2010. 89(11): p. 1247-1253.

39. Bizzarro, S., et al., Subgingival microbiome in smokers and non-smokers in periodontitis: an exploratory study using traditional targeted techniques and a next-generation sequencing. J Clin Periodontol, 2013. 40(5): p. 483-92.

40. Delima, S.L., et al., Response of Subgingival Bacteria to Smoking Cessation. 2010. 48(7): p. 2344-2349.

41. Kumar, P.S., et al., Tobacco Smoking Affects Bacterial Acquisition and Colonization in Oral Biofilms. Infection and Immunity, 2011. 79(11): p. 4730-4738.

42. Zonuz, A.T., et al., Effect of cigarette smoke exposure on the growth of Streptococcus mutans and Streptococcus sanguis: An in vitro study. 2008. 10(1): p. 63-67.

43. Armitage, G.C., Clinical evaluation of periodontal diseases. 1995. 7(1): p. 39-53.

44. Luis Muñoz-Carrillo, J., et al., Pathogenesis of Periodontal Disease. 2020, IntechOpen.

45. Papapanou, P.N., et al., Periodontitis: Consensus report of workgroup 2 of the 2017 World Workshop on the Classification of Periodontal and Peri-Implant Diseases and Conditions. Journal of Periodontology, 2018. 89: p. S173-S182.

46. Kinane, D.F., P.G. Stathopoulou, and P.N. Papapanou, Periodontal diseases. Nature Reviews Disease Primers, 2017. 3: p. 17038.

47. Nazir, M.A., Prevalence of periodontal disease, its association with systemic diseases and prevention. International journal of health sciences, 2017. 11(2): p. 72-80.

48. Sanz, M., et al., Periodontitis and Cardiovascular Diseases. Consensus Report. Global Heart, 2020. 15(1): p. 1.

49. Kassebaum, N.J., et al., Global, Regional, and National Prevalence, Incidence, and Disability-Adjusted Life Years for Oral Conditions for 195 Countries, 1990-2015: A Systematic Analysis for the Global Burden of Diseases, Injuries, and Risk Factors. Journal of Dental Research, 2017. 96(4): p. 380-387.

50. Eke, P.I., et al., Update on Prevalence of Periodontitis in Adults in the United States: NHANES 2009 to 2012. Journal of Periodontology, 2015. 86(5): p. 611-622.

51. Gu, Z., et al., Marijuana-Derived Cannabinoids Trigger a CB2/PI3K Axis of Suppression of the Innate Response to Oral Pathogens. Frontiers in Immunology, 2019. 10.

52. Chung, J.H., et al., Associations Between Periodontitis and Chronic Obstructive Pulmonary Disease: The 2010 to 2012 Korean National Health and Nutrition Examination Survey. J Periodontol, 2016. 87(8): p. 864-71.

53. Paju, S. and F.A. Scannapieco, Oral biofilms, periodontitis, and pulmonary infections. Oral diseases, 2007. 13(6): p. 508-512.

54. Zeng, X.-T., et al., Periodontal Disease and Risk of Chronic Obstructive Pulmonary Disease: A Meta-Analysis of Observational Studies. PLoS ONE, 2012. 7(10): p. e46508.

55. Gogeneni, H., et al., Increased infection with key periodontal pathogens during gestational diabetes mellitus. Journal of Clinical Periodontology, 2015. 42(6): p. 506-512.

56. Teeuw, W.J., V.E.A. Gerdes, and B.G. Loos, Effect of Periodontal Treatment on Glycemic Control of Diabetic Patients: A systematic review and meta-analysis. Diabetes Care, 2010. 33(2): p. 421-427.

57. Janket, S.-J., et al., Meta-analysis of periodontal disease and risk of coronary heart disease and stroke. Oral Surgery, Oral Medicine, Oral Pathology, Oral Radiology, and Endodontology, 2003. 95(5): p. 559-569. 
58. Sanz, M., et al., European workshop in periodontal health and cardiovascular disease-scientific evidence on the association between periodontal and cardiovascular diseases: a review of the literature. European Heart Journal Supplements, 2010. 12(Suppl B): p. B3B12.

59. de Pablo, P., T. Dietrich, and T.E. McAlindon, Association of periodontal disease and tooth loss with rheumatoid arthritis in the US population. The Journal of rheumatology, 2008. 35(1): p. 70-76.

60. Detert, J., et al., The association between rheumatoid arthritis and periodontal disease. 2010. 12(5): p. 218.

61. Bartold, P.M., R.I. Marshall, and D.R. Haynes, Periodontitis and Rheumatoid Arthritis: A Review. Journal of Periodontology, 2005. 76(11-s): p. 2066-2074.

62. Mercado, F.B., R.I. Marshall, and P.M. Bartold, Inter-relationships between rheumatoid arthritis and periodontal disease. Journal of Clinical Periodontology, 2003. 30(9): p. 761772.

63. Greene, R.M. and M.M. Pisano, Developmental toxicity of e-cigarette aerosols. Birth Defects Research, 2019.

64. Fitzpatrick, S.G. and J. Katz, The association between periodontal disease and cancer: $A$ review of the literature. Journal of Dentistry, 2010. 38(2): p. 83-95.

65. Tezal, M., et al., Chronic Periodontitis and the Risk of Tongue Cancer. Archives of Otolaryngology-Head \& Neck Surgery, 2007. 133(5): p. 450.

66. Yao, Q.-W., et al., Association of periodontal disease with oral cancer: a meta-analysis. Tumor Biology, 2014. 35(7): p. 7073-7077.

67. Gao, S., et al., Presence of Porphyromonas gingivalis in esophagus and its association with the clinicopathological characteristics and survival in patients with esophageal cancer. 2016. 11(1).

68. Michaud, D.S., et al., Periodontal Disease, Tooth Loss, and Cancer Risk. Epidemiologic Reviews, 2017. 39(1): p. 49-58.

69. Duque, A.D., et al., Strategies for the prevention of periodontal disease and its impact on general health in Latin America. Section III: Prevention. Brazilian Oral Research, 2020. 34(suppl 1).

70. Tomar, S.L. and S. Asma, Smoking-Attributable Periodontitis in the United States: Findings From NHANES III. Journal of Periodontology, 2000. 71(5): p. 743-751.

71. Nair, P., et al., Gingival bleeding on probing increases after quitting smoking. J Clin Periodontol, 2003. 30(5): p. 435-7.

72. Moynihan, P.J., The role of diet and nutrition in the etiology and prevention of oral diseases. Bulletin of the World Health Organization, 2005. 83(9): p. 694-699.

73. Chapple, I.L.C. and J.B. Matthews, The role of reactive oxygen and antioxidant species in periodontal tissue destruction. Periodontology 2000, 2007. 43(1): p. 160-232.

74. Yan, Y., et al., Vitamin C induces periodontal ligament progenitor cell differentiation via activation of ERK pathway mediated by PELP1. Protein \& Cell, 2013. 4(8): p. 620-627.

75. Nishida, M., et al., Dietary Vitamin $C$ and the Risk for Periodontal Disease. Journal of Periodontology, 2000. 71(8): p. 1215-1223.

76. Rajendran, M., et al., Systemic Antibiotic Therapy Reduces Circulating Inflammatory Dendritic Cells and Treg-Th17 Plasticity in Periodontitis. The Journal of Immunology, 2019. 202(9): p. 2690-2699.

77. Pal, A., et al., Is the Use of Antimicrobial Photodynamic Therapy or Systemic Antibiotics More Effective in Improving Periodontal Health When Used in Conjunction with Localised 
Non-Surgical Periodontal Therapy? A Systematic Review. Dentistry Journal, 2019. 7(4): p. 108.

78. Garg, T., et al., Scaffold: A Novel Carrier for Cell and Drug Delivery. Critical Reviews ${ }^{\mathrm{TM}}$ in Therapeutic Drug Carrier Systems, 2012. 29(1): p. 1-63.

79. Van Der Weijden, G.A., G.J. Dekkers, and D.E. Slot, Success of non-surgical periodontal therapy in adult periodontitis patients: A retrospective analysis. International Journal of Dental Hygiene, 2019. 17(4): p. 309-317.

80. Haffajee, A.D., et al., The effect of SRP on the clinical and microbiological parameters of periodontal diseases. 1997. 24(5): p. 324-334.

81. Gross, A.J., et al., Periodontitis: a global disease and the primary care provider's role. Postgrad Med J, 2017. 93(1103): p. 560-565.

82. Slots, J., Periodontitis: facts, fallacies and the future. Periodontology 2000, 2017. 75(1): p. 7-23.

83. Hussain, M., C.M. Stover, and A. Dupont, P. gingivalis in Periodontal Disease and Atherosclerosis $\hat{a} \epsilon^{\prime \prime}$ Scenes of Action for Antimicrobial Peptides and Complement. Frontiers in Immunology, 2015. 6.

84. Graziani, F., et al., Nonsurgical and surgical treatment of periodontitis: how many options for one disease? Periodontology 2000, 2017. 75(1): p. 152-188.

85. Loesche, W.J., The specific plaque hypothesis and the antimicrobial treatment of periodontal disease. Dent Update, 1992. 19(2): p. 68, 70-2, 74.

86. Socransky, S.S., et al., Microbial complexes in subgingival plaque. Journal of Clinical Periodontology, 1998. 25(2): p. 134-144.

87. Hajishengallis, G. and R.J. Lamont, Beyond the red complex and into more complexity: the polymicrobial synergy and dysbiosis (PSD) model of periodontal disease etiology. Molecular Oral Microbiology, 2012. 27(6): p. 409-419.

88. Nowicki, E.M., et al., Microbiota and Metatranscriptome Changes Accompanying the Onset of Gingivitis. mBio, 2018. 9(2): p. e00575-18.

89. Michalowicz, B.S., et al., Evidence of a substantial genetic basis for risk of adult periodontitis. J Periodontol, 2000. 71(11): p. 1699-707.

90. D'Aiuto, F., et al., Gene polymorphisms in pro-inflammatory cytokines are associated with systemic inflammation in patients with severe periodontal infections. Cytokine, 2004. 28(1): p. 29-34.

91. Scott, D.A. and J. Krauss, Neutrophils in Periodontal Inflammation. 2011, KARGER. p. 5683.

92. Shapira, L., A. Wilensky, and D.F. Kinane, Effect of genetic variability on the inflammatory response to periodontal infection. J Clin Periodontol, 2005. 32 Suppl 6: p. 72-86.

93. Zhang, Y., Evidence of a founder effect for four cathepsin $C$ gene mutations in PapillonLefevre syndrome patients. Journal of Medical Genetics, 2001. 38(2): p. 96-101.

94. Wani, A.A., et al., Description of Two New Cathepsin C Gene Mutations in Patients With Papillon-Lefèvre Syndrome. Journal of Periodontology, 2006. 77(2): p. 233-237.

95. Hewitt, C., et al., The role of cathepsin C in Papillon-Lefèvre syndrome, prepubertal periodontitis, and aggressive periodontitis. Hum Mutat, 2004. 23(3): p. 222-8.

96. Shirodaria, S., et al., Polymorphisms in the IL-1A gene are correlated with levels of interleukin-1alpha protein in gingival crevicular fluid of teeth with severe periodontal disease. J Dent Res, 2000. 79(11): p. 1864-9.

97. Albandar, J.M. and T.E. Rams, Global epidemiology of periodontal diseases: an overview. Periodontology 2000, 2002. 29(1): p. 7-10. 
98. Albandar, J.M., J.A. Brunelle, and A. Kingman, Destructive periodontal disease in adults 30 years of age and older in the United States, 1988-1994. J Periodontol, 1999. 70(1): p. 1329.

99. Shiau, H.J. and M.A. Reynolds, Sex Differences in Destructive Periodontal Disease: A Systematic Review. Journal of Periodontology, 2010. 81(10): p. 1379-1389.

100. Furuta, M., et al., Gender differences in the association between metabolic syndrome and periodontal disease: the Hisayama Study. Journal of Clinical Periodontology, 2013. 40(8): p. 743-752.

101. Ioannidou, E., The Sex and Gender Intersection in Chronic Periodontitis. Frontiers in Public Health, 2017. 5.

102. Grossi, S.G., et al., Assessment of Risk for Periodontal Disease. I. Risk Indicators for Attachment Loss. Journal of Periodontology, 1994. 65(3): p. 260-267.

103. Grossi, S.G., et al., Assessment of risk for periodontal disease. II. Risk indicators for alveolar bone loss. J Periodontol, 1995. 66(1): p. 23-9.

104. Ebersole, J.L., et al., Aging, inflammation, immunity and periodontal disease. 2016. 72(1): p. 54-75.

105. Rheu, G.-B., et al., Risk assessment for clinical attachment loss of periodontal tissue in Korean adults. 2011. 3(1): p. 25.

106. Albandar, J.M., Global risk factors and risk indicators for periodontal diseases. Periodontology 2000, 2002. 29(1): p. 177-206.

107. Preshaw, P.M. and S.M. Bissett, Periodontitis and diabetes. British Dental Journal, 2019. 227(7): p. 577-584.

108. Kinane, D.F., M. Peterson, and P.G. Stathopoulou, Environmental and other modifying factors of the periodontal diseases. Periodontology 2000, 2006. 40(1): p. 107-119.

109. Soskolne, W.A. and A. Klinger, The relationship between periodontal diseases and diabetes: an overview. Ann Periodontol, 2001. 6(1): p. 91-8.

110. Bascones-Martínez, A., J. González-Febles, and J. Sanz-Esporrín, Diabetes and periodontal disease. Review of the literature. Am J Dent, 2014. 27(2): p. 63-7.

111. Sima, C. and M. Glogauer, Diabetes Mellitus and Periodontal Diseases. 2013. 13(3): p. 445452.

112. Reners, M. and M. Brecx, Stress and periodontal disease. International Journal of Dental Hygiene, 2007. 5(4): p. 199-204.

113. Rai, B., et al., Salivary stress markers, stress, and periodontitis: a pilot study. J Periodontol, 2011. 82(2): p. 287-92.

114. Sundararajan, S., S. Muthukumar, and S.R. Rao, Relationship between depression and chronic periodontitis. Journal of Indian Society of Periodontology, 2015. 19(3): p. 294-296.

115. Dumitrescu, A.L., Depression and Inflammatory Periodontal Disease Considerations-An Interdisciplinary Approach. Frontiers in Psychology, 2016. 7.

116. Shariff, J.A. and B.L. Edelstein, Medicaid Meets Its Equal Access Requirement For Dental Care, But Oral Health Disparities Remain. Health Affairs, 2016. 35(12): p. 2259-2267.

117. Chisini, L.A., et al., Is the use of Cannabis associated with periodontitis? A systematic review and meta-analysis. Journal of Periodontal Research, 2019. 54(4): p. 311-317.

118. Mullally, B.H., The Influence of Tobacco Smoking on the Onset of Periodontitis in Young Persons. 2004. 2(2): p. 53.

119. Fisher, S., et al., Progression of periodontal disease in a maintenance population of smokers and non-smokers: a 3-year longitudinal study. J Periodontol, 2008. 79(3): p. 4618. 
120. Calsina, G., J.M. Ramón, and J.J. Echeverría, Effects of smoking on periodontal tissues. J Clin Periodontol, 2002. 29(8): p. 771-6.

121. Heasman, L., et al., The effect of smoking on periodontal treatment response: a review of clinical evidence. Journal of Clinical Periodontology, 2006. 33(4): p. 241-253.

122. Bergström, J., S. Eliasson, and J. Dock, Exposure to tobacco smoking and periodontal health. J Clin Periodontol, 2000. 27(1): p. 61-8.

123. Sreedevi, M., A. Ramesh, and C. Dwarakanath, Periodontal Status in Smokers and Nonsmokers: A Clinical, Microbiological, and Histopathological Study. International Journal of Dentistry, 2012. 2012: p. 1-10.

124. Haffajee, A.D. and S.S. Socransky, Relationship of cigarette smoking to attachment level profiles. J Clin Periodontol, 2001. 28(4): p. 283-95.

125. Machuca, G., et al., Effect of cigarette smoking on periodontal status of healthy young adults. J Periodontol, 2000. 71(1): p. 73-8.

126. Rabkin, S.W., The Effect of Nicotine and Tobacco on Aortic Matrix Metalloproteinases in the Production of Aortic Aneurysm. Curr Vasc Pharmacol, 2016. 14(6): p. 514-522.

127. Katono, T., et al., Nicotine Treatment Induces Expression of Matrix Metalloproteinases in Human Osteoblastic Saos-2 Cells. 2006. 38(12): p. 874-882.

128. James, J.A., et al., Effects of tobacco products on the attachment and growth of periodontal ligament fibroblasts. J Periodontol, 1999. 70(5): p. 518-25.

129. Giannopoulou, C., A. Geinoz, and G. Cimasoni, Effects of nicotine on periodontal ligament fibroblasts in vitro. J Clin Periodontol, 1999. 26(1): p. 49-55.

130. Anand, N., et al., Effect of a volatile smoke component (acrolein) on human gingival fibroblasts: An in vitro study. Journal of Indian Society of Periodontology, 2011. 15(4): p. 371-375.

131. Rezavandi, K., et al., Expression of ICAM-1 and E-selectin in gingival tissues of smokers and non-smokers with periodontitis. Journal of Oral Pathology \& Medicine, 2002. 31(1): p. 5964.

132. Scott, D. and D. Singer, Suppression of overt gingival inflammation in tobacco smokers clinical and mechanistic considerations. International Journal of Dental Hygiene, 2004. 2(3): p. 104-110.

133. Sales, M.P.U., et al., Update on the approach to smoking in patients with respiratory diseases. Jornal Brasileiro de Pneumologia, 2019. 45(3).

134. Leite, F.R.M., et al., Effect of Smoking on Periodontitis: A Systematic Review and Metaregression. American Journal of Preventive Medicine, 2018. 54(6): p. 831-841.

135. Machtei, E.E., et al., Longitudinal study of prognostic factors in established periodontitis patients. 1997. 24(2): p. 102-109.

136. Bergström, J., Tobacco smoking and risk for periodontal disease. Journal of clinical periodontology, 2003. 30(2): p. 107-113.

137. Ryder, M.I., The influence of smoking on host responses in periodontal infections. Periodontol 2000, 2007. 43: p. 267-77.

138. Jiang, Y., et al., The Impact of Smoking on Subgingival Microflora: From Periodontal Health to Disease. Frontiers in Microbiology, 2020. 11(66).

139. Archana, M.S., A. Bagewadi, and V. Keluskar, Assessment and comparison of phagocytic function and viability of polymorphonuclear leukocytes in saliva of smokers and nonsmokers. Arch Oral Biol, 2015. 60(2): p. 229-33.

140. Geng, Y., et al., Effects of nicotine on the immune response. II. Chronic nicotine treatment induces T cell anergy. J Immunol, 1996. 156(7): p. 2384-90. 
141. Madretsma, S., et al., In-vivo effect of nicotine on cytokine production by human nonadherent mononuclear cells. 1996. 8(10): p. 1017-1020.

142. Bostrom, L., L.E. Linder, and J. Bergstrom, Clinical expression of TNF-alpha in smokingassociated periodontal disease. Journal of Clinical Periodontology, 1998. 25(10): p. 767773.

143. Bostrom, L., L.E. Linder, and J. Bergstrom, Smoking and crevicular fluid levels of IL-6 and TNF-a in periodontal disease. Journal of Clinical Periodontology, 1999. 26(6): p. 352-357.

144. Giannopoulou, C., J.J. Kamma, and A. Mombelli, Effect of inflammation, smoking and stress on gingival crevicular fluid cytokine level. J Clin Periodontol, 2003. 30(2): p. 145-53.

145. Liu, K.Z., et al., Increased local matrix metalloproteinase-8 expression in the periodontal connective tissues of smokers with periodontal disease. 2006. 1762(8): p. 775-780.

146. Söder, B., et al., Levels of matrix metalloproteinases-8 and -9 with simultaneous presence of periodontal pathogens in gingival crevicular fluid as well as matrix metalloproteinase9 and cholesterol in blood. J Periodontal Res, 2006. 41(5): p. 411-7.

147. Leite, F.R.M., et al., RANKL expression is differentially modulated by TLR2 and TLR4 signaling in fibroblasts and osteoblasts. Immunology Innovation, 2014. 2(1): p. 1.

148. Hienz, S.A., S. Paliwal, and S. Ivanovski, Mechanisms of Bone Resorption in Periodontitis. Journal of Immunology Research, 2015. 2015: p. 1-10.

149. Tebloeva, L.M., et al. Differences in immune response to Porphyromonas gingivalis. The journal of contemporary dental practice, 2014. 15, 573-575 DOI: 10.5005/jp-journals10024-1581.

150. Dye, B.A., et al., Serum antibodies to periodontal bacteria as diagnostic markers of periodontitis. J Periodontol, 2009. 80(4): p. 634-47.

151. Graswinckel, J.E., et al., Plasma antibody levels in periodontitis patients and controls. J Clin Periodontol, 2004. 31(7): p. 562-8.

152. Matthews, J.B., et al., Effect of nicotine, cotinine and cigarette smoke extract on the neutrophil respiratory burst. J Clin Periodontol, 2011. 38(3): p. 208-18.

153. Benowitz, N.L. and P.J. lii, Daily intake of nicotine during cigarette smoking. Clinical Pharmacology and Therapeutics, 1984. 35(4): p. 499-504.

154. Cuff, M.J., et al., The presence of nicotine on root surfaces of periodontally diseased teeth in smokers. J Periodontol, 1989. 60(10): p. 564-9.

155. Tanur, E., et al., Effects of nicotine on the strength of attachment of gingival fibroblasts to glass and non-diseased human root surfaces. J Periodontol, 2000. 71(5): p. 717-22.

156. Austin, G.W., et al., Effect of nicotine on fibroblast beta 1 integrin expression and distribution in vitro. J Periodontol, 2001. 72(4): p. 438-44.

157. Tipton, D.A. and M.K. Dabbous, Effects of nicotine on proliferation and extracellular matrix production of human gingival fibroblasts in vitro. J Periodontol, 1995. 66(12): p. 1056-64.

158. Gamal, A.Y. and M.M. Bayomy, Effect of cigarette smoking on human PDL fibroblasts attachment to periodontally involved root surfaces in vitro. J Clin Periodontol, 2002. 29(8): p. 763-70.

159. Wendell, K.J. and S.H. Stein, Regulation of cytokine production in human gingival fibroblasts following treatment with nicotine and lipopolysaccharide. J Periodontol, 2001. 72(8): p. 1038-44.

160. Johnson, G.K. and C.C. Organ, Prostaglandin E2 and interleukin-1 concentrations in nicotine-exposed oral keratinocyte cultures. J Periodontal Res, 1997. 32(5): p. 447-54.

161. Payne, J.B., et al., Nicotine effects on PGE2 and IL-1 beta release by LPS-treated human monocytes. J Periodontal Res, 1996. 31(2): p. 99-104. 
162. Hollinger, J.O., et al., Impact of nicotine on bone healing. J Biomed Mater Res, 1999. 45(4): p. 294-301.

163. Riebel, G.D., et al., The effect of nicotine on incorporation of cancellous bone graft in an animal model. Spine (Phila Pa 1976), 1995. 20(20): p. 2198-202.

164. Theiss, S.M., et al., The effect of nicotine on gene expression during spine fusion. Spine (Phila Pa 1976), 2000. 25(20): p. 2588-94.

165. Mosely, L.H., F. Finseth, and M. Goody, Nicotine and its effect on wound healing. Plast Reconstr Surg, 1978. 61(4): p. 570-5.

166. Talhout, R., et al., Hazardous Compounds in Tobacco Smoke. International Journal of Environmental Research and Public Health, 2011. 8(2): p. 613-628.

167. Mehta, H., K. Nazzal, and R.T. Sadikot, Cigarette smoking and innate immunity. Inflammation Research, 2008. 57(11): p. 497-503.

168. Chang, Y.C., et al., Mechanisms of cytotoxicity of nicotine in human periodontal ligament fibroblast cultures in vitro. J Periodontal Res, 2002. 37(4): p. 279-85.

169. Lallier, T.E., J.T. Moylan, and E. Maturin, Greater Sensitivity of Oral Fibroblasts to Smoked Versus Smokeless Tobacco. Journal of Periodontology, 2017. 88(12): p. 1356-1365.

170. Zhang, Y., et al., Effect of tobacco on periodontal disease and oral cancer. Tobacco Induced Diseases, 2019. 17(May).

171. Ng, T.K., et al., Cigarette smoking hinders human periodontal ligament-derived stem cell proliferation, migration and differentiation potentials. Scientific Reports, 2015. 5(1): p. 7828.

172. Mason, M.R., et al., The subgingival microbiome of clinically healthy current and never smokers. The ISME Journal, 2015. 9(1): p. 268-272.

173. Yu, G., et al., The effect of cigarette smoking on the oral and nasal microbiota. Microbiome, 2017. 5(1): p. 3.

174. Hutcherson, J.A., D.A. Scott, and J. Bagaitkar, Scratching the surface - tobacco-induced bacterial biofilms. Tobacco Induced Diseases, 2015. 13(1): p. 1.

175. Zhang, S., N. Yu, and R.M. Arce, Periodontal inflammation: Integrating genes and dysbiosis. Periodontology 2000, 2020. 82(1): p. 129-142.

176. Grover, N., et al., Long-term effect of tobacco on unstimulated salivary $\mathrm{pH}$. Journal of oral and maxillofacial pathology : JOMFP, 2016. 20(1): p. 16-19.

177. Scott, D. and R. Palmer, The influence of tobacco smoking on adhesion molecule profiles. 2003. 1(1): p. 7.

178. Souto, G.R., et al., Effect of smoking on immunity in human chronic periodontitis. Immunobiology, 2014. 219(12): p. 909-915.

179. Hajishengallis, G. and R.J. Lamont, Breaking bad: manipulation of the host response by Porphyromonas gingivalis. Eur J Immunol, 2014. 44(2): p. 328-38.

180. Bostanci, N., et al., Porphyromonas gingivalis Regulates TREM-1 in Human Polymorphonuclear Neutrophils via Its Gingipains. 2013. 8(10): p. e75784.

181. Kilian, M., et al., The oral microbiome - an update for oral healthcare professionals. British Dental Journal, 2016. 221(10): p. 657-666.

182. Hajishengallis, G., R.P. Darveau, and M.A. Curtis, The keystone-pathogen hypothesis. Nature Reviews Microbiology, 2012. 10(10): p. 717-725.

183. Igboin, C.O., A.L. Griffen, and E.J. Leys, Porphyromonas gingivalis Strain Diversity. 2009. 47(10): p. 3073-3081.

184. Kawada, M., et al., Prevalence of Porphyromonas gingivalis in relation to periodontal status assessed by real-time PCR. Oral Microbiol Immunol, 2004. 19(5): p. 289-92. 
185. Darveau, R.P., G. Hajishengallis, and M.A. Curtis, Porphyromonas gingivalis as a Potential Community Activist for Disease. Journal of Dental Research, 2012. 91(9): p. 816-820.

186. Sundqvist, G., et al., Phagocytosis and virulence of different strains of Porphyromonas gingivalis. 1991. 99(2): p. 117-129.

187. How, K.Y., K.P. Song, and K.G. Chan, Porphyromonas gingivalis: An Overview of Periodontopathic Pathogen below the Gum Line. Front Microbiol, 2016. 7: p. 53.

188. Brunner, J., et al., The capsule of Porphyromonas gingivalis reduces the immune response of human gingival fibroblasts. 2010. 10(1): p. 5.

189. Olsen, I. and J. Potempa, Strategies for the inhibition of gingipains for the potential treatment of periodontitis and associated systemic diseases. Journal of Oral Microbiology, 2014. 6(1): p. 24800.

190. Li, N. and C.A. Collyer, Gingipains from Porphyromonas gingivalis - complex domain structures confer diverse functions. 2011. 1(1): p. 41-58.

191. Guentsch, A., et al., Comparison of Gingival Crevicular Fluid Sampling Methods in Patients With Severe Chronic Periodontitis. Journal of Periodontology, 2011. 82(7): p. 1051-1060.

192. McAlister, A.D., et al., Gingipain enzymes from Porphyromonas gingivalis preferentially bind immobilized extracellular proteins: a mechanism favouring colonization? 2009. 44(3): p. 348-353.

193. NM, O.B.-S., et al., Porphyromonas gingivalis gingipains: the molecular teeth of a microbial vampire. Curr Protein Pept Sci, 2003. 4(6): p. 409-26.

194. Lee, J.Y., et al., Maturation of the Mfa1 Fimbriae in the Oral Pathogen Porphyromonas gingivalis. Frontiers in Cellular and Infection Microbiology, 2018. 8.

195. Curtis, M.A., et al., Attenuation of the Virulence of Porphyromonas gingivalis by Using a Specific Synthetic Kgp Protease Inhibitor. Infection and Immunity, 2002. 70(12): p. 69686975.

196. Yonezawa, H., K. Ishihara, and K. Okuda, Arg-Gingipain A DNA Vaccine Induces Protective Immunity against Infection by Porphyromonas gingivalis in a Murine Model. 2001. 69(5): p. 2858-2864.

197. Enersen, M., K. Nakano, and A. Amano, Porphyromonas gingivalis fimbriae. 2013. 5(0).

198. Yoshimura, F., et al., Surface components of Porphyromonas gingivalis. 2009. 44(1): p. 112.

199. Hamada, S., et al., The importance of fimbriae in the virulence and ecology of some oral bacteria. 1998. 13(3): p. 129-138.

200. Sojar, H.T., Porphyromonas gingivalis Fimbriae Bind to Cytokeratin of Epithelial Cells. 2002. 70(1): p. 96-101.

201. Bagaitkar, J., et al., Tobacco upregulates $P$. gingivalis fimbrial proteins which induce TLR2 hyposensitivity. PLoS One, 2010. 5(5): p. e9323.

202. Lamont, R.J., et al., Role of the Streptococcus gordonii SspB protein in the development of Porphyromonas gingivalis biofilms on streptococcal substrates. Microbiology, 2002. 148(6): p. 1627-1636.

203. Davey, M., et al., Bacterial Fimbriae Stimulate Proinflammatory Activation in the Endothelium through Distinct TLRs. The Journal of Immunology, 2008. 180(4): p. 21872195.

204. Hiramine, H., et al., Porphyromonas gingivalis67-kDa fimbriae induced cytokine production and osteoclast differentiation utilizing TLR2. FEMS Microbiology Letters, 2003. 229(1): p. 49-55.

205. Raetz, C.R.H. and C. Whitfield, Lipopolysaccharide Endotoxins. Annual Review of Biochemistry, 2002. 71(1): p. 635-700. 
206. Bertani, B. and N. Ruiz, Function and Biogenesis of Lipopolysaccharides. EcoSal Plus, 2018. 8(1): p. 10.1128/ecosalplus.ESP-0001-2018.

207. Pekarova, M., et al., The unique role of dietary l-arginine in the acceleration of peritoneal macrophage sensitivity to bacterial endotoxin. Immunologic Research, 2013. 56(1): p. 7384.

208. Aida, Y., et al., Lipopolysaccharides from periodontal pathogens prime neutrophils for enhanced respiratory burst: differential effect of a synthetic lipid a precursor IVA (LA-14PP). J Periodontal Res, 1995. 30(2): p. 116-23.

209. Wang, P.L. and K. Ohura, Porphyromonas gingivalisLipopolysaccharideSignaling inGingivalFibroblasts-CD14andToll-likeReceptors. Critical Reviews in Oral Biology \& Medicine, 2002. 13(2): p. 132-142.

210. Diya, Z., et al., Lipopolysaccharide (LPS) of Porphyromonas gingivalis induces IL-16, TNF- $\alpha$ and IL-6 production by THP-1 cells in a way different from that of Escherichia coli LPS. Innate Immunity, 2008. 14(2): p. 99-107.

211. Qi, M., H. Miyakawa, and H.K. Kuramitsu, Porphyromonas gingivalis induces murine macrophage foam cell formation. Microbial pathogenesis, 2003. 35(6): p. 259-267.

212. R., l., life below the gum. 1998.

213. Grossi, S.G., et al., Mechanical Therapy With Adjunctive Minocycline Microspheres Reduces Red-Complex Bacteria in Smokers. Journal of Periodontology, 2007. 78(9): p. 1741-1750.

214. Haffajee, A.D. and S.S. Socransky, Relationship of cigarette smoking to the subgingival microbiota. J Clin Periodontol, 2001. 28(5): p. 377-88.

215. Zambon, J.J., et al., Cigarette smoking increases the risk for subgingival infection with periodontal pathogens. J Periodontol, 1996. 67(10 Suppl): p. 1050-4.

216. Eggert, F.M., M.H. McLeod, and G. Flowerdew, Effects of Smoking and Treatment Status on Periodontal Bacteria: Evidence That Smoking Influences Control of Periodontal Bacteria at the Mucosal Surface of the Gingival Crevice. Journal of Periodontology, 2001. 72(9): p. $1210-1220$.

217. Guglielmetti, M.R., et al., Detection and Quantification of Periodontal Pathogens in Smokers and Never-Smokers With Chronic Periodontitis by Real-Time Polymerase Chain Reaction. Journal of Periodontology, 2014. 85(10): p. 1450-1457.

218. Dhar, P., Measuring tobacco smoke exposure: quantifying nicotine/cotinine concentration in biological samples by colorimetry, chromatography and immunoassay methods. J Pharm Biomed Anal, 2004. 35(1): p. 155-68.

219. Cogo, K., et al., In vitro evaluation of the effect of nicotine, cotinine, and caffeine on oral microorganisms. Can J Microbiol, 2008. 54(6): p. 501-8.

220. Zeller, I., et al., Cigarette smoke reduces short chain fatty acid production by a Porphyromonas gingivalis clinical isolate. Journal of Periodontal Research, 2019.

221. Bondy-Carey, J.L., et al., Neutrophils alter epithelial response toPorphyromonas gingivalisin a gingival crevice model. Molecular Oral Microbiology, 2013. 28(2): p. 102113.

222. Graves, D.T., et al., Animal models to study host-bacteria interactions involved in periodontitis. Frontiers of oral biology, 2012. 15: p. 117-132.

223. Oz, H.S. and D.A. Puleo, Animal Models for Periodontal Disease. Journal of Biomedicine and Biotechnology, 2011. 2011: p. 1-8.

224. Graves, D.T., et al., The use of rodent models to investigate host-bacteria interactions related to periodontal diseases. Journal of Clinical Periodontology, 2008. 35(2): p. 89-105. 
225. An, J.Y., R. Darveau, and M. Kaeberlein, Oral health in geroscience: animal models and the aging oral cavity. GeroScience, 2018. 40(1): p. 1-10.

226. Coretti, L., et al., Subgingival dysbiosis in smoker and non-smoker patients with chronic periodontitis. 2017.

227. Gonzalez-Quintela, A., et al., Serum levels of immunoglobulins (IgG, IgA, IgM) in a general adult population and their relationship with alcohol consumption, smoking and common metabolic abnormalities. 2007. 151(1): p. 42-50.

228. Linden, G.J. and B.H. Mullally, Cigarette Smoking and Periodontal Destruction in Young Adults. 1994. 65(7): p. 718-723.

229. Baker, P.J., R.T. Evans, and D.C. Roopenian, Oral infection with Porphyromonas gingivalis and induced alveolar bone loss in immunocompetent and severe combined immunodeficient mice. Arch Oral Biol, 1994. 39(12): p. 1035-40.

230. Graves, D.T., et al., Animal Models to Study Host-Bacteria Interactions Involved in Periodontitis. 2011, KARGER. p. 117-132.

231. Kinane, D.F. and G. Hajishengallis, Polymicrobial infections, biofilms, and beyond. J Clin Periodontol, 2009. 36(5): p. 404-5.

232. Gao, L., et al., Oral microbiomes: more and more importance in oral cavity and whole body. Protein \& Cell, 2018. 9(5): p. 488-500.

233. Beertsen, W., et al., Impaired Phagosomal Maturation in Neutrophils Leads to Periodontitis in Lysosomal-Associated Membrane Protein-2 Knockout Mice. The Journal of Immunology, 2008. 180(1): p. 475-482.

234. Alshammari, A. and S. Amar, Proposal for a novel murine model of human periodontitis using Porphyromonas gingivalis and type II collagen antibody injections. The Saudi Dental Journal, 2019. 31(2): p. 181-187.

235. Abe, T. and G. Hajishengallis, Optimization of the ligature-induced periodontitis model in mice. Journal of Immunological Methods, 2013. 394(1-2): p. 49-54.

236. Kubota, M., et al., The Effects of Cigarette Smoke Condensate and Nicotine on Periodontal Tissue in a Periodontitis Model Mouse. PLOS ONE, 2016. 11(5): p. e0155594.

237. Nogueira-Filho, G.d.R., et al., Low- and High-Yield Cigarette Smoke Inhalation Potentiates Bone Loss During Ligature-Induced Periodontitis. Journal of Periodontology, 2007. 78(4): p. 730-735.

238. César-Neto, J.B., et al., Smoking Cessation May Present a Positive Impact on Mandibular Bone Quality and Periodontitis-Related Bone Loss: A Study in Rats. Journal of Periodontology, 2005. 76(4): p. 520-525.

239. Chang, K.M., et al., Infection with a gram-negative organism stimulates gingival collagenase production in nondiabetic and diabetic germfree rats. 1988. 23(4): p. 239-244.

240. Klausen, B., et al., Periodontal bone level and gingival proteinase activity in gnotobiotic rats immunized with Bacteroides gingivalis. Oral Microbiol Immunol, 1991. 6(4): p. 193201.

241. Lee, S.F., et al., Immune Response and Alveolar Bone Resorption in a Mouse Model of Treponema denticola Infection. 2009. 77(2): p. 694-698.

242. Garlet, G.P., et al., Cytokine pattern determines the progression of experimental periodontal disease induced by Actinobacillus actinomycetemcomitans through the modulation of MMPs, RANKL, and their physiological inhibitors. Oral Microbiol Immunol, 2006. 21(1): p. 12-20.

243. Sharma, A., et al., Tannerella forsythia-induced alveolar bone loss in mice involves leucinerich-repeat BspA protein. J Dent Res, 2005. 84(5): p. 462-7. 
244. Baker, P.J., et al., CD4(+) T cells and the proinflammatory cytokines gamma interferon and interleukin-6 contribute to alveolar bone loss in mice. Infection and immunity, 1999. 67(6): p. 2804-2809.

245. Bainbridge, B., et al., Role of Porphyromonas gingivalis Phosphoserine Phosphatase Enzyme SerB in Inflammation, Immune Response, and Induction of Alveolar Bone Resorption in Rats. 2010. 78(11): p. 4560-4569.

246. Kesavalu, L., et al., Rat Model of Polymicrobial Infection, Immunity, and Alveolar Bone Resorption in Periodontal Disease. 2007. 75(4): p. 1704-1712.

247. Baker, P.J., et al., Heterogeneity of Porphyromonas gingivalis strains in the induction of alveolar bone loss in mice. Oral Microbiology and Immunology, 2000. 15(1): p. 27-32.

248. Okada, Y., et al., Blockade of sympathetic B-receptors inhibits Porphyromonas gingivalisinduced alveolar bone loss in an experimental rat periodontitis model. Archives of Oral Biology, 2010. 55(7): p. 502-508.

249. Baker, P.J., M. Dixon, and D.C. Roopenian, Genetic control of susceptibility to Porphyromonas gingivalis-induced alveolar bone loss in mice. Infect Immun, 2000. 68(10): p. 5864-8.

250. Gemmell, E., et al., Differences in mouse strain influence leukocyte and immunoglobulin phenotype response to Porphyromonas gingivalis. 2003. 18(6): p. 364-370.

251. Dixon, D.R., B.W. Bainbridge, and R.P. Darveau, Modulation of the innate immune response within the periodontium. 2004. 35(1): p. 53-74.

252. Breivik, T., et al., Nicotinic acety/choline receptor activation mediates nicotine-induced enhancement of experimental periodontitis. Journal of Periodontal Research, 2009. 44(3): p. 297-304.

253. Geng, Y.M., et al., Effects of Nicotine on the Immune Response. I. Chronic Exposure to Nicotine Impairs Antigen Receptor-Mediated Signal Transduction in Lymphocytes. 1995. 135(2): p. 268-278.

254. Sopori, M.L., et al., Effect of nicotine on the immune system: possible regulation of immune responses by central and peripheral mechanisms. Psychoneuroendocrinology, 1998. 23(2): p. 189-204.

255. De Vries, T.J., et al., Genes Critical for Developing Periodontitis: Lessons from Mouse Models. Frontiers in Immunology, 2017. 8.

256. Kuula, H., et al., Local and Systemic Responses in Matrix Metalloproteinase 8-Deficient Mice during Porphyromonas gingivalis-Induced Periodontitis. Infection and Immunity, 2009. 77(2): p. 850-859.

257. Pavlica, Z., et al., Measurement of total antioxidant capacity in gingival crevicular fluid and serum in dogs with periodontal disease. Am J Vet Res, 2004. 65(11): p. 1584-8.

258. Elliott, D.R., et al., Cultivable Oral Microbiota of Domestic Dogs. Journal of Clinical Microbiology, 2005. 43(11): p. 5470-5476.

259. Attström, R., M. Graf-de Beer, and H.E. Schroeder, Clinical and histologic characteristics of normal gingiva in dogs. J Periodontal Res, 1975. 10(3): p. 115-27.

260. Johnson, G.K., et al., Effects of topical and systemic nicotine on gingival blood flow in dogs. J Dent Res, 1991. 70(5): p. 906-9.

261. Kraal, J.H., et al., Variations in the gingival polymorphonuclear leukocyte migration rate in dogs induced by chemotactic autologous serum and migration inhibitor from tobacco smoke. J Periodontal Res, 1977. 12(4): p. 242-9.

262. Struillou, X., et al., Experimental Animal Models in Periodontology: A Review. The Open Dentistry Journal, 2010. 4(1): p. 37-47. 
263. Sorensen, W.P., H. Loe, and S.P. Ramfjord, Periodontal disease in the beagle dog A cross sectional clinical study. 1980. 15(4): p. 380-389.

264. Giannobile, W.V., R.D. Finkelman, and S.E. Lynch, Comparison of canine and non-human primate animal models for periodontal regenerative therapy: results following a single administration of PDGF/IGF-I. J Periodontol, 1994. 65(12): p. 1158-68.

265. Socransky, S.S. and A.D. Haffajee, The bacterial etiology of destructive periodontal disease: current concepts. J Periodontol, 1992. 63(4 Suppl): p. 322-31.

266. Madden, T.E. and J.G. Caton, [9] Animal models for periodontal disease, in Methods in Enzymology. 1994, Academic Press. p. 106-119.

267. Holt, S., et al., Implantation of Bacteroides gingivalis in nonhuman primates initiates progression of periodontitis. Science, 1988. 239(4835): p. 55-57.

268. Weinberg, M.A. and M. Bral, Laboratory animal models in periodontology. J Clin Periodontol, 1999. 26(6): p. 335-40.

269. Marchesan, J., et al., An experimental murine model to study periodontitis. Nature protocols, 2018. 13(10): p. 2247-2267.

270. Neal, R.E., et al., Developmental cigarette smoke exposure II: Hepatic proteome profiles in 6 month old adult offspring. 2016. 65: p. 414-424.

271. Park, S.-N. and J.-K. Kook, Development of Streptococcus gordonii -specific quantitative real-time polymerase chain reaction primers based on the nucleotide sequence of rpoB. 2013. 57(8): p. 583-588.

272. Daep, C.A., et al., Structural Dissection and In Vivo Effectiveness of a Peptide Inhibitor of Porphyromonas gingivalis Adherence to Streptococcus gordonii. 2011. 79(1): p. 67-74.

273. Hutcherson, J.A., et al., Porphyromonas gingivalis genes conferring fitness in a tobaccorich environment. Molecular Oral Microbiology, 2020. 35(1): p. 10-18.

274. Mulhall, H., O. Huck, and S. Amar, Porphyromonas gingivalis, a Long-Range Pathogen: Systemic Impact and Therapeutic Implications. Microorganisms, 2020. 8(6): p. 869.

275. Nascimento, G.G., et al., Is weight gain associated with the incidence of periodontitis? A systematic review and meta-analysis. Journal of Clinical Periodontology, 2015. 42(6): p. 495-505.

276. Fentoglu, O. and F.Y. Bozkurt, The Bi-Directional Relationship between Periodontal Disease and Hyperlipidemia. European journal of dentistry, 2008. 2(2): p. 142-146.

277. Chiolero, A., et al., Consequences of smoking for body weight, body fat distribution, and insulin resistance. The American Journal of Clinical Nutrition, 2008. 87(4): p. 801-809.

278. Audrain-Mcgovern, J. and N.L. Benowitz, Cigarette Smoking, Nicotine, and Body Weight. Clinical Pharmacology \& Therapeutics, 2011. 90(1): p. 164-168.

279. Huot, I., G. Paradis, and M. Ledoux, Factors associated with overweight and obesity in Quebec adults. International Journal of Obesity, 2004. 28(6): p. 766-774.

280. Lee, S.F., Oral colonization and immune responses to Streptococcus gordonii: potential use as a vector to induce antibodies against respiratory pathogens. Current Opinion in Infectious Diseases, 2003. 16(3): p. 231-235.

281. Lee, S.F., et al., Oral colonization and immune responses to Streptococcus gordonii expressing a pertussis toxin S1 fragment in mice. 2002. 208(2): p. 175-178.

282. Loach, D.M., H.F. Jenkinson, and G.W. Tannock, Colonization of the murine oral cavity by Streptococcus gordonii. Infect Immun, 1994. 62(5): p. 2129-31.

283. Demuth, D.R., et al., Discrete Protein Determinant Directs the Species-Specific Adherence of Porphyromonas gingivalis to Oral Streptococci. 2001. 69(9): p. 5736-5741.

284. Al-Ghamdi, H.S. and S. Anil, Serum Antibody Levels in Smoker and Non-Smoker Saudi Subjects With Chronic Periodontitis. Journal of Periodontology, 2007. 78(6): p. 1043-1050. 
285. Zhang, Q., et al., Interleukin-10 Inhibits Bone Resorption: A Potential Therapeutic Strategy in Periodontitis and Other Bone Loss Diseases. BioMed Research International, 2014. 2014: p. 1-5.

286. Sasaki, H., et al., T Cell Response Mediated by Myeloid Cell-Derived IL-12 Is Responsible for Porphyromonas gingivalis-Induced Periodontitis in IL-10-Deficient Mice. The Journal of Immunology, 2008. 180(9): p. 6193-6198.

287. Yamada, A., et al., Interleukin-4 inhibition of osteoclast differentiation is stronger than that of interleukin-13 and they are equivalent for induction of osteoprotegerin production from osteoblasts. 2007. 120(4): p. 573-579.

288. Zhao, B. and L.B. Ivashkiv, Negative regulation of osteoclastogenesis and bone resorption by cytokines and transcriptional repressors. Arthritis Research \& Therapy, 2011. 13(4): p. 234.

289. Prakasam, S. and M. Srinivasan, Evaluation of salivary biomarker profiles following nonsurgical management of chronic periodontitis. Oral Dis, 2014. 20(2): p. 171-7.

290. Zein Elabdeen, H.R., et al., Cytokine profile in gingival crevicular fluid and plasma of patients with aggressive periodontitis. Acta Odontol Scand, 2017. 75(8): p. 616-622.

291. Queiroz, A.C.D., et al., Inflammation markers in healthy and periodontitis patients: a preliminary data screening. Brazilian Dental Journal, 2008. 19(1): p. 3-8.

292. Hou, L.-T., et al., Interleukin-16, clinical parameters and matched cellular-histopathologic changes of biopsied gingival tissue from periodontitis patients. Journal of Periodontal Research, 2003. 38(3): p. 247-254.

293. Kinane, D.F., et al., Bioassay of interleukin 1 (IL-1) in human gingival crevicular fluid during experimental gingivitis. Arch Oral Biol, 1992. 37(2): p. 153-6.

294. Taba, M., et al., Diagnostic Biomarkers for Oral and Periodontal Diseases. Dental Clinics of North America, 2005. 49(3): p. 551-571.

295. Rawlinson, A., et al., Interleukin 1 and receptor antagonist levels in gingival crevicular fluid in heavy smokers versus non-smokers. Journal of Clinical Periodontology, 2003. 30(1): p. 42-48.

296. Sorsa, T., L. Tjäderhane, and T. Salo, Matrix metalloproteinases (MMPs) in oral diseases. 2004. 10(6): p. 311-318.

297. Boelen, G.-J., et al., Matrix metalloproteinases and inhibitors in dentistry. Clinical Oral Investigations, 2019. 23(7): p. 2823-2835.

298. de Morais, E.F., et al., Matrix metalloproteinase-8 levels in periodontal disease patients: A systematic review. J Periodontal Res, 2018. 53(2): p. 156-163.

299. Yabluchanskiy, A., et al., Matrix metalloproteinase-9: Many shades of function in cardiovascular disease. Physiology (Bethesda), 2013. 28(6): p. 391-403.

300. Zanoni, I., et al., CD14 regulates the dendritic cell life cycle after LPS exposure through NFAT activation. Nature, 2009. 460(7252): p. 264-268.

301. Antal-Szalmas, P., et al., Quantitation of surface CD14 on human monocytes and neutrophils. Journal of Leukocyte Biology, 1997. 61(6): p. 721-728.

302. Zanoni, I. and F. Granucci, Role of CD14 in host protection against infections and in metabolism regulation. Frontiers in Cellular and Infection Microbiology, 2013. 3.

303. Kirschning, C.J. and S. Bauer, Toll-like receptors: cellular signal transducers for exogenous molecular patterns causing immune responses. International Journal of Medical Microbiology, 2001. 291(4): p. 251-260.

304. Cross, J.L., et al., CD45 Regulates TLR-Induced Proinflammatory Cytokine and IFN-6 Secretion in Dendritic Cells. The Journal of Immunology, 2008. 180(12): p. 8020-8029. 
305. Donovan, J.A. and G.A. Koretzky, CD45 and the immune response. Journal of the American Society of Nephrology, 1993. 4(4): p. 976-985.

306. Hermiston, M.L., Z. Xu, and A. Weiss, CD45: A Critical Regulator of Signaling Thresholds in Immune Cells. Annual Review of Immunology, 2003. 21(1): p. 107-137.

307. Chen, H., et al., Tobacco Smoking Inhibits Expression of Proinflammatory Cytokines and Activation of IL-1R-Associated Kinase, $p 38$, and NF- B in Alveolar Macrophages Stimulated with TLR2 and TLR4 Agonists. 2007. 179(9): p. 6097-6106.

308. Radvar, M., et al., The effect of smoking on inflammatory cell infiltrate subtypes in gingival tissue of patients with chronic periodontitis. Electronic Physician, 2017. 9(8): p. 49614967.

309. Kumar, V. and M. Faizuddin, Effect of smoking on gingival microvasculature: A histological study. Journal of Indian Society of Periodontology, 2011. 15(4): p. 344-348.

310. Sutton, J.D., M.L. Salas Martinez, and M.M. Gerkovich, Environmental Tobacco Smoke and Periodontitis in United States Non-Smokers, 2009 to 2012. Journal of periodontology, 2017. 88(6): p. 565-574.

311. Rosa, G.M., G.Q. Lucas, and O.N. Lucas, Cigarette smoking and alveolar bone in young adults: a study using digitized radiographs. J Periodontol, 2008. 79(2): p. 232-44.

312. Costa-Rodrigues, J., I. Rocha, and M.H. Fernandes, Complex Osteoclastogenic Inductive Effects of Nicotine Over Hydroxyapatite. Journal of Cellular Physiology, 2017.

313. Alasmari, F., et al., A computerized exposure system for animal models to optimize nicotine delivery into the brain through inhalation of electronic cigarette vapors or cigarette smoke. Saudi Pharmaceutical Journal, 2018. 26(5): p. 622-628.

314. Sumer, A.P., et al., Association of Interleukin-10 Gene Polymorphisms With Severe Generalized Chronic Periodontitis. Journal of Periodontology, 2007. 78(3): p. 493-497.

315. Hirasawa, M., et al., Improvement of periodontal status by green tea catechin using a local delivery system: A clinical pilot study. Journal of Periodontal Research, 2002. 37(6): p. 433438.

316. Lauritano, D., et al., Why should patients with systemic disease and tobacco smokers go to the dentist? J Biol Regul Homeost Agents, 2016. 30(2 Suppl 1): p. 135-41.

317. Wang, Q., et al., Comparison of Experimental Diabetic Periodontitis Induced byPorphyromonas gingivalisin Mice. Journal of Diabetes Research, 2016. 2016: p. 1-10.

318. Schick, S., Philip Morris toxicological experiments with fresh sidestream smoke: more toxic than mainstream smoke. Tobacco Control, 2005. 14(6): p. 396-404.

319. Grossi, S.G., et al., EFFECTS OF SMOKING AND SMOKING CESSATION ON HEALING AFTER MECHANICAL PERIODONTAL THERAPY. The Journal of the American Dental Association, 1997. 128(5): p. 599-607.

320. Aghaloo, T., et al., In Vitro Models, Standards, and Experimental Methods for Tobacco Products. Advances in Dental Research, 2019. 30(1): p. 16-21.

321. Lei, W., et al., Myofibroblast differentiation and its functional properties are inhibited by nicotine and e-cigarette via mitochondrial OXPHOS complex III. Scientific Reports, 2017. 7(1): p. 43213. 


\section{CURRICULUM VITAE}

Mina Iskander

ADDRESS: Dept. of Oral Immunology and Infectious Diseases

University of Louisville School of Dentistry

501 South Preston Louisville, KY 40202

E-mail: mmiska01@louisville.edu,

dr.mina.medht@gmail.com.

Work History

- Graduate Research Assistant, 10/2018 till present (Dr. David Scott's Lab).

Master of Oral Biology Program, School of Dentistry, University of Louisville, KY, USA.

- Dental Laboratory Technician, 01/2018 to 09/2018

Glidewell Company - Louisville, KY

- Dentist, $04 / 2012$ to $08 / 2017$

Private Dental Clinic - Giza, Egypt.

- Oral Surgeon, $03 / 2011$ to $08 / 2017$

Memorial Eye Institute - Giza, Egypt.

- General Dentist, $10 / 2010$ to 03/2011

Family Health Centers, Ministry of Health - Giza, Egypt. 
- General Dentist, 07/2009 to 09/2010

\section{Education}

National Board Dental Examination ( NBDE 1 ), February 2020

- NBDE part 1 Passed

Master's Degree Candidate - Oral Biology, Spring 2019

School of Dentistry, University of Louisville, KY, USA

- Cumulative total GPA 3.7

Diploma: Medical Applications of Laser in Dentistry, 2013

National Institute of Laser Enhanced Science (NILES)-Cairo University, Egypt

- Graduated with 3.33 GPA

Higher Dental Diploma: Oral and Dental Surgery, 2010

Faculty of Oral and Dental Medicine - Cairo University, Egypt.

Bachelor of Dental Surgery: Oral and Dental Medicine, 2007

October 6th University - October 6th city, Egypt

- Graduated with 3.9 GPA

\section{Meetings and Conference Presentations}

Research! Louisville, Louisville, KY

September 10, 2019 - "Tobacco enhances bacterial-induced periodontitis in mice", poster presentation.

Hinman Student Research Conference, Memphis, TN 
November 1-3, 2019 - "Tobacco enhances bacterial-induced periodontitis in mice", invited to represent University of Louisville School of Dentistry, poster presentation.

\section{Volunteer work}

- American Red Cross: March 2020-Present

- Kentucky science Center: December 2019-Present

- St. Paul Medical Missions: 2014-2017

Charitable dental missions in underserved communities in Uganda, Malawi, Zimbabwe, Malaysia, Bangladesh and Liberia.

\section{Additional Information}

Workshops:

- Level II animal training-RRC, Louisville, $K Y$

November 2019 - in person level II animal training, Dr Karen Powell

- Publishing Academy, Louisville, KY

April 2019 - School of Interdisciplinary and Graduate Studies, University of Louisville

Certificate of completion Publishing Academy

- Cognitive \& skills evaluation, Louisville, $K Y$

February 2019 - in accordance with the curriculum of American heart association basic life support (CPR \& AED) program.

- Fundamentals of Basic and Advanced Implant Dentistry course (American Dental Association with Egyptian Society of Oral Implantology), October 2016 
- Laminate Veneer from $A$ to $Z$ workshop (Future University in Egypt), March 2016.

- The 2nd Egyptian Dental Syndicate International Congress, September 2015. 